\title{
A Biodegradable Stent with Surface Functionalization of Combined-Therapy Drugs for Colorectal Cancer
}

DOI:

10.1002/adhm.201801213

Document Version

Accepted author manuscript

Link to publication record in Manchester Research Explorer

\section{Citation for published version (APA):}

Xie, X., Zheng, X., Han, Z., Chen, Y., Zheng, Z., Zheng, B., He, X., Wang, Y., Kaplan, D. L., Li, Y., Li, G., Wang, X., \& Lan, P. (2018). A Biodegradable Stent with Surface Functionalization of Combined-Therapy Drugs for Colorectal Cancer. Advanced Healthcare Materials, 7(24), e1801213. [1801213].

https://doi.org/10.1002/adhm.201801213

Published in:

Advanced Healthcare Materials

\section{Citing this paper}

Please note that where the full-text provided on Manchester Research Explorer is the Author Accepted Manuscript or Proof version this may differ from the final Published version. If citing, it is advised that you check and use the publisher's definitive version.

\section{General rights}

Copyright and moral rights for the publications made accessible in the Research Explorer are retained by the authors and/or other copyright owners and it is a condition of accessing publications that users recognise and abide by the legal requirements associated with these rights.

\section{Takedown policy}

If you believe that this document breaches copyright please refer to the University of Manchester's Takedown Procedures [http://man.ac.uk/04Y6Bo] or contact uml.scholarlycommunications@manchester.ac.uk providing relevant details, so we can investigate your claim.

\section{OPEN ACCESS}




\section{Silk fibroin-based biodegradable intestinal stents loaded with combined-therapy drugs for colorectal cancer}

Xusheng Xie ${ }^{\text {a, } 1}$, Xiaobin Zheng ${ }^{\text {b, } 1}$, Zhifen Han ${ }^{c}$, Yufeng Chen ${ }^{\text {b }}$, Zhuzhao Zheng ${ }^{\text {a }}$, Bin Zheng ${ }^{\text {b }}$, Xiaowen

$\mathrm{He}^{\mathrm{b}}$, Yongfeng Wang ${ }^{\mathrm{a}}$, David L Kaplan ${ }^{\mathrm{d}}, \mathrm{Yi} \mathrm{Li}^{\mathrm{e}}$, Gang Li ${ }^{\mathrm{a},{ }^{*}}$, Xiaoqin Wang ${ }^{\mathrm{a},{ }^{* *}}$, Ping Lan ${ }^{\mathrm{b}, * * *}$

${ }^{a}$ National Engineering Laboratory for Modern Silk, College of Textile and Clothing Engineering, Soochow University, Suzhou 215123, P.R.China

${ }^{b}$ Department of Colorectal Surgery, The Sixth Affiliated Hospital of Sun Yat-Sen University, Guangzhou 510655, China

${ }^{c}$ Department of Medical Oncology, Shuguang Hospital, Shanghai University of Traditional Chinese Medicine, Shanghai 201203, China

${ }^{d}$ Department of Biomedical Engineering, Tufts University, 4 Colby St, Medford, MA 02155, USA

${ }^{e}$ School of Materials, The University of Manchester, Manchester M13 9PL, UK

"Corresponding authors'email: tcligang@suda.edu.cn; wangxiaoqin@suda.edu.cn; lpzm@yahoo.com

${ }^{1}$ These authors contributed to this manuscript equally. 
Abstract: In-stent restenosis caused by tumor ingrowth is a major problem for patients undergoing stent placement because conventional stents often lack sustainable anti-tumor capabilities. The aim of this work was to develop a silk fibroin (SF)-based polydioxanone (PDO) stent with a combination of weft-knitting and electrospinning technologies to address mechanical, biodegradation and drug delivery requirements. The inner layer of the stent was knitted from PDO monofilaments and SF yarns. In order to improve treatment effectiveness, a combination of therapeutic drugs, i.e., curcumin (CUR) and 5-fluorouracil (5-FU), were dissolved with Poly(ethyleneglycol) (PEG) in SF solution at three concentrations (0.15/0.25, 0.3/0.5 and $0.45 / 0.75 \mathrm{wt} \%$ in SF solution), and eletrospun onto the weft-knitted SF/PDO stent. The morphology, chemical structure, mechanical properties and in vitro drug release profiles of the drug-loaded devices were characterized. The anti-tumor efficacy was assessed in vitro and in vivo using a human colorectal cancer cell line HCT116, normal cells NCM460 and tumor-bearing BALB/c nude mice. The results showed that the release of dual drugs from the three membranes lasted 210 to 400 hours. In vitro and in vivo studies on the membrane-coated stents demonstrated improved anti-tumor effects for the CUR/5-FU dual drug system which can be attributed to cell cycle arrest in the S phase in association with induced apoptosis in tumor cells by blocking Stat3 and NF-אB signaling pathways, suggesting potential in the treatment of colorectal cancer.

Keywords: colorectal cancer; weft-knitted stent; curcumin; 5-fluorouracil; silk fibroin; polydioxanone. 


\section{Introduction}

Colon and rectal cancer (CRC) are some of the most serious cancers in terms of both incidence and mortality globally [1]. Intestinal obstruction and stenosis are main symptoms of CRC patients, with mortality over $80-90 \%$ within five years without effective treatment [2, 3]. In the clinic, stent placement in combination with radio-chemotherapy is an effective palliative treatment for colorectal cancer patients with advanced acute obstruction, high emergent surgical risk, multiple transfer rate and/or in poor general health [4]. However, postoperative complications and in-stent restenosis caused by tumor ingrowth are major problems for patients undergoing stent displacement [4-6]. However, conventional stents made from metal materials only meet the requirements of mechanical expansion and temporary treatment $[5,6]$. Therefore, development of new intestinal stents with good biocompatibility, degradability and drug delivery functions is of particular importance [7]. The concept of this type of intestinal stent with drug delivery functions is shown in Fig. 1, where the stenosis site can be expanded and the tumor site can be locally treated by drugs released from membranes on the stent.

5-Fluorouracil (5-FU) has been used for the treatment of patients with CRC [2], however, the short half-life (10-20 minutes), low utilization rate (10-30\%), poor sensitivity, and toxicity to normal cells [8, 9] are problems. Hence, development of a device that can encapsulate and stabilize 5-FU is important for the improved utilization of the drug to achieve desired clinical outcomes. In previous studies, a drugloaded polydioxanone weft-knitted stent was developed to treat CRC by slow releasing 5-FU [2, 3]. The half maximal inhibitory concentration $\left(\mathrm{IC}_{50}\right)$ and the median lethal dose $\left(\mathrm{LD}_{50}\right)$ demonstrated that these drug-loaded membranes had better anti-tumor effects than pure 5-FU due to the sustainable drug

\section{Silk fibroin-based biodegradable intestinal stents loaded with combined- therapy drugs for colorectal cancer}


releasing property of the coated membranes on the stent [2, 3]. A 5-FU/paclitaxel loaded esophageal stent was also developed for the treatment of esophageal cancer and these treatment modalities were evaluated in vivo after implantation into the porcine esophagus [10]. The results illustrated that the drugloaded stents had a dual function as a local drug delivery device, which provided potential treatment with high efficacy and reduced systematic toxicity for the treatment of esophageal cancer.

Combination therapy uses more than one medication or modality, with the major benefit of reduction in development of drug resistance, since a pathogen or tumor is less likely to have resistance to multiple drugs simultaneously. New evidence suggests that the combined use of chemopreventive agents has an inhibitory effect on CRC [11]. Curcumin (diferuloylmethane, 1,7-bis(4-hydroxy-3-methoxy-phenyl)-1,6heptadiene-3,5-dione) (CUR), obtained from the spice turmeric, exhibits numerous biological activities including anti-tumor, anti-inflammation and anti-angiogenesis, as well as inhibiting the proliferation and metastasis of CRC [12]. However, CUR has poor water solubility and low bioavailability in vivo, which limited clinical applications. One strategy to address this problem is to combine CUR with 5-FU, and recent studies have demonstrated the coordinative and improved anti-tumor effect of CUR and 5-FU in chemotherapeutic treatment [13]. Toden et al. [13] carried out an in vitro and vivo study to examine the effects of CUR and 5-FU individually, and in combination. Both CUR and 5-FU were dissolved in dimethyl sulfoxide (DMSO) and diluted to appropriate concentrations with tissue culture medium, and then intraperitoneally injected into mice daily for 40 days. The results demonstrated that CUR-mediated sensitization to 5-FU in CRC cells occurred through the suppression of the epithelial-mesenchymal transition (EMT) and polycomb repressive complex (PRC), which are regulated by microRNAs. This study provided evidence for the use of CUR as an adjunct to 5-FU-based chemotherapy in CRC. However, this is still a traditional chemotherapeutic treatment in which the disadvantages of the dual drugs were illustrated. The development of a new drug delivery system in which CUR and 5-FU are incorporated and function simultaneously, with a goal towards medical device needs, was the focus of 
the present study. Our hypothesis was that the combined use of the two drugs may not only improve the utilization, sensitivity and anti-tumor effect of the device, but also reduce the side effects of 5-FU.

Silk fibroin (SF), a natural protein polymer with excellent processability, mechanical properties, biocompatibility and biodegradability, has been studied for many biomedical uses [14, 15]. SF can be processed into fibers, gels, membranes, micro/nano-particles and porous scaffolds, which have been used in tissue engineering [16-19], enzyme immobilization and drug controlled release [20-22]. The biosafety and biocompatibility of SF has been demonstrated in previous studies [23, 24], as well as in FDA approved medical devices. SF can also carry and release CUR effectively during enzymatic digestion [20, 25, 26]. Electrospinning technology has been widely used to fabricate micro or nano fibrous materials for drug delivery applications [25-29]. Importantly, poorly water-soluble drugs loaded into water-soluble and water-insoluble fibrous SF fibers using electrospinning can be useful in tissue engineering and topical drug administration goals [26, 30, 31].

The aim of the present study was to develop a SF-modified polydioxanone (PDO) stent with a combination of weft-knitting and electrospinning technologies. SF/PDO stents were first weft-knitted, and then drug-loaded electro-spun SF membranes were produced by adding CUR and 5-FU into the SF spinning solution for sustained drug release. The morphology, secondary structure, and in vitro drug release properties of the coated membranes were analyzed. The anti-tumor efficacy was assessed in vitro and in vivo using the human colorectal cancer cell line HCT116, normal human colon mucosal epithelial cell line NCM460, and tumor-bearing BALB/c nude mice.

\section{Materials and Methods}

\subsection{Experimental design (Fig. 2)}

PDO monofilament (Samyang Co., Korea) with a linear density of 105 tex and SF multifilament with a linear density of 5 tex were knitted into a tubular stent $60 \pm 2 \mathrm{~mm}$ long and $25 \mathrm{~mm}$ in diameter using a 
circular weft-knitting machine (Model ST-06SL), needle number 22/44 needles, circular type, machine diameter: 30 mm, gauge: 7 (Shanghai Sailing Ltd. Co., China). Generally, the length and diameter of the stents can be adjusted according to computed tomography (CT) assessments of the intestine with stenosis or obstructions in patients. CT is a diagnostic imaging test used to create three dimensional and detailed images of internal organs, bones, and soft tissue like intestine and blood vessels. CT scanning is often the best method for detecting different cancers, since the images allow confirmation of the presence, size and location of a tumor. In this study, the stent size was set based on commercially available metal stents commercially [32]. Drug-loaded SF fibrous membranes were electrospun onto the surface of the prepared PDO/SF stents (Figs. 2c, d). Subsequently, disk-shape drug-loaded membranes were cut from the stent to investigate the in vitro and in vivo anti-tumor potential using HCT116, NCM460 cells and BALB/c nude mice (Fig. 2e, 2f, 2g).

\subsection{Materials}

Anticancer compounds, CUR and 5-FU, were obtained from Sigma (Springdale, AR, USA). PDO was purchased from Samyang Co., Korea. Poly(ethyleneglycol) (PEG) with a molecular weight of 400 was purchased from Dow Chemical Company, USA. Mulberry silk was supplied by Shengzhou Xiehe silk Co., Ltd. China. Other reagents and solvents were analytical grade. HCT116 and NCM460 cells were obtained from the Cell Bank of the Chinese Academy of Science (Shanghai, China). BALB/c nude mice were supplied by the Laboratory Animal Center of Sun Yat-Sen University (Guangzhou, China).

\subsection{Preparation of the CUR/5-FU membranes}

SF solution at $23 \mathrm{wt} \%$ was prepared following a standard procedure developed in our lab, which contains steps of degumming silk, fiber dissolution by lithium bromide, dialysis to remove salt, centrifugation to remove insoluble aggregates, and determination of SF concentration [23, 24]. Three different drug loaded membranes were prepared by mixing CUR/5-FU at concentration ratios of 0.15/0.25\%, $0.3 / 0.5 \%$ and $0.45 / 0.75 \%$ by weight to SF solution of $23 \mathrm{wt} \%$. The above dual drugs were 
dissolved into 60\% PEG-400 with an Ultrasonic cell disruptor (JY92-IIDN, China) at 40\% power output for 30 minutes. The mixed solution containing drugs and SF was added to a plastic syringe with a stainless steel needle (inner diameter is $0.5 \mathrm{~mm}$ ), and the plastic syringe was placed in a high-speed rotating electrospinning machine (NEC-10, Kato Tech Co., Ltd., Japan). The voltage was set at $25 \pm 0.5$ $\mathrm{kV}$, the distance between the needle tip and the roller was set at $220 \pm 5 \mathrm{~mm}$, and the injection speed of spinning solution was set at $0.2 \pm 0.05 \mathrm{~mL} / \mathrm{h}$. All samples were vacuum-dried at $60^{\circ} \mathrm{C}$ for 12 hours to remove solvent before characterization.

\subsection{Characterization on CUR/5-FU loaded membranes}

\subsubsection{Morphology and pore size distribution}

The morphologies of the membranes were examined using scanning electron microscopy (SEM) (Hitachi S-4800, Japan) at an acceleration voltage of $3 \mathrm{kV}$. All films were placed in fume hood for 12 hrs, then sputter-coated with gold (E-1045, Japan Co., Ltd.) for 90s. Image J software (National Institute of Mental Health, USA) was used to measure the diameters of 30 fibers randomly chosen from the SEM images, and their mean value and standard deviation were calculated. The pore size distributions in the membranes were measured by a capillary flow porometer (Porometer 3G, Quanta chrome Instruments, USA). All tested samples were cut into round membranes with a diameter of $25 \mathrm{~mm}$. During the measurement, the wetting liquid was expelled through the pores in samples. Air pressure was automatically applied on the membrane, and the air flow through the pores was accurately recorded. The actual pressure applied to the sample was measured independently.

\subsubsection{Hydrophilicity test}

In order to investigate the hydrophilicity of the membranes, the apparent contact angle was examined by a Krüss DSA 100 (Krüss Company, Germany) apparatus, using a sessile drop (5 $\mu \mathrm{L}$ drop of pure water) 
method. The apparent static contact angle values were measured by Image J software (National Institute of Mental Health, USA).

\subsubsection{Structural analysis}

The secondary structure of the drug-loaded membranes was examined using Fourier Transform Infrared Spectroscopy (FT-IR) with a MIRacle ${ }^{\mathrm{TM}}$ attenuated total reflection (ATR) Ge crystal cell in the reflection mode (Nicolet 5700, Thermo Electron Corp, Waltham, MA). FT-IR wave numbers were set from 4000 to $400 \mathrm{~cm}^{-1}$ during 32 scans, with $2 \mathrm{~cm}^{-1}$ resolutions. The major vibration bands were attributed to specific chemical groups. The internal crystalline structure of the drug-loaded membranes was examined via an X-ray diffractometer (X'Pert-Pro MPD, PANalytical BV, Almelo, Netherlands) using a $\mathrm{Cu} \mathrm{K} \alpha$ radiation source. Two dimensional $\mathrm{X}$-ray diffraction patterns were obtained at the following irradiation settings: $\mathrm{Cu}, \mathrm{K} \alpha$, wave length $0.154 \mathrm{~nm}$, range $5-60^{\circ}, 40 \mathrm{kV}$ and $35 \mathrm{~mA}$ at a scanning rate of $5^{\circ} \mathrm{min}^{-1}$.

\subsubsection{Drug release}

A membrane with $4 \mathrm{mg}$ of drug loading was soaked in $2 \mathrm{~mL}$ phosphate-buffered saline (PBS), $\mathrm{pH}=7.4$, at room temperature in a tube that was placed in a shaking water bath (Shanghai Yiheng Co., China) set at 100 cycles/min. The release solution of $1 \mathrm{~mL}$ was collected at $0,1,3,6,9,12,24,48,72,96,120$, 300, and 400-hour intervals, and the release solution was supplemented with $1 \mathrm{~mL}$ PBS after sampling. The concentration of 5-FU in the release solution was measured by High Performance Liquid Chromatography (HPLC) (1260 series, Agilent Technologies, USA) that was equipped with waters $\mathrm{C}_{18}$ column $(250 \mathrm{~mm} \times 4.6 \mathrm{~mm}, 5 \mu \mathrm{m})$. Prior to the sample $(10 \mu \mathrm{L})$ injection, the release solution was filtered with $0.22 \mu \mathrm{m}$ filters. The UV absorbance wavelength of $265 \mathrm{~nm}$ was used for detection. The mobile phase was composed of $90 \%$ deionized water and $10 \%$ methanol $(10: 90, \mathrm{~V} / \mathrm{V})$ purged at a flow rate of $1 \mathrm{~mL} / \mathrm{min}$. The concentration of $5-\mathrm{FU}$ was calculated according to the standard equation 
$\left(\mathrm{Y}=41.03 \mathrm{X}+4.432, \mathrm{R}^{2}=0.999\right.$. The concentration of CUR in the release solution was measured by UV absorbance at $425 \mathrm{~nm}$. The release solution of $200 \mu \mathrm{L}$ was dropped into 96-well plates and the absorbance of the solution was determined by using a microplate reader (Bio-TeK synergy H1, USA). The concentration of CUR was calculated by the standard equation ( $\left.Y=26.11 X-0.476, R^{2}=0.999\right)$.

\subsubsection{Cell culture and morphology}

HCT116 and NCM460 cells were cultured as a monolayer at $37^{\circ} \mathrm{C}$ in the Roswell Park Memorial Institute (RPMI) 1640 medium (Gibco, Invitrogen) supplemented with 10\% FBS (Gibco, Invitrogen) and $1 \%$ pen-strep (100 U/mL penicillin and $100 \mathrm{mg} / \mathrm{mL}$ streptomycin) (Gibco, Invitrogen) in a humidified incubator containing $5 \% \mathrm{CO}_{2}$. The culture medium was refreshed every 48 hrs and the amount of cells was counted using a Cellometer Auto T4 (Nexcelom Bioscience LLC, USA). Diskshaped samples were cut from the membranes and placed on the bottom of 6-well plates. The membranes were either fixed to the bottom of the wells with rubber rings or not fixed (membrane floated in the medium during culture). Prior to cell seeding, the membranes were pre-sterilized under ${ }^{60} \mathrm{Co}$ radiation at $18 \mathrm{kGy}$ (Irradiation Technology Institute of Soochow University, China). A total of $1.0 \times 10^{5}$ HCT116 and NCM460 cells in 2 mL medium were added into one well of 6-well plates containing experimental samples (Control, SF membrane, CUR of $\mathrm{IC}_{50}$, 5-FU of $\mathrm{IC}_{50}$, CUR/5-FU of IC 50 , CUR/5FU loaded membrane of 0.15/0.25 wt $\%, 0.30 / 0.50 \mathrm{wt} \%$ and $0.45 / 0.75 \mathrm{wt} \%)$. For imaging, cells were fixed with 4\% paraformaldehyde in phosphate-buffered saline (PBS) (pH 7.4) for 5 mins at room temperature, washed three times with PBS, and kept at $4^{\circ} \mathrm{C}$ until use. The actin cytoskeleton and DNA were stained with rhodamine-labeled phalloidin and 4', 6-diamidino-2-phenylindole dihydrochloride (DAPI), respectively, and observed using a Keyence BZ-X710 fluorescent microscope (Keyence, USA).

\subsubsection{Cell Proliferation Assay}

Both the anti-tumor effects on HCT116 cells and cytotoxicity on NCM460 cells of drug-loaded membranes were determined by MTS assay. Briefly, $5.0 \times 10^{3}$ cells in $100 \mu \mathrm{L}$ medium were pre- 7 - 
cultivated in each well of the 96-well plates for 12 hrs and then the culture medium was replaced with treatment medium containing experimental samples as described above. After 12, 24, 48, 72, 96 and 120 hrs incubation, the medium was aspirated and cells were washed with PBS for three times. Subsequently, $100 \mu \mathrm{L}$ fresh serum-free medium supplemented with $20 \mu \mathrm{L}$ CellTiter 96® AQueous One Solution Reagent (Promega) was added and incubated for another 3hrs. The absorbance values were measured at $490 \mathrm{~nm}$ using a microplate reader (Model Synergy 2, Bio-Tek, Vermont, USA) in a dark environment. Cell viability was calculated using Eq. (1) below:

$$
\text { Cell viability }(\%)=\frac{\text { Absorbance of test groups }}{\text { Absorbance of control groups }} \times 100 \%
$$

Where the test groups were the cells subjected to different treatments, and the control groups were the untreated cells.

\subsubsection{Cell cycle and apoptosis measurement}

HCT116 and NCM460 cells were seeded in 6-well plates for 12 hrs, followed by co-culturing with experimental samples as described above. After 24 and 48 hrs co-culture, cells were harvested by trypsinization, washed and resuspended in PBS. Then, $1.0 \times 10^{6}$ cells were fixed with ethanol $(70 \%$, $20^{\circ} \mathrm{C}$ ) by vortexing mildly and maintained at $4^{\circ} \mathrm{C}$ for at least 12 hrs. Thereafter, the cells were resuspended in $1 \mathrm{~mL}$ PBS containing $50 \mu \mathrm{g} / \mathrm{mL}$ propidium iodide (PI) and $50 \mu \mathrm{g} / \mathrm{mL}$ RNase and incubated in the dark for $30 \mathrm{~min}$ at $25^{\circ} \mathrm{C}$. The stained cell samples were then read and analyzed using a BD FACS CatoII flow cytometer (BD Biosciences, USA). For apoptosis analysis, $3.0 \times 10^{6}$ cells of each experimental group were harvested, washed with PBS and resuspended in $500 \mu \mathrm{L}$ ice-cold binding buffer. After adding $5 \mu \mathrm{L}$ of Annexin V-FITC and $10 \mu \mathrm{L}$ of PI solutions, all samples were incubated in the dark for 5 min at $4^{\circ} \mathrm{C}$. The stained samples were read and analyzed using a BD FACS Cato II flow cytometer (BD Biosciences, USA). 


\subsubsection{Cell Western blot analysis}

HCT116 and NCM460 cells were seeded in 6-well plates for 12 hrs, followed by co-culturing with experimental samples as described above (2.4.5). After 24 hrs co-culture, cells were lysed in the RIPA buffer (50 mM Tris-HCl, $\mathrm{pH}$ 8.0, 150Mm NaCl, 0.5\% sodium deoxycholate, 1\% NP-40\%, and 0.1\% SDS), supplemented with 1\% complete EDTA-free protease inhibitor cocktail (Roche Diagnostics, Mannhein, Germany). The supernatant was separated by centrifugation at $12,000 \mathrm{rpm}$ for $15 \mathrm{~min}$ at $4^{\circ} \mathrm{C}$ and the protein concentration was detected by BCA protein assay kit (Thermo Pierce, USA) using bovine serum albumin as standard. Equal amounts of the protein extracts of each sample were mixed with $5 \times$ loading buffer and denatured in the boiling water for $10 \mathrm{~min}$. Next, the samples were subjected to sodium dodecyl sulfate-polyacrylamide gel electrophoresis, and transferred onto polyvinylidene fluoride membranes (Bio-Rad Laboratories, Hercules, CA). Each membrane was blocked at room temperature for 2 hrs and incubated with specific primary antibodies (signal transducer and activator of transcription 3 (Stat3), Cell Signaling Technology (CST), 4904S; NF-кB P65, CST, 8242) for $4^{\circ} \mathrm{C}$ overnight. Then, the membranes were washed in TBST and reacted with secondary horseradish peroxidase-conjugated antibody for $1 \mathrm{hr}$ at room temperature, and the immunoreactive bands were visualized using an ECL kit (Bio-Rad Laboratories).

\subsubsection{Cell immunocytochemistry}

Cells were treated with experimental samples for 24 hrs and plated on a glass slide. The slides were airdried for 15 mins at room temperature and fixed with 3.7\% formaldehyde. After washing, slides were incubated with a rabbit polyclonal anti-human E-cadherin IgG antibody (1/100 dilution) overnight at $4^{\circ} \mathrm{C}$. The day after, slides were washed and incubated with goat anti-rabbit IgG antibody (Thermo Fisher, A-11034) (green) (1/100 dilution) for $1 \mathrm{hr}$ and DAPI (blue) for 5 mins at the room temperature. Cells were observed using a Keyence BZ-X710 fluorescent microscope (Keyence, USA). 


\subsubsection{Animal preparation}

A total of 25 female BALB/c nude mice (6-8 weeks old, $20 \pm 2$ g) were maintained in a pathogen-free environment (temperature $23 \pm 2^{\circ} \mathrm{C}$ and humidity $55 \% \pm 5$ ) on a 12-hr light, 12 -hr dark cycle with food and water supplied during the whole experimental period. Animal care and surgical protocols were approved by the Animal Care Committees of Sun Yat-sen University (Guangzhou, China). All animals were treated appropriately and used in a scientifically valid and ethical manner. To establish CRC allografts for in vivo studies, $2.0 \times 10^{5}$ HCT116 cells were subcutaneously injected into the right side of the back of BALB/c nude mice. After ten days, all mice developed a tumor with a volume exceeding $100 \mathrm{~mm}^{3}$. The mice were randomly separated into five groups and five mice per group according to the volume of tumor that is calculated by Eq. (2). The tumor volume and mice weight change ratios (\%) were calculated using Eqs. (3) and (4), respectively.

$$
\begin{gathered}
\text { Tumor volume }(V)=\mathrm{L} \times \mathrm{W}^{2} / 2 \\
\text { Tumor volume change ratio }(\%)=\left(\frac{\mathrm{V}_{1}}{\mathrm{~V}_{\mathrm{N}}}-1\right) \times 100 \% \\
\text { Mice weight change ratio }(\%)=\left(\frac{\mathrm{W}_{1}}{\mathrm{~W}_{\mathrm{N}}}-1\right) \times 100 \%
\end{gathered}
$$

Where $\mathrm{V}, \mathrm{L}$ and $\mathrm{W}$ is the volume, length and width of tumors, respectively; $\mathrm{V}_{1}$ and $\mathrm{V}_{\mathrm{N}}$ are the tumor volume measured at first day and $\mathrm{N}$ days after implantation of samples, respectively; $\mathrm{W}_{1}$ and $\mathrm{W}_{\mathrm{N}}$ are the mouse weight measured at first day and $\mathrm{N}$ days after treatment of samples, respectively.

The five groups were identified as follows: (1) did not take any treatment as control; (2) implantation with pure SF membrane; (3-4) intraperitoneal injection with either (3) 5-FU or (4) CUR/5-FU solution at a median lethal dose $\left(\mathrm{LD}_{50}\right)$; (5) implantation with CUR/5-FU (0.30/0.50 wt\%) loaded membrane. After 12 days observation, all the mice were placed under general anesthesia by intraperitoneal injection of pentobarbital sodium (30 $\mu \mathrm{g} / \mathrm{g}$ body wt $\%$ ) and the membrane were implanted into the tumor as shown in Fig. 5A. Briefly, a straight skin incision about $1 \mathrm{~cm}$ was performed near the tumor and subcutaneous 
tissue around the tumor was separated slightly for embedding the membrane. Finally, the incision was sutured so that the tumor could be treated locally by the coating on the membrane.

\subsubsection{H\&E staining analysis}

Twelve weeks after implantation, mice were euthanized and the specimens along with the adjacent tissues were collected for histological examination. All the tumors were fixed in $10 \%$ formalin solution, embedded in paraffin and sectioned at $5 \mu \mathrm{m}$ thickness. Sections were then stained with hematoxylin and eosin (H\&E) (Sigma-Aldrich, St. Louis, MO) to visualize the cell nuclei and cytoplasm. A slide of each tumor was evaluated and digital imaged at a high magnification ( $\times 50$ and $\times 200$-fold) using the Leica DM IRB inverted research microscope (Leica Microsystems, Wetzlar, Germany).

\subsubsection{Animal xenograft western blot analysis}

Tumors were lysed in RIPA buffer, supplemented with $1 \%$ complete EDTA-free protease inhibitor cocktail (Roche Diagnostics, Mannhein, Germany). The supernatant was separated by centrifugation at 12,000 rpm for 15 mins at $4^{\circ} \mathrm{C}$ and the total protein concentration was determined by BCA protein assay kit (Thermo Pierce, USA) using bovine serum albumin as standard. Protein samples were mixed with $5 \times$ loading buffer, denatured in the boiling water for 10 min and stored at $-20^{\circ} \mathrm{C}$ until use. Protein expression was determined as described above.

\subsection{Statistical analysis}

Each experiment was repeated three times and all data sets are expressed in terms of their mean and standard deviation. Statistical analysis was performed using one-way ANOVA. The statistical difference between two groups of data was considered to be significant when $\mathrm{p}<0.05$. 


\section{Results and Discussion}

\subsection{Morphology of membrane nanofibers}

The surface morphology of the fibrous membranes and the diameter distribution of the fibers were observed by SEM and optical microscopy, respectively (Fig. 3A). The SF/PEG membranes showed smaller $(1.45 \pm 0.41 \mu \mathrm{m})$ and homogeneously distributed fiber diameters compared to the pure SF membrane. Some beads were associated with the pure SF fibers. The electrospinning process generated smooth fibers, likely due to the addition of PEG-400 which increased the viscosity of the solution, which is beneficial for the formation of uniform fibrous structure. These average diameters of the fibers in the drug-loaded membranes were higher than in the SF and SF/PEG membranes without the drugs, due to the addition of CUR/5-FU. The viscosity of spinning solutions decreased with increased content of CUR/5-FU. Since surface tension cane increase with a decrease in the viscosity, either this factor or viscosity played a role in determining the diameter of the electrospun fibers [33]. However, the electrical conductivity of spinning solutions increased with increase content of CUR/5-FU. Increasing the electrical conductivity of spinning solutions can promote decreased fiber diameter. The diameter of the fibers decreased from $2.74 \pm 0.77 \mu \mathrm{m}$ to $1.73 \pm 0.54 \mu \mathrm{m}$, when the drug loading of CUR/5-FU was increased to $0.3 \mathrm{wt} \%$ and $0.5 \mathrm{wt} \%$, respectively. While the drug loading of CUR and 5-FU increased to $0.45 \mathrm{wt} \%$ and $0.75 \mathrm{wt} \%$, the diameter of the fibers increased to $4.63 \pm 1.77 \mu \mathrm{m}$. The fiber beads, irregular shape, and uneven distribution of diameters of the fibers were observed in the membranes with the high drug loadings, likely due to insoluble drug particles in the spinning solutions and the increased surface tension of the spinning solution [2].

\subsection{Structural analysis}

Characteristic peaks for silk I structure around $1652 \mathrm{~cm}^{-1}$ (Amide I), $1543 \mathrm{~cm}^{-1}$ (Amide II), $1242 \mathrm{~cm}^{-1}$ (Amide III) and $669 \mathrm{~cm}^{-1}$ (Amide V), and silk II peaks around $1626 \mathrm{~cm}^{-1}$ (Amide I), $1532 \mathrm{~cm}^{-1}$ (Amide II), $1236 \mathrm{~cm}^{-1}$ (Amide III) and $696 \mathrm{~cm}^{-1}$ (Amide V) have been reported [34, 35]. As shown in Fig. 3B, 
the major peaks at $1542.3 \mathrm{~cm}^{-1}$ and $1648.2 \mathrm{~cm}^{-1}$ that accompany $\alpha$-helix and random coil structures were found in SF membranes (curve a). The characteristic peaks at $1520.7 \mathrm{~cm}^{-1}$ and $1629.5 \mathrm{~cm}^{-1}$ indicated the presence of $\beta$-sheet structure in the SF/PEG membrane (curve b). This is consistent with our previous observations that addition of PEG-400 promoted a structural transformation from $\alpha$-helix and random coil dominated material to $\beta$-sheet dominated structure in the material [36]. For the drug-loaded membranes of $0.15 / 0.25,0.3 / 0.5$ and $0.45 / 0.75 \%$ by weight of CUR/5-FU (curves c-e), the characteristic peaks of CUR at $1447.5 \mathrm{~cm}^{-1}, 1170.6 \mathrm{~cm}^{-1}$ and $955.1 \mathrm{~cm}^{-1}$, and 5-FU at $2932.7 \mathrm{~cm}^{-1}, 2875.7 \mathrm{~cm}^{-1}, 1423.4$ $\mathrm{cm}^{-1}$ and $551.9 \mathrm{~cm}^{-1}$ were identified, suggesting that the dual drugs were encapsulated in the membranes with chemical structures still present. The result also showed that the addition of drugs did not influence the secondary structures of SF.

The secondary structure of SF (a) and SF/PEG (b) membranes were mainly alpha helical, with a higher content than that in the drug-loaded SF membranes (c-e) $(* *, \mathrm{P}<0.05)$ (Fig 3C). The beta sheet content of the drug-loaded SF membranes was significantly higher than that of the control group SF(a) and SF/PEG (b) (***, $\mathrm{P}<0.01)$, indicating that drug loading promoted the formation of beta sheet. The beta sheet content in the drug loaded membranes reached $40.44 \%$ when the proportion of CUR/5-FU was increased to $0.3 / 0.5 \mathrm{wt} \%$, significantly higher than that of $0.15 / 0.25 \mathrm{wt} \%$ group c (34.23\%) and 0.45/0.75 wt\% group e (34.73\%). This increase was likely because the hydrophobic CUR binds to the hydrophobic region of SF, which induced the secondary structure of SF to transition to beta sheet, with the main structure of the drug-loaded membrane as silk II after adding CUR/5-FU. This is consistent with the XRD analysis (Fig. 3D). The content of beta sheet increased from $34.23 \%$ to $40.44 \%$ when the proportion of CUR/5-FU was increased from $0.15 / 0.25 \mathrm{wt} \%$ (c) to $0.3 / 0.5 \mathrm{wt} \%$ (d). However, as the drug concentration was increased, the content of beta sheet decreased, possibly due to the negative effect of increase of 5-FU loading content that easily binds to the hydrophilic region of SF. 
According to previous studies on silk crystal structures using WAXD analysis, the main reflection peaks located at $12.1^{\circ}, 19.8^{\circ}, 24.1^{\circ}, 28.5^{\circ}$ and $33.3^{\circ}$ were ascribed to the silk I structure, and those located at $9.1^{\circ}, 18.8^{\circ}$, and $20.5^{\circ}$ were ascribed to the silk II structure [16]. Fig. 3D shows the transition of the reflection peak at $23.1^{\circ}$ in the SF membrane to $20.1^{\circ}$ in the SF/PEG membrane, indicating that the addition of PEG-400 induced the transformation of SF membrane from silk I to silk II structure, consistent with the FT-IR observations. The reflection peaks of three CUR/5-FU loaded membranes were all at $20.7^{\circ}$, demonstrating the presence of silk II structure. Thus, in line with the FT-IR observations, the X-ray diffraction data confirmed that the incorporation of the dual drugs in the membrane did not significantly influence the secondary structure and crystallization of the silk protein in the membranes. Maintenance of a high content of crystalline $\beta$-sheet structure would increase mechanical strength, sustain drug release, and prevent material degradation, thus benefiting in vivo applications.

\subsection{Pore size distribution}

The pore size of a membrane is important for fluid permeability and cellular behavior. Pores provide sufficient space for cells ingrowth, thus promoting the release of drugs from the interface of the material into the surrounding tissues [37]. According to literatures, there is a close relationship between fiber diameter and pore size distribution [38]. The pore size distributions of electrospun membranes were examined using capillary flow porometry (Fig. 3E). The smallest pore size and fiber diameter of the SF/PEG membranes were $23.1 \pm 0.5 \mu \mathrm{m}$ and $1.45 \pm 0.41 \mu \mathrm{m}$, respectively. With the increase of drug loading from $0.15 / 0.25 \mathrm{wt} \%$ to $0.3 / 0.5 \mathrm{wt} \%$, the pore size and fiber diameter of the CUR/5-FU membranes increased from $24.2 \pm 0.5 \mu \mathrm{m}$ and $1.73 \pm 0.54 \mu \mathrm{m}$ to $31.1 \pm 0.5 \mu \mathrm{m}$ and $2.75 \pm 0.78 \mu \mathrm{m}$, respectively. When the drug loadings were increased to $0.45 / 0.75 \mathrm{wt} \%$, the pore size and fiber diameter of the membranes increased to $42.7 \pm 0.5 \mu \mathrm{m}$ and $4.63 \pm 1.77 \mu \mathrm{m}$, respectively, but uneven fiber structure and beads were found in the membranes, consistent with reports in the literature [38]. 


\subsection{Hydrophilic test}

The hydrophilicity of drug-loaded membranes is important because drug delivery often comes in contact with various biological fluids during use $[39,40]$. CUR/5-FU in the hydrophilic drug-loaded membranes distributed readily in the extracellular matrix (ECM) and diffused efficiently through intercellular spaces, so releasing anti-tumor drugs after arrival at tumor sites could significantly facilitate deep tumor penetration [41]. As shown in Fig. 4 and Table 1, the SF membrane showed a hydrophobic surface with a water contact angle (WCA) of $134.4 \pm 0.2^{\circ}$ at the beginning of analysis, and the WCA gradually decreased as the contact time was prolonged. In contrast, the SF/PEG membranes showed a hydrophilic surface with a contact angle of $63.9 \pm 0.5^{\circ}$ at the beginning of the analysis, and the contact angle decreased to $41.3 \pm 0.5^{\circ}$ after 20 seconds, much lower than the pure SF membrane. This result indicated that the addition of PEG-400 improved hydrophilicity of the membranes. The CUR/5-FU loaded membrane showed a more hydrophobic surface as compared to the pure SF and SF/PEG membranes, indicating that the addition of CUR, which is hydrophobic, increased hydrophobicity of the drug-loaded membranes, consistent with that reported in the literatures [43, 44]. Such hydrophilicity will be useful for the in vivo applications of stents because drug-loaded membranes provide novel hydrophilic drug delivery with improved functional properties, such as mucus permeation and improved cellular uptake, which lead to a raised bioavailability of the hydrophilic drug in the loaded membranes [42].

\subsection{Drug release}

As shown in Fig. 3F, the concentrations of the dual drugs in the release medium increased with the increase of drug loading in the membranes. The cumulative release rate increased with increased loading of CUR and 5-FU in the membranes. The drug-loaded membranes showed a fast release profile within 72 hrs and then release remained stable during 210 - 400 hrs. Particularly, the cumulative release of 5FU reached $95.63 \%$ at 96 hrs, while the CUR reached this percentage at 210 hrs. This is due to the water 
solubility of 5-FU, is higher than that of CUR. For all three membranes with different drug loadings, CUR and 5-FU were completely released within 400 hrs. It is likely that the fast release at the beginning was due to the diffusion of free drug from the nanofibrous membranes, while residual drugs inside the membranes were responsible for the sustained release along with the material degradation [45, 46].

\subsection{In vitro anti-tumor capability and cytotoxicity of drug-loaded membranes}

In order to evaluate the time-dependent in vitro anti-tumor effect of the CUR/5-FU loaded membranes, HCT116 cells were treated with pure drugs at their IC $_{50}$ concentration or drug-loaded membranes for 120 hrs, and cell viabilities were determined at different time points (Fig. 5A). After 12 hrs, cell viability of the 5-FU group was lower than those of CUR and CUR/5-FU groups. This could partly be because the addition of CUR reduced the inhibitive effect of 5-FU on HCT116 cells during the initial stages of exposure. As the treatments prolonged, the viability of HCT116 cells for the CUR, 5-FU and CUR/5-FU pure drug groups decreased rapidly, likely due to increased drug uptake efficiency by the cells [47, 48]. After 120 hrs treatment, cell viabilities of these groups were 50.01\%, 50.02\% and 21.72\%, respectively. The drug-loaded (0.3/0.5 wt\%) membranes groups exhibited a more rapid decrease of cell viability as compared to the pure drug groups, with $8.70 \pm 0.39 \%$ after 120 hrs treatment, significantly lower than that of CUR/5-FU pure drug groups $(21.26 \pm 0.90 \%)$ at the same time point $(\mathrm{p}<0.05)$. These results suggest that the drug-encapsulated SF membranes exhibited more efficient and more sustained antitumor effects as compared to the pure drugs, likely due to the stable and long term exposure of drugs in the drug-loaded membrane groups. The long-term in vitro toxic effects of CUR/5-FU loaded membranes were evaluated using non-cancerous NCM460 cells. As shown in Fig. 4B, the trend of cell viability change of NCM460 cells treated with experimental samples was similar to that of HCT116 cells. NCM460 cells co-cultured with the SF groups exhibited normal growth after cell adhesion, and the cell viability was close to the level of the control group. For drug-loaded $(0.3 / 0.5 \mathrm{wt} \%)$ membranes, cell 
viability narrowed to $9.99 \pm 0.99 \%$ at 120 hrs from $48.03 \pm 0.91 \%$ at 12 hrs because of slow and controlled release of CUR/5-FU.

\subsection{Cell cycle and apoptosis analysis}

Cell cycle anomalies induced by DNA replication errors are often observed in different types of cell damage [49]. DNA damage caused by chemo-drugs, such as 5-FU, interrupt cell cycle progression, leading to S phase arrest [50]. HCT116 cells treated with the CUR/5-FU combination treatment had a higher percentage of S phase cells (35.63\%) as compared to the single treatment group (CUR: $31.52 \%$ and 5-FU: 33.45\%) after 24 hrs treatment (Fig. 5C). This result indicated a synergistic effect of the combination treatment, which might have promoted S phase arrest. CUR/5-FU 0.3/0.5\% membrane treatment induced a stronger effect as compared to the solution combination treatment, with the percentage of S phase cells reaching $54.69 \%$ after 48 hrs of treatment. These data suggest that the drugloaded SF membranes had a higher anti-tumor effect as compared to the control of drugs in a soluble form, demonstrating the capability of SF material as a carrier to provide controlled drug release. The effect of CUR and 5-FU on the cell cycle of NCM460 cells was also determined. NCM460 cells (Fig. 5D) showed S phase arrest after 48 hrs treatment, similar to HCT116 cells.

We next performed Annexin-V/PI double staining to evaluate apoptosis-induced cell suicide, which may be another anti-tumor mechanism in addition to cell cycle arrest [51]. Annexin $\mathrm{V}(\mathrm{aV})$ reacted with phosphatidylserine (PS) was used as a marker of apoptosis. Presidium iodide (PI), which was utilized to detect plasma membrane integrity, was employed to detect necrotic cell death. Cell status was determined based on the percentage of $\mathrm{aV}-\mathrm{Vesidium}$ iodideaV-/PI+ (necrotic), $\mathrm{aV}+/ \mathrm{PI}-$ (apoptotic), and $\mathrm{aV}+/ \mathrm{PI}+$ (late apoptotic). HCT116 and NCM460 cells were stained and the apoptosis status of cells treated for 24 hrs and 48 hrs are shown in Fig. 5E and F. In the SF-treated group, very few apoptotic cells were found, indicating the silk membranes had excellent cytocompatibility and promoted the

proliferation of both HCT116 and NCM460 cells. The single treatment with either CUR or 5-FU after 48 
hrs induced a similar percentage (25.54\% and 28.94\%) of apoptotic HCT116 cells, respectively. In line with cell cycle analysis results, the combination treatment of CUR/5-FU presented higher apoptosis (38.85\%) after 48 hrs. The controlled release CUR/5-FU (0.3/0.5 wt\%) loaded membranes demonstrated the best anti-tumor effects, reaching an apoptotic cell percentage of $42.94 \%$, consistent with the results from cell cycle analysis. Similar results were found for the NCM460 cells, indicating that CUR and 5FU inevitably induced the apoptosis of non-cancerous epithelial cells. The ratios between 5-FU/CUR or other chemotherapy drug combinations will need to be optimized in the future to minimize toxicity to non-cancerous epithelial cells.

Based on the results of cell cycle and apoptosis, we found that CUR/5-FU loaded membranes had a higher anti-cancer effect compared to the single drug-loaded membranes. These results were similar to our previous study on 5-FU-loaded poly-L-lactide membranes for the treatment of colorectal cancer [2], which indicated that the mechanisms of inhibition of both HCT116 and NCM460 cells were due to increased apoptosis associated with cell cycle arrest. The mechanism of CUR/5-FU induced cell

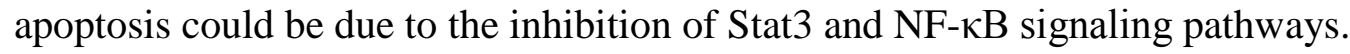

\subsection{Effect on drug resistance inhibition}

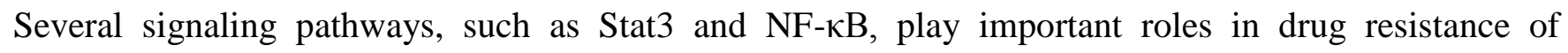
colorectal cancer cells after chemo-therapies, such as with $5-\mathrm{FU}[52,53]$. NF- $\mathrm{BB}$ is a crucial regulator of many physiological and pathophysiological processes including control of inflammation and cancer progression. Stat3 relays signals from activated receptors in the plasma membrane to the nucleus, where it accumulates and regulates target gene expression [54]. Combination treatment with drugs targeting these pathways presents synergistic effects. The protein expressions of P-Stat3 and P-P65 in HCT116 and NCM460 cells with the treatment of pure drugs and drug-loaded SF membranes were analyzed (Fig. 5G-J). The expression of P-Stat3 and P-P65 decreased in the single CUR or 5-FU-treated groups as compared to either the control group or the SF group, suggesting that the CUR or 5-FU treatments could 
inhibit drug resistance. The CUR/5-FU treatment showed a stronger drug resistance-inhibiting effect, as the expression of both proteins was lower than the single CUR or 5-FU treatments. The strongest inhibition effect, especially on Stat3 signaling pathway, was observed in the SF membranes loaded with CUR/5-FU (0.3/0.5 wt\%). These data indicate that the SF membranes as a delivery carrier may promote the anti-tumor effect of CUR and 5-FU through regulating Stat3 and NF- $\kappa$ B pathways. These results indicated that the Stat3 and NF-кB signaling pathway in HCT116 and NCM460 cells was suppressed due to the CUR/5-FU released from the drug-loaded SF membranes.

\subsection{In vivo study of the anti-tumor effect}

For toxicity analysis, the median lethal dose $\left(\mathrm{LD}_{50}\right)$ was used to evaluate acute toxicity as approved by the FDA in our previous study [55]. The control and SF membrane groups showed no difference in terms of tumor volumes; both increased to approximately 350\% after 12 days post-surgery (Fig. 6B, left). The body weight changes of mice were measured every two days. No significant difference was found between the control and SF-treated groups (Fig. 6B, right). A significant decline of body weight was observed in the other three drug-treated groups from day 2, but no significant difference was found between these groups. These data indicated that the SF membranes as a drug delivery carrier was safe for use in vivo, without causing severe side effects. After the mice were sacrificed at day 12, the tumors were removed and processed for microscopy (Fig. 6C, left). The tumor volumes of the CUR/5-FU LD 50 combination group were $139.25 \pm 9.59 \%$ compared to original volume after 12 days, smaller than that of the single 5-FU LD 50 treatment group $(178.16 \pm 10.89 \%)$ as well as the control and SF membrane groups, indicating a synergistic anti-tumor effect for the combination treatment, consistent with the in vitro results. The strongest anti-tumor effect was found in the group of CUR/5-FU (0.3/0.5\%) loaded SF membranes; the tumor volume decreased to $99.97 \pm 8.76 \%$ of initial volume. These data indicated that the SF membranes with controlled release features extended the duration for drugs to be absorbed by the 
tumor cells, resulting in improved anti-tumor effects. The expression of P-Stat3 and P-P65 in the tumors was analyzed, and the results were similar to that obtained in the in vitro study (Fig. 6C, right).

Representative images for histopathology are illustrated in Fig. 6D. Partial necrosis was found in the control and SF groups, mainly because of the rapid tumor growth. Single drug treatments with 5-FU $\mathrm{LD}_{50}$ and the CUR/5-FU LD 50 treatment induced both necrosis and apoptosis, indicating that necrosis of intestinal cells was an unavoidable side effect of the localized high-concentration of 5-FU or CUR/5-FU treatment. However, CUR/5-FU (0.3/0.5\%) loaded membranes induced more apoptosis, while few necrotic cells were observed. The results showed that the drug-loaded membranes provided more efficient and sustained anti-tumor effects, mainly attributed to the drug-controlled release properties. Decreased levels of P-Stat3 were observed when treated with single 5-FU LD50 or the CUR/5-FU combination. The group of CUR/5-FU (0.3/0.5 wt\%) loaded SF membranes indicated the lowest level of P-Stat3 (Fig. 6E). This result corresponded to the previous in vitro cell signaling analysis (Fig. 5G), suggesting that the drug-loaded membrane could provide improved induction of apoptosis in vivo, which might be associated with the inhibited Stat3 signaling pathway.

\section{Conclusions}

CUR and 5-FU were dissolved with PEG in SF solution at three concentrations $(0.15 / 0.25 \%, 0.3 / 0.5 \%$ and $0.45 / 0.75 \%$ by weight to the SF solution), and the solutions were electrospun onto weft-knitted SF/PDO stents. The results showed that the incorporation of the dual drugs in the membranes did not significantly influence secondary structure and crystallization of the silk protein in the membranes. The drug-loaded membranes showed burst-release behavior within 72 hours and subsequently the release kinetics remained stable during 210-400 hrs. CUR/5-FU loaded membranes showed better anti-tumor effects. This can be attributed to cell cycle arrest in the S phase in association with induced apoptosis in tumor cells by blocking Stat3 and NF-אB signaling pathways. Furthermore, in vivo, the implanted 
CUR/5-FU loaded membranes showed the smallest tumor volume and lightest tumor weight, and induced more apoptosis with few necrotic cells observed. Therefore, the weft-knitted SF/PDO stents coated with CUR/5-FU loaded membranes have potential in the management of cancer progress and drug-resistance of tumor cells.

\section{Acknowledgements}

This work was supported by the National Natural Science Foundation of China (51603140), Natural Science Foundation of Jiangsu Province (BK20150372), and "National Key R\&D Program of China (No. 2017YFC1308800)". The authors would like to thank the support of China Postdoctoral Science Foundation, University Science Research Project of Jiangsu Province (16KJB540003) and Key Industry Technology Innovation, Science and Technology Project of Suzhou (SYG201638), and Sino-Germany Joint Project (GZ1094).

\section{Author contributions}

Xusheng Xie and Xiaobin Zheng designed the work, prepared the biomaterials and wrote the manuscript. Zhifen Han with the background of traditional Chinese medicine characterized the drugs and identified the anti-tumor mechanism. Yufeng Chen, Bin Zheng and Xiaowen He from the gastrointestinal hospital assisted with cell and animal experiments. Zhaozhu Zheng and Yongfeng Wang did the materials characterization and scientific analysis. David L Kaplan and Yi Li instructed the writing including layout, interpretation and English. Gang Li, Xiaoqin Wang and Ping Lan are the main principle investigators of this cooperation and instructed the whole process of this study including design of experiment, preparation and biological evaluation and so on since this is an interdisciplinary project.

\section{Disclosure}

The authors have nothing to disclose regarding the conflict of interest. 
Fig. 1. Schematic of mechanisms and processes of drug-loaded stent deployment and functions for the treatment of colorectal cancer; (a) deflated balloon catheter and compressed drug-loaded stent are inserted into the stenosis site; (b) inflated balloon expands the stent and compresses the tumor to restore the intestinal lumen; (c) stent-widened intestine; (d) and (e) the drugs are released from the coating membrane and the tumor is treated locally. 
Fig. 2. Experimental design: (a): PDO polymer was synthesized by a conventional bulk ring-opening polymerization method; (b): PDO monofilament was weft-knitted into a tubular stent; (c): the principle diagram and photos of the modified electro spinning machine; (d): the prepared stent with drug-loaded coating membrane; (e) and (f): anti-tumour effect of the drug-loaded membrane was examined in vitro and in vivo using HCT116, NCM460 cells and BALB/c nude mice. 

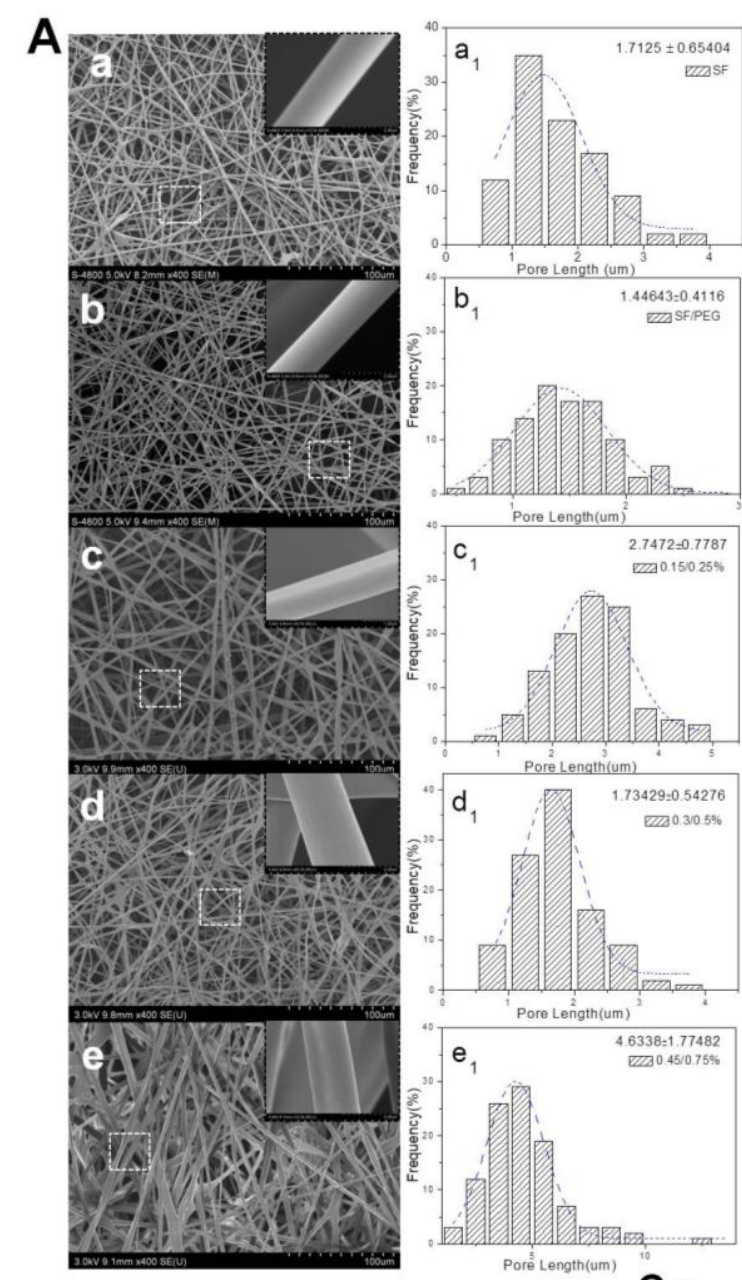

B
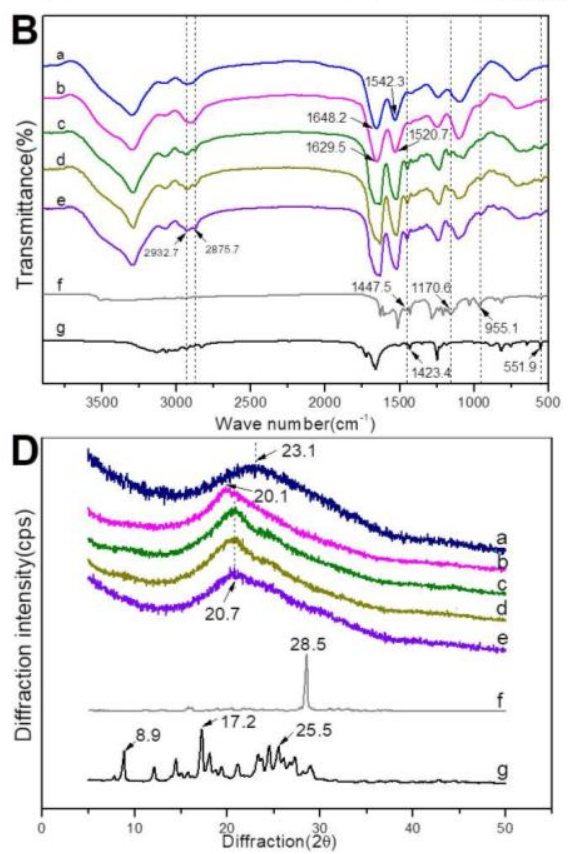
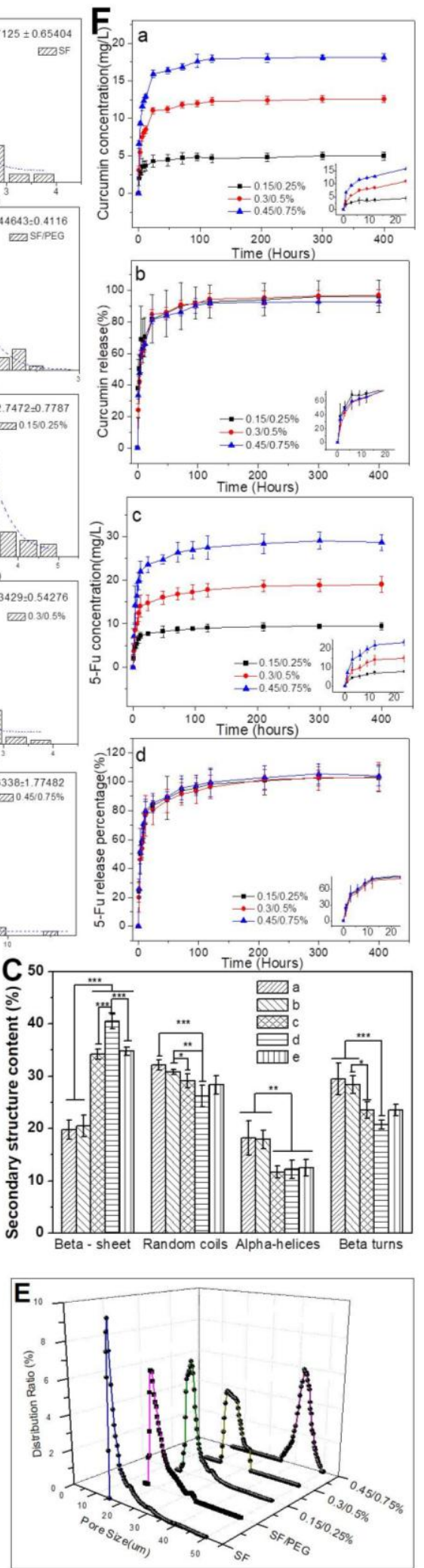

Fig. 3. (A) Micrographs and fiber diameter distribution of drug-loaded membranes; FT-IR spectrums (B), WAXD spectrums (C), Pore size distribution (D) and Images of WCA (E) of the membranes: (A-E, a-e) 
represent SF, SF/PEG and three groups of SF/PEG/drug fibrous membranes with 0.15/0.25, 0.3/0.5 and 0.45/0.75 wt\% of CUR/5-FU, respectively. In vitro drug release profiles (F) of three SF/PEG/drug membranes with $0.15 / 0.25,0.3 / 0.5$ and $0.45 / 0.75 \mathrm{wt} \%$ of CUR/5-FU loadings; Data presented is the mean $( \pm)$ standard deviation of at least four measurements $(n=4)$.

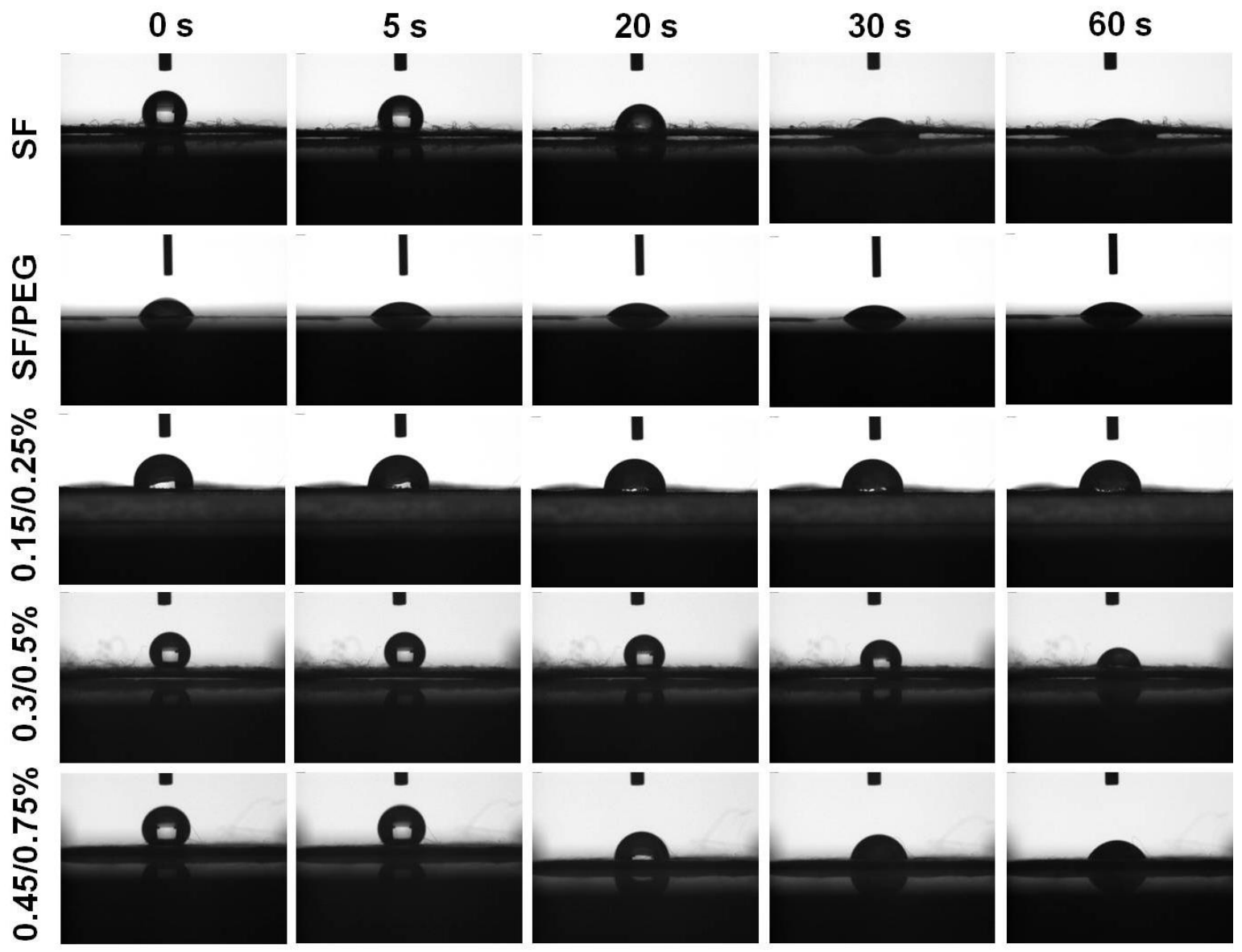

Fig. 4. Images of WCA of SF, SF/PEG and three drug membrane groups of SF/PEG/drug fibrous membranes with $0.15 / 0.25,0.3 / 0.5$ and $0.45 / 0.75 \mathrm{wt} \%$ of CUR/5-FU. 

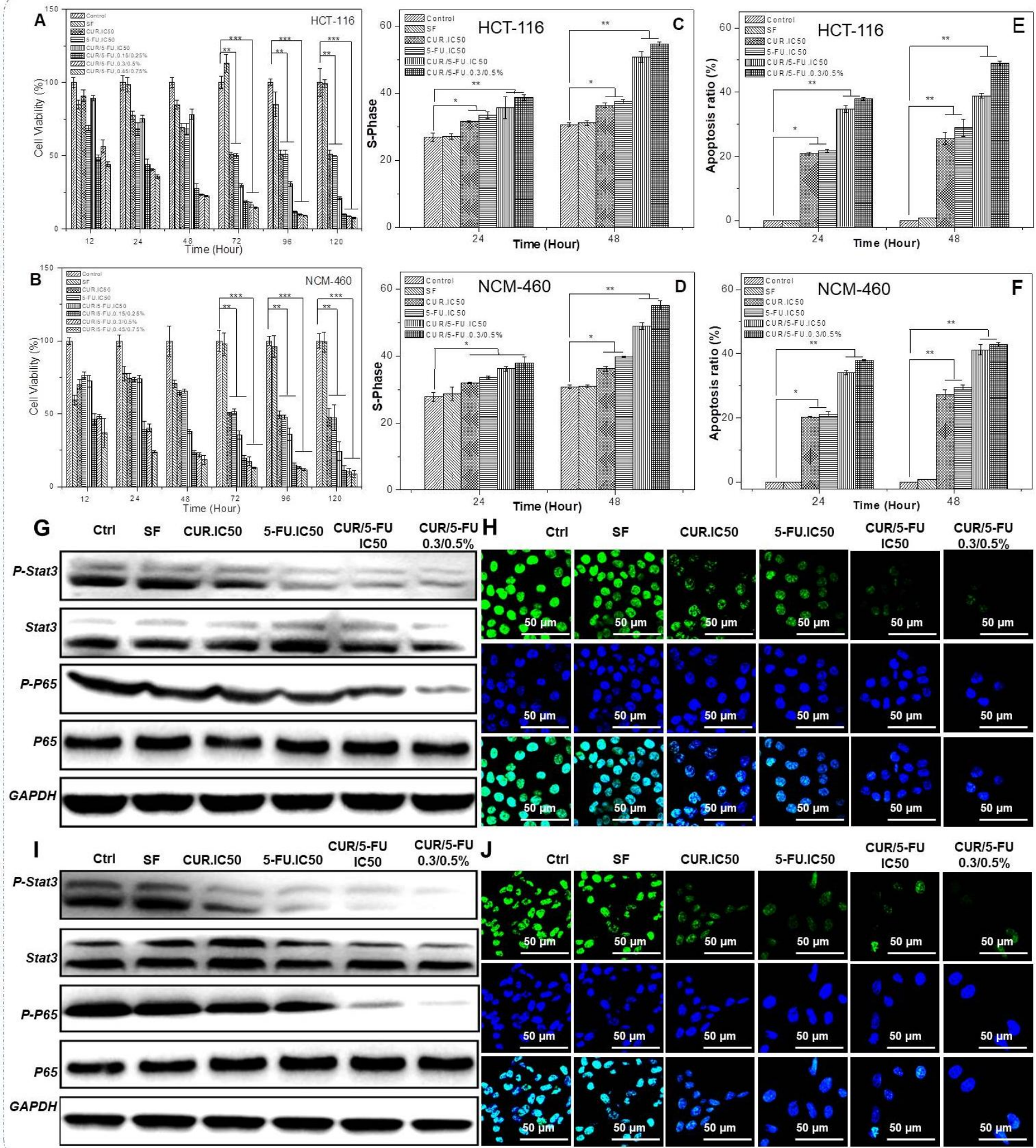

CUR/5-FU
$0.3 / 0.5 \%$

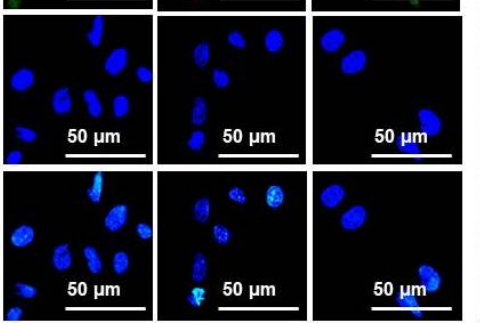

Fig. 5. (A, B) Time-dependent in vitro anti-cancer effect of drug-loaded membranes on HCT116 cells and cytotoxicity on NCM460 cells within 120 hrs, Quantitative analysis of Cell cycle (C, D) and Apoptotic progression (E, F) of HCT116 and NCM460 cells co-cultured with experimental samples at 
24 and 48 hrs. Western blot of GAPDH, NF-кB (P-P65) and P-Stat3 protein levels in HCT116 and NCM460 cells co-cultured with experimental samples at 24 and 48 hrs (G, I); expression of P-Stat3 protein levels in cell nucleus morphology determined by goat anti-rabbit IgG (green) and DAPI (blue) $(\mathrm{H}, \mathrm{J})$. All the data was obtained from at least three independent experiments. The statistical significance is expressed as $* * * \mathrm{p}<0.001, * * \mathrm{p}<0.01,{ }^{*} \mathrm{p}<0.05$. 

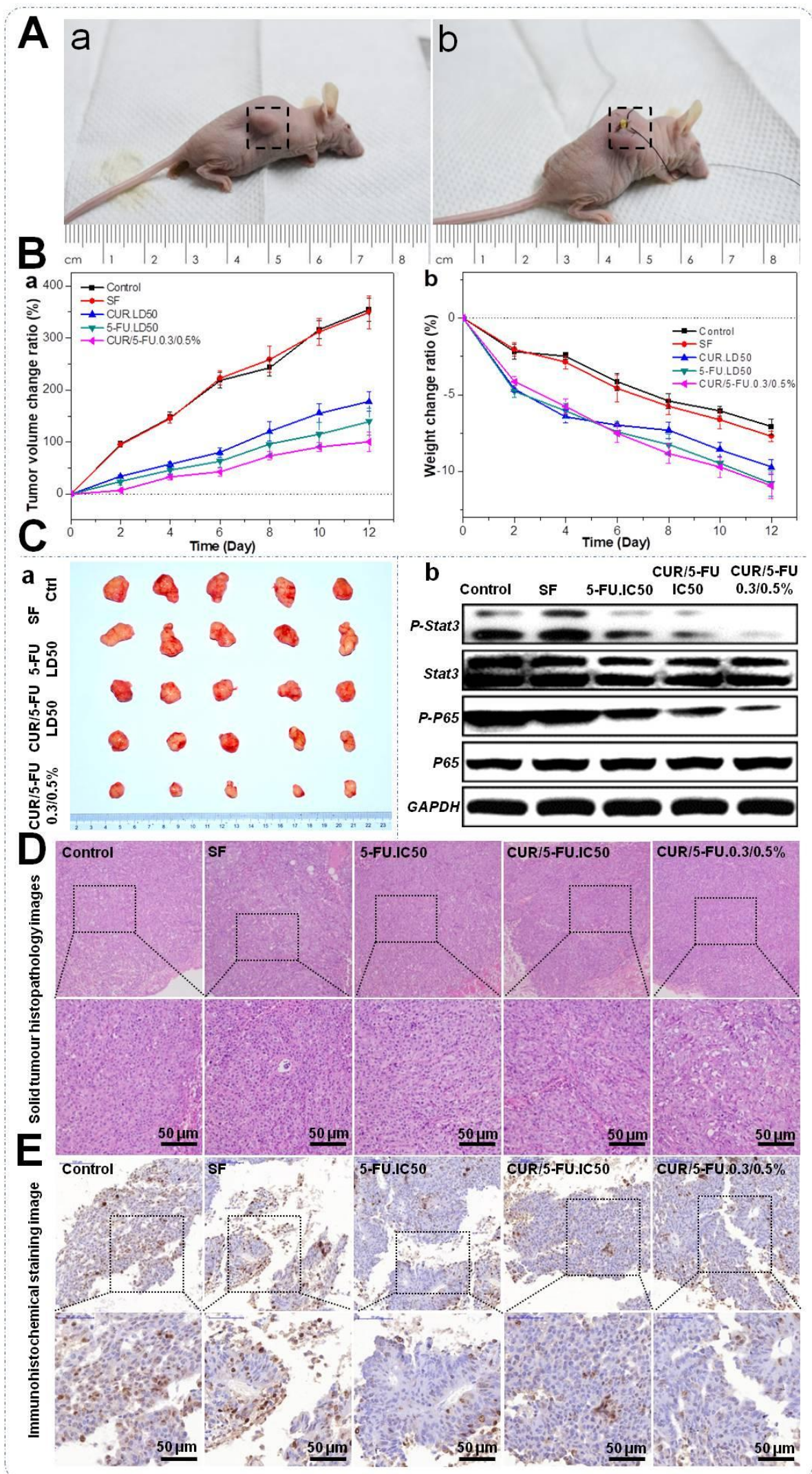

Fig. 6. (A) Operative procedure for membrane implantation into the tumor; (a): the mouse was given general anesthesia induced by intraperitoneal injection of pentobarbital sodium ( $30 \mu \mathrm{g} / \mathrm{g}$ body weight); -28 - 
(b): the drug membrane was implanted into the tumor. In vivo investigation of tumor inhibition effects of the CUR/5-FU membrane: (B) tumor growth curves and body weight change ratios of mice treated by different groups during the experimental periods; (C) macroscopic images of exposed tumor; and Western blot of tumor extracts in experimental mice. Solid tumor histopathological images on apoptosis and necrosis (D) and immunohistochemical staining images of P-Stat3 (E) for the tumors in mice treated with blank control; pure SF membrane; 5-FU and CUR/5-FU solution ( $\left.\mathrm{LD}_{50}\right)$, CUR/5-FU membrane (0.30/0.50 wt\%) after 12 days. The apoptotic cells showed well maintained integrity of nucleus and cytoplasm while necrotic cells displayed dispersed basophilic spots within weakly eosinophilic cytoplasm. Black arrows indicate positive P-Stat3 staining. 


\section{Supplemental Data}

In order to determine cell morphology, the nucleus and cytoskeleton of HCT116 and NCM460 cells were visualized (Supplemental Fig. 1A and B). In line with the determination of total cell metabolic activity, both cell lines treated with SF alone showed similar features to those in the control group, with cells spreading and growing to a high density. Either CUR or 5-FU treatment inhibited cell growth of both cell lines or the combination treatment further enhanced the inhibitory effect. Consistent with the results from MTS assay, treatments with CUR/5-FU (0.3/0.5 wt\%) loaded membranes significantly reduced the growth rate and numbers of both cell lines. In addition, these reductions were even lower than CUR/5-FU group. These data indicate that drug-loaded membranes could be used as a material to inhibit cancer cell growth, although non-cancerous cells were inevitably affected to some extent.

The results of cell cycle and FACS distributions (\%) of apoptotic HCT116 and NCM460 cells cocultured with experimental samples at 24 and 48 hrs are shown in Supplemental Fig 1C and D. The inhibition effect on S phase arrest was similar between NCM460 and HCT116 cells after 48 hrs treatment. 


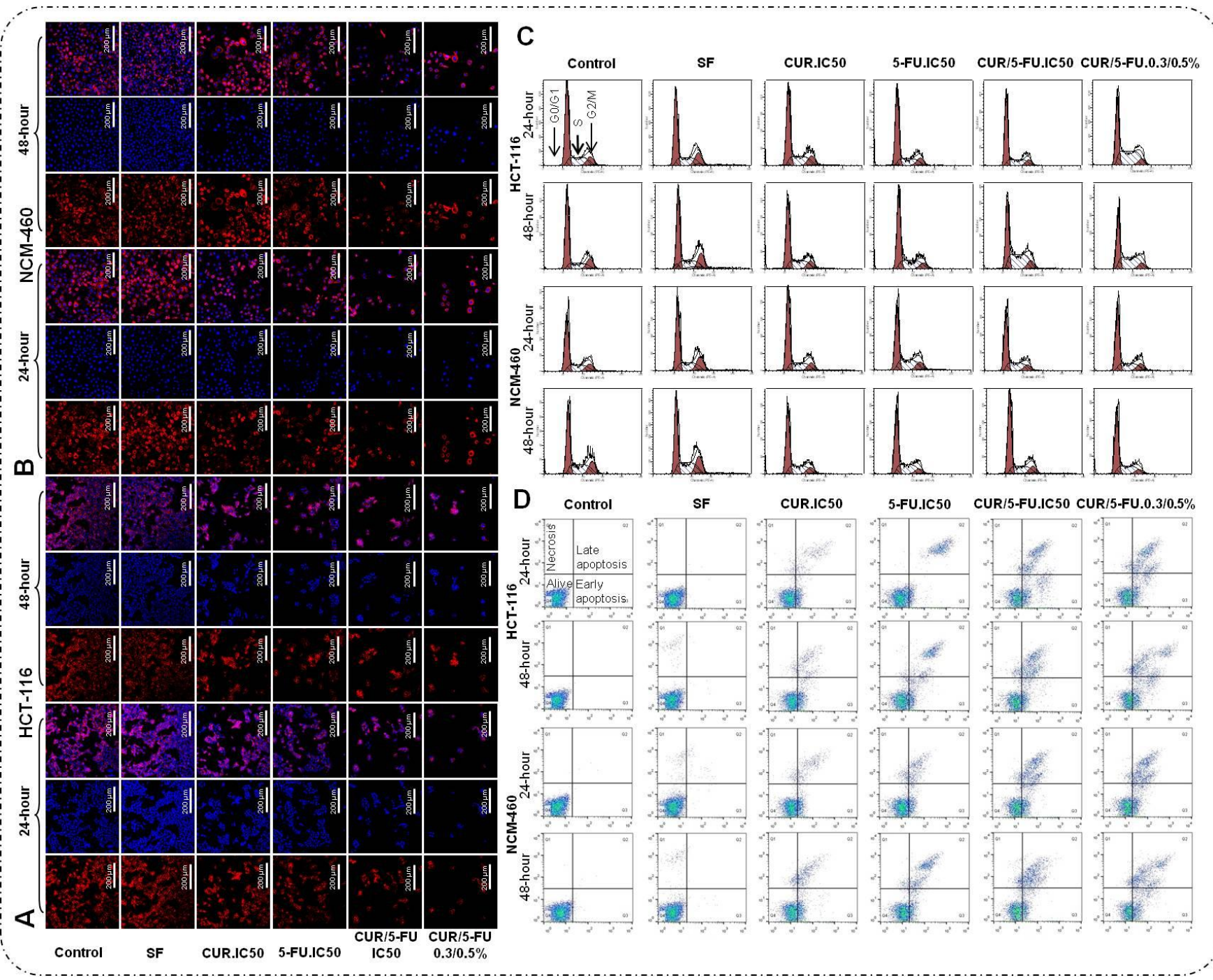

Supplemental Figure 1. (A, B) Microscopic images of HCT116 and NCM460 cells co-cultured with experimental samples at 24 and 48 hrs with DAPI (blue) and rhodamine-phalloidin (red) staining; (C, D) Cell cycle and FACS distributions (\%) of apoptotic HCT116 and NCM460 cells co-cultured with experimental samples at 24 and 48 hrs. All the data was obtained from at least three independent experiments. The statistical significance is expressed as ${ }^{* * *} \mathrm{p}<0.001,{ }^{* *} \mathrm{p}<0.01,{ }^{*} \mathrm{p}<0.05$. 


\section{Table}

Table 1. WCA of SF, SF/PEG and three groups of SF/PEG/drug loaded membranes.

\begin{tabular}{|c|c|c|c|c|c|}
\hline $\begin{array}{l}\text { Time } \\
\text { Samples }\end{array}$ & $0 \mathrm{~s}$ & $5 \mathrm{~s}$ & $20 \mathrm{~s}$ & $30 \mathrm{~s}$ & $60 \mathrm{~s}$ \\
\hline SF & $134.4^{\circ} \pm 0.6^{\circ}$ & $125.8^{\circ} \pm 0.6^{\circ}$ & $79.2^{\circ} \pm 0.1^{\circ}$ & $37.1^{\circ} \pm 0.2^{\circ}$ & $22.4^{\circ} \pm 0.3^{\circ}$ \\
\hline SF/PEG & $63.9^{\circ} \pm 0.4^{\circ}$ & $48.7^{\circ} \pm 0.2^{\circ}$ & $41.3^{\circ} \pm 0.3^{\circ}$ & $40.3^{\circ} \pm 0.3^{\circ}$ & $27.9^{\circ} \pm 0.1^{\circ}$ \\
\hline $0.15 / 0.25$ wt $\%$ & $108.6^{\circ} \pm 0.5^{\circ}$ & $102.3^{\circ} \pm 0.5^{\circ}$ & $96.7^{\circ} \pm 0.4^{\circ}$ & $86.3^{\circ} \pm 0.4^{\circ}$ & $63.6^{\circ} \pm 0.4^{\circ}$ \\
\hline $0.15 / 0.25 \mathrm{wt} \%$ & $158.2^{\circ} \pm 0.7^{\circ}$ & $147.9^{\circ} \pm 0.4^{\circ}$ & $134.9^{\circ} \pm 0.3^{\circ}$ & $103.2^{\circ} \pm 0.3^{\circ}$ & $59.3^{\circ} \pm 0.3^{\circ}$ \\
\hline $0.45 / 0.75$ wt $\%$ & $162.7^{\circ} \pm 0.5^{\circ}$ & $151.3^{\circ} \pm 0.6^{\circ}$ & $82.1^{\circ} \pm 0.7^{\circ}$ & $79.3^{\circ} \pm 0.5^{\circ}$ & $32.7^{\circ} \pm 0.2^{\circ}$ \\
\hline
\end{tabular}




\section{References}

[1] Tao L, Mei HL, Harms B, Kennedy G, Lin C. MicroRNA-21 as a potential colon and rectal cancer biomarker. World J Gastroentero 2013;19:5615-21.

[2] Li G, Chen Y, Hu J, Wu X, Hu J, He X, et al. A 5-fluorouracil-loaded polydioxanone weft-knitted stent for the treatment of colorectal cancer. Biomaterials 2013;34:9451-61.

[3] Watson AJ, Shanmugam V, Mackay I, Chaturvedi S, Loudon MA, Duddalwar V, et al. Outcomes after placement of colorectal stents. Colorectal Dis 2005;7:70-3.

[4] Saranovic D, Djuric-Stefanovic A, Ivanovic A, Masulovic D, Pesko P. Fluoroscopically guided insertion of self-expandable metal esophageal stents for palliative treatment of patients with malignant stenosis of esophagus and cardia: comparison of uncovered and covered stent types. Dis Esophagus 2005;18:230-8.

[5] CamuEz F, Echenagusia A, Simo G, Turegano F, Vazquez J, Barreiro-Meiro I. Malignant colorectal obstruction treated by means of self-expanding metallic stents: effectiveness before surgery and in palliation. Radiology 2000;216:492-7.

[6] Uurto I, Kotsar A, Isotalo T, Mikkonen J, Martikainen PM, Kellomaki M, et al. Tissue biocompatibility of new biodegradable drug-eluting stent materials. J Mater Sci-Mater M 2007;18:1543-7.

[7] Saito Y, Minami K, Kobayashi M, Nakao Y, Omiya H, Imamura H, et al. New tubular bioabsorbable knitted airway stent: biocompatibility and mechanical strength. J Thorac Cardiov Sur 2002;123:161-7.

[8] Akbulut H, Tang Y, Maynard J, Zhang L, Pizzorno G, Deisseroth A. Vector targeting makes 5-fluorouracil chemotherapy less toxic and more effective in animal models of epithelial neoplasms. Clin Cancer Res 2004;10:7738-46.

[9] Andre T, Boni C, Navarro M, Tabernero J, Hickish T, Topham C, et al. Improved overall survival with oxaliplatin, fluorouracil, and leucovorin as adjuvant treatment in stage II or III colon cancer in the MOSAIC trial. J Clin Oncol 2009;27:3109-16.

[10]Liu J, Wang Z, Wu K, Li J, Chen W, Shen Y, et al. Paclitaxel or 5-fluorouracil/esophageal stent combinations as a novel approach for the treatment of esophageal cancer. Biomaterials 2015;53:592-9.

[11]Toden S, Okugawa Y, Hur K, Jascur TA, Burhrmann C, Nattamai D, et al. Abstract 4119: Novel evidence for chemopreventive effects of curcumin and boswellic acid through regulation of mir-27a and mir-34a in human colorectal cancer. Cancer Res 2014;74:4119.

[12]Radhakrishnan VM, Kojs P, Young G, Ramalingam R, Jagadish B, Mash EA, et al. pTyr421 Cortactin Is Overexpressed in Colon Cancer and Is Dephosphorylated by Curcumin: Involvement of Non-Receptor Type 1 Protein Tyrosine Phosphatase (PTPN1). Plos One 2014;9:e85796.

[13]Toden S, Okugawa Y, Jascur T, Wodarz D, Komarova NL, Buhrmann C, et al. Curcumin mediates chemosensitization to 5-fluorouracil through miRNA-induced suppression of epithelial-to-mesenchymal transition in chemoresistant colorectal cancer. Carcinogenesis 2015;36:355-67. 
[14]Li G, Li Y, Chen G, He J, Han Y, Wang X, et al. Silk-based biomaterials in biomedical textiles and fiber-based implants. Adv healthc mater 2015;4:1134-51.

[15]Zhao Z, Li Y, Xie MB. Silk fibroin-based nanoparticles for drug delivery. Int J Mol Sci 2015;16:4880-903.

[16]Li G, Li F, Zheng Z, Luo T, Liu J, Wu J, et al. Silk microfiber-reinforced silk composite scaffolds: fabrication, mechanical properties, and cytocompatibility. J Mater Sci 2016;51:3025-35.

[17]Li G, Liu J, Zheng Z, Wang X, Kaplan DL. Structural Mimetic Silk Fiber-Reinforced Composite Scaffolds Using Multi-Angle Fibers. Macromol Biosci 2015;15:1125-33.

[18]Perrone GS, Leisk GG, Lo TJ, Moreau JE, Haas DS, Papenburg BJ, et al. The use of silk-based devices for fracture fixation. Nat commun 2014;5:3385.

[19]Marina Z, Annalisa A, Claudia V, Claudio T, Franco F, Piacentino MG. Study on cast membranes and electrospun nanofibers made from keratin/fibroin blends. Biomacromolecules 2008;9:2819-25.

[20]Yucel T, Lovett ML, Kaplan DL. Silk-based biomaterials for sustained drug delivery. J Control Release 2014;190:381-97.

[21]He C, Zheng Z, Zhang J, Li G, Wang X. Controlled Release of Natural Antibacterial Drug Loaded by Silk Biomaterials. J Fiber Bioeng Inform 2016;10:77-90.

[22]Vepari C, Matheson D, Drummy L, Naik R, Kaplan DL. Surface modification of silk fibroin with poly(ethylene glycol) for antiadhesion and antithrombotic applications. J Biomed Mater Res A 2010;93:595-606.

[23]Zhou Y, Yang H, Xin L, Mao J, Gu S, Xu W. Electrospinning of carboxyethyl chitosan/poly(vinyl alcohol)/silk fibroin nanoparticles for wound dressings. Int J Biol Macromol 2013;53:88-92.

[24]Wei K, Kim BS, Kim IS. Fabrication and biocompatibility of electrospun silk biocomposites. Membr 2011;1:275-98.

[25]Wu J, Xie X, Zheng Z, Li G, Wang Y, Wang X. Effect of pH on polyethylene glycol (PEG)-induced silk microsphere formation for drug delivery. Mat Sci Eng C 2017;80:549-57.

[26]Xie X, Liu L, Zheng Z, Han Z, Zhi M, Kaplan DL, et al. Silk fibroin-based fibrous anal fistula plug with drug delivery function. Macromo Biosci 2018. Online. DOI: 10.1002/mabi.201700384

[27]Hang Y, Zhang Y, Jin Y, Shao H, Hu X. Preparation and characterization of electrospun silk fibroin/sericin blend fibers, J Mater Res 2011;26:2931-7.

[28]Kenawy ER, Bowlin GL, Mansfield K, Layman J, Sanders E, Simpson DG, et al. Release of tetracycline hydrochloride from electrospun. Polym 2002;43:457-8.

[29]Verreck G, Chun I, Rosenblatt J, Peeters J, Dijck AV, Mensch J, et al. Incorporation of drugs in an amorphous state into electrospun nanofibers composed of a water-insoluble, nonbiodegradable polymer. J Control Release 2003;92:349.

[30]Li Z, Liu Q, Wang H, Song L, Shao H, Xie M, et al. Bladder Acellular Matrix Graft Reinforced Silk Fibroin Composite Scaffolds Loaded VEGF with Aligned Electrospun Fibers in Multiple Layers, ACS Biomater. Sci Eng 2015;1:238-46. 
[31]Liu Q, Zhou S, Zhao Z, Wu T, Wang R, Xu S, et al. Silk fibroin/polyethylene glycolnano fibrous membranes loaded with curcumin. Therm Sci 2017;21:1587-93.

[32]Loscertales IG, Barrero A, Guerrero I, Cortijo R, Marquez M, Ganan-Calvo AM. Micro/nano encapsutation via electrified coaxial liquid jets. Sci 2002;295:1695-8.

[33]Metter RB, Ifkovits JL, Hou K, Vincent L, Hsu B, Wang L, et al. Biodegradable fibrous scaffolds with diverse properties by electrospinning candidates from a combinatorial macromer library. Acta Biomater 2010;6:1219-26.

[34]Li G, Li Y, Lan P, He X, Zhao Z, Li Z, et al. Study of heat-setting treatment for biomedical polydioxanone stents. J Ind Text 2015;46.

[35]Sun Z, Fan C, Tang X, Zhao J, Song Y, Shao Z, et al. Characterization and antibacterial properties of porous fibers containing silver ions. Appl Surf Sci 2016;387:828-38.

[36] Taddei P, Arai T, Boschi A, Monti P, Tsukada M, Freddi G. In vitro study of the proteolytic degradation of Antheraea pernyi silk fibroin. Biomacromolecules 2006;7:259-67.

[37] Yang G, Zhang L, Cao X, Liu Y. Structure and microporous formation of cellulose/silk fibroin blend membranes: Part II. Effect of post-treatment by alkali. J Membrane Sci 2002;210:379-87.

[38]Wang X, Partlow B, Liu J, Zheng Z, Su B, Wang Y, et al. Injectable silk-polyethylene glycol hydrogels. Acta Biomater 2015;12:51-61.

[39]Ran Q, Yang W, Hu Y, Shen X, Yu Y, Xiang Y, et al. Osteogenesis of 3D printed porous Ti6Al4V implants with different pore sizes. J Mech Behav Biomed 2018;84:1.

[40]Diamond S. Mercury porosimetry : An inappropriate method for the measurement of pore size distributions in cement-based materials. Cement Concrete Res 2000;30:1517-25.

[41] Vashisth P, Raghuwanshi N, Srivastava AK, Singh H, Nagar H, Pruthi V. Ofloxacin loaded gellan/PVA nanofibers-Synthesis, characterization and evaluation of their gastroretentive/ mucoadhesive drug delivery potential. Mat Sci Eng C 2016;71.

[42]Dong J, Sun Q, Wang J. Basic study of corn protein, zein, as a biomaterial in tissue engineering, surface morphology and biocompatibility. Biomaterials 2004;25:4691-7.

[43]Liu Y, Lian L, Li L, Zhou Z, Wang F, Xiong X, et al. Programmed drug delivery system based on optimized "size decrease and hydrophilicity/hydrophobicity transformation" for enhanced hepatocellular carcinoma therapy of doxorubicin. Nanomedicine 2018;14.

[44]Garcia M. Design of lipid nanoparticles for the oral delivery of hydrophilic macromolecules. Colloid Surface B 2003;27:159-68.

[45]Karthikeyan K, Guhathakarta S, Rajaram R, Korrapati PS. Electrospun zein/eudragit nanofibers based dual drug delivery system for the simultaneous delivery of aceclofenac and pantoprazole. Int J Pharm 2012;438:117-22.

[46] Aditya NP, Aditya S, Yang H, Kim HW, Park SO, Ko S. Co-delivery of hydrophobic curcumin and hydrophilic catechin by a water-in-oil-in-water double emulsion. Food Chem 2015;173:7.

[47]Rizwan SB, Hanley T, Boyd BJ, Rades T, Hook S. Liquid crystalline systems of phytantriol and glyceryl monooleate containing a hydrophilic protein: Characterisation, swelling and release kinetics. J Pharm Sci 2009;98:4191. 
[48]Han K, Pan X, Chen M, Wang R, Xu Y, Feng M, et al. Phytantriol-based inverted type bicontinuous cubic phase for vascular embolization and drug sustained release. Eur J Pharm Sci 2010;41:692-9.

[49]Howells LM, Sale S, Sriramareddy SN, Irving GRB, Jones DJL, Ottley CJ, et al. Curcumin ameliorates oxaliplatinr vascular embolization and drug sustained release. Eur J Pharm Sci 2011;129:476-86.

[50]Kim C, Hong Y, Lee H, Kang H, Lee EK. MicroRNA-195 Desensitizes HCT116 Human Colon Cancer Cells to 5-Fluorouracil. Cancer Lett 2017;412.

[51] Otto T, Sicinski P. Cell cycle proteins as promising targets in cancer therapy. Nat Rev Cancer 2017;17:93-115.

[52]Lin Y, Zhen Y, Zhao Y, Wei J, Hu G. Rhein Lysinate Induced S-Phase Arrest and Increased the Anti-Tumor Activity of 5-FU in HeLa Cells. Am J Chinese Med 2011;39:817-25.

[53]Pham NA, Jacobberger JW, Schimmer AD, Cao P, Gronda M, Hedley DW. The dietary isothiocyanate sulforaphane targets pathways of apoptosis, cell cycle arrest, and oxidative stress in human pancreatic cancer cells and inhibits tumor growth in severe combined immunodeficient mice. Mol Cancer Ther 2004;3:1239-48.

[54]Cho ML, Kang JW, Moon YM, Nam HJ, Jhun JY, Heo SB, et al. STAT3 and NF-кB Signal Pathway Is Required for IL-23-Mediated IL-17 Production in Spontaneous Arthritis Animal Model IL-1 Receptor Antagonist-Deficient Mice. J Immunol 2006;176:5652-61.

[55]Kang TS, Wang W, Zhong H, Dong Z, Huang Q, Mok SW, et al. An anti-prostate cancer benzofuran-conjugated iridium(III) complex as a dual inhibitor of STAT3 and NF- $\kappa$ B. Cancer Lett 2017;396:76-84.

[56]Martincuks A, Andryka K, Kuster A, Schmitzvan dLH, Komorowski M, Mullernewen G. Nuclear translocation of STAT3 and NF- $\kappa$ B are independent of each other but NF- $\kappa$ B supports expression and activation of STAT3. Cell Signal 2017;32:36-47.

[57]Xie M, Fan D, Chen Y, Zhao Z, He X, Li G, et al. An implantable and controlled drug-release silk fibroin nanofibrous matrix to advance the treatment of solid tumour cancers. Biomaterials 2016;103:33-43. 
Table 1. WCA of SF, SF/PEG and three groups of SF/PEG/drug loaded membranes.

\begin{tabular}{|c|c|c|c|c|c|}
\hline Time & $0 \mathrm{~s}$ & $5 \mathrm{~s}$ & $20 \mathrm{~s}$ & $30 \mathrm{~s}$ & $60 \mathrm{~s}$ \\
\hline SF & $134.4^{\circ} \pm 0.6^{\circ}$ & $125.8^{\circ} \pm 0.6^{\circ}$ & $79.2^{\circ} \pm 0.1^{\circ}$ & $37.1^{\circ} \pm 0.2^{\circ}$ & $22.4^{\circ} \pm 0.3^{\circ}$ \\
\hline $\mathrm{SF} / \mathrm{PEG}$ & $63.9^{\circ} \pm 0.4^{\circ}$ & $48.7^{\circ} \pm 0.2^{\circ}$ & $41.3^{\circ} \pm 0.3^{\circ}$ & $40.3^{\circ} \pm 0.3^{\circ}$ & $27.9^{\circ} \pm 0.1^{\circ}$ \\
\hline $0.15 / 0.25 w t \%$ & $108.6^{\circ} \pm 0.5^{\circ}$ & $102.3^{\circ} \pm 0.5^{\circ}$ & $96.7^{\circ} \pm 0.4^{\circ}$ & $86.3^{\circ} \pm 0.4^{\circ}$ & $63.6^{\circ} \pm 0.4^{\circ}$ \\
\hline $0.15 / 0.25 w t \%$ & $158.2^{\circ} \pm 0.7^{\circ}$ & $147.9^{\circ} \pm 0.4^{\circ}$ & $134.9^{\circ} \pm 0.3^{\circ}$ & $103.2^{\circ} \pm 0.3^{\circ}$ & $59.3^{\circ} \pm 0.3^{\circ}$ \\
\hline $0.45 / 0.75 w t \%$ & $162.7^{\circ} \pm 0.5^{\circ}$ & $151.3^{\circ} \pm 0.6^{\circ}$ & $82.1^{\circ} \pm 0.7^{\circ}$ & $79.3^{\circ} \pm 0.5^{\circ}$ & $32.7^{\circ} \pm 0.2^{\circ}$ \\
\hline
\end{tabular}



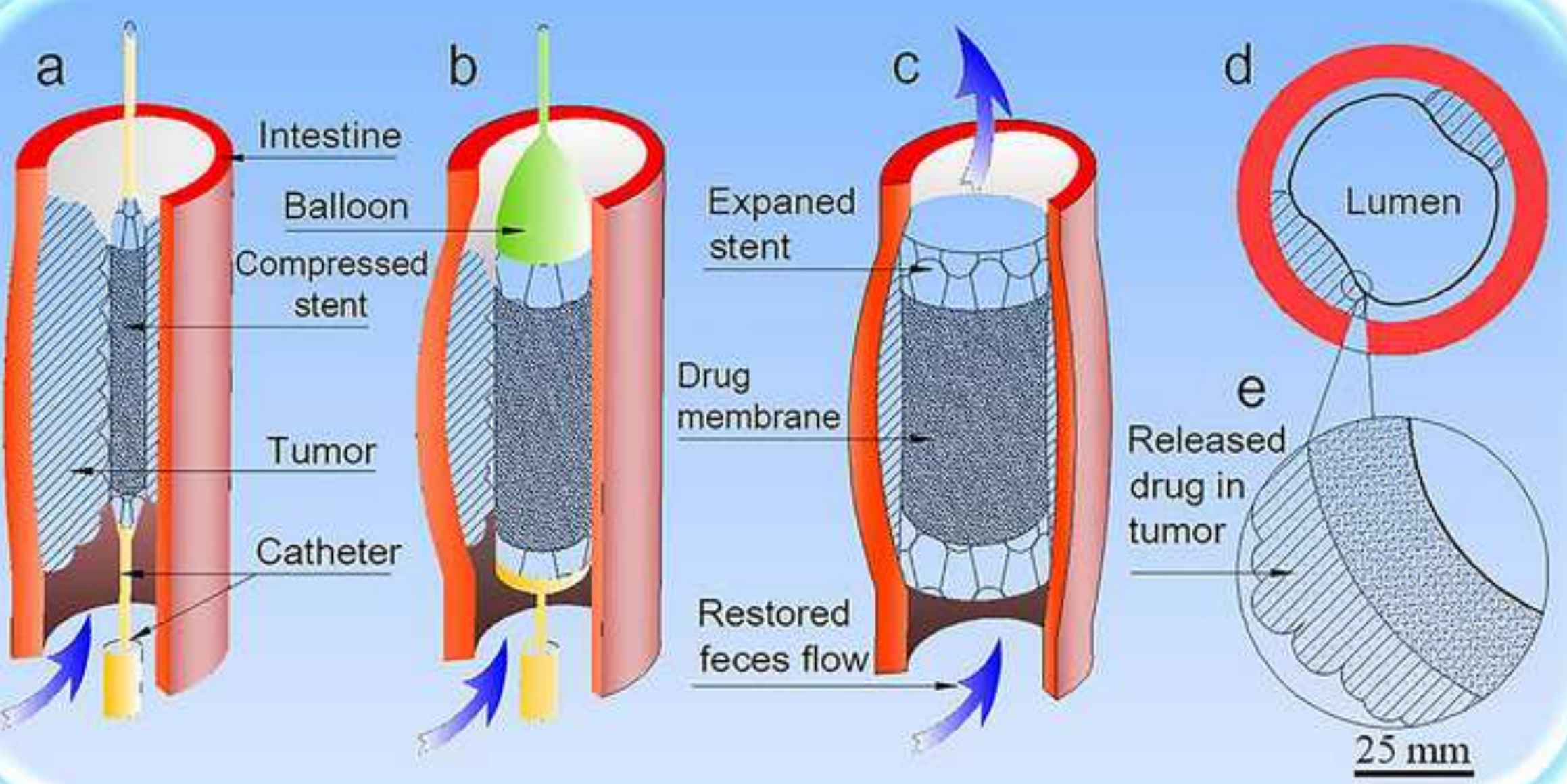
Click here to download high resolution image

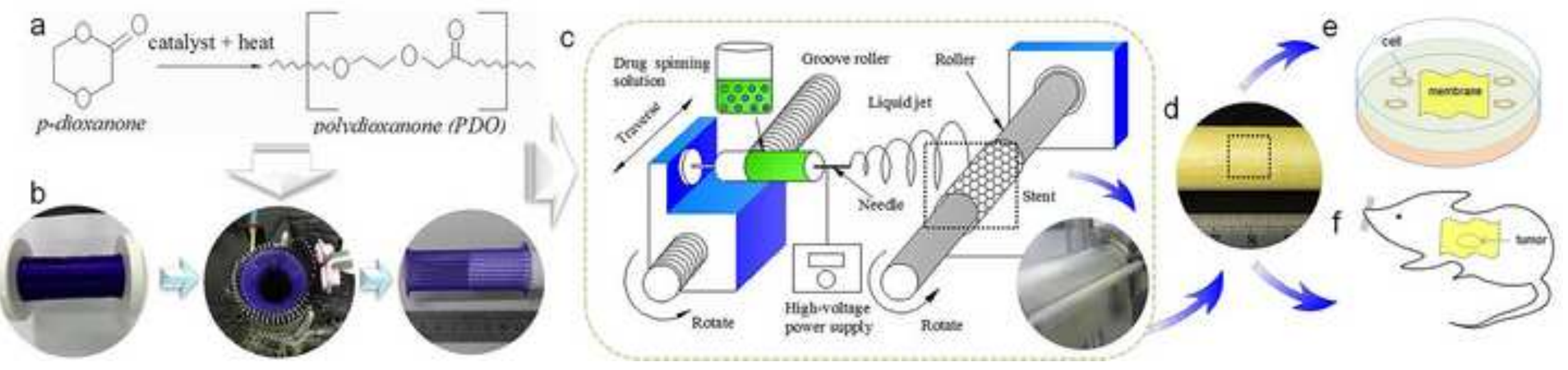




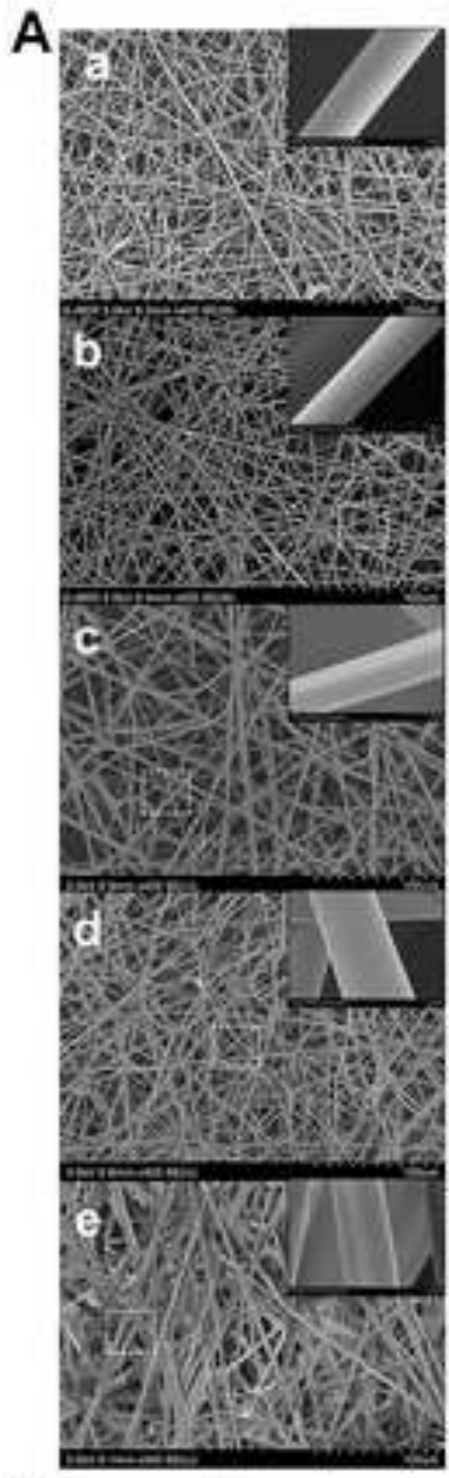

B
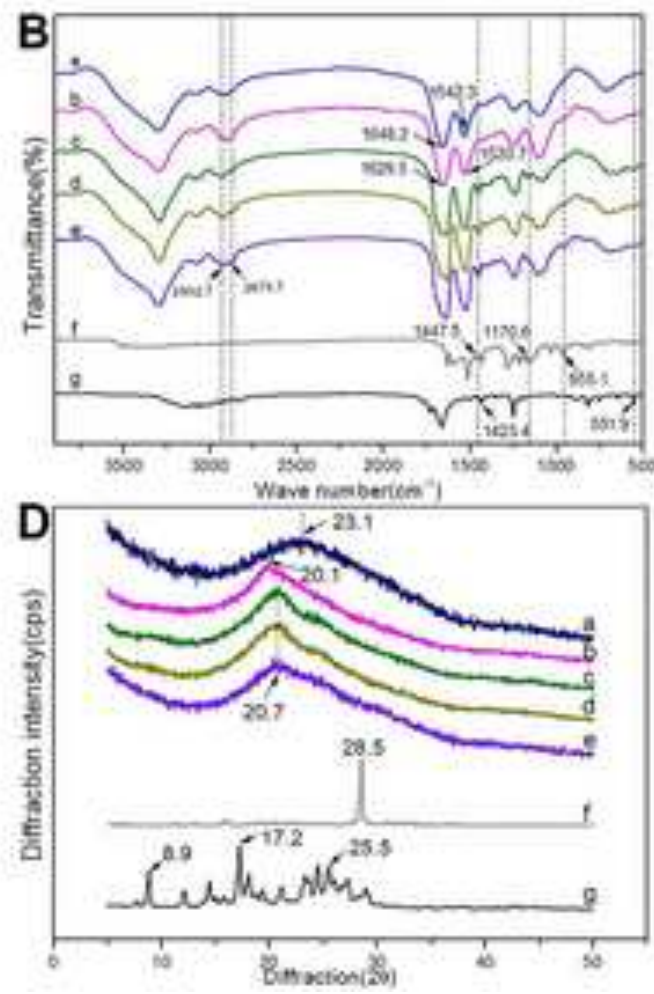
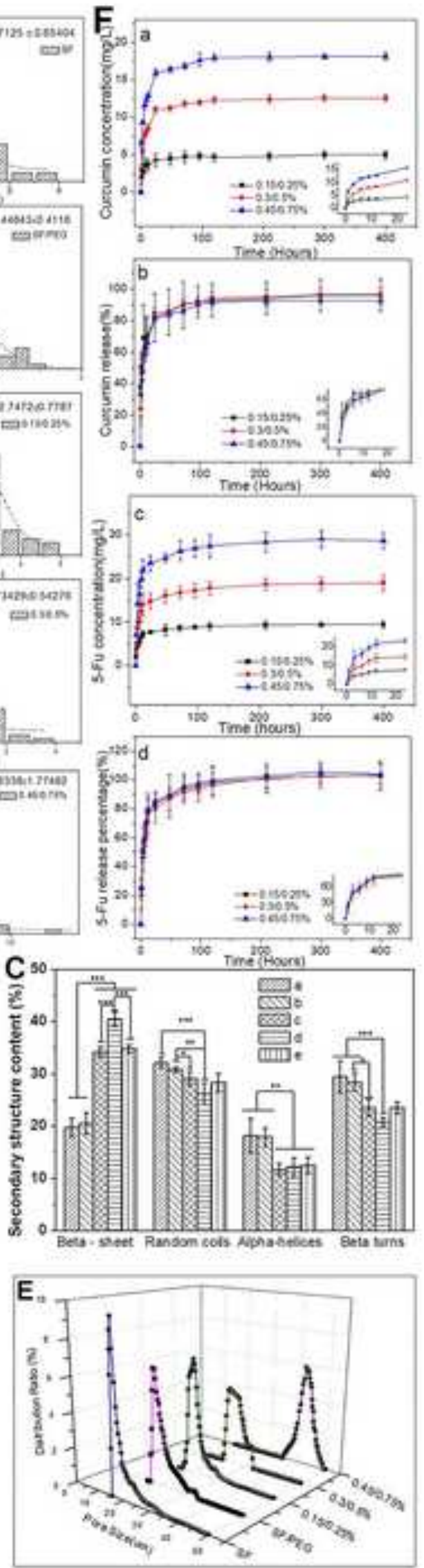
A

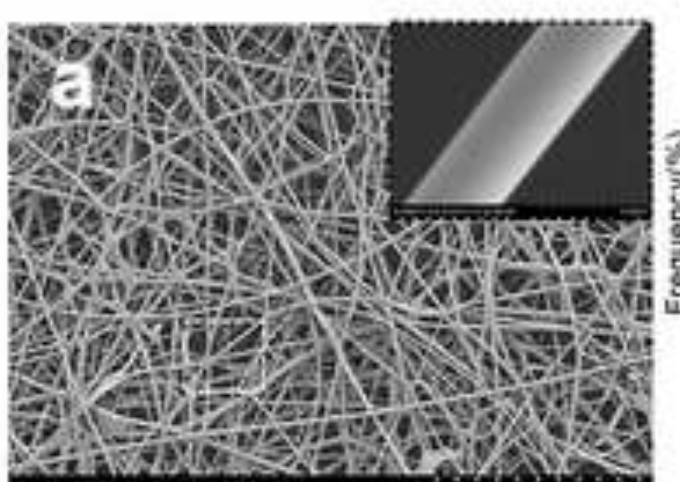

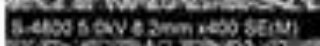

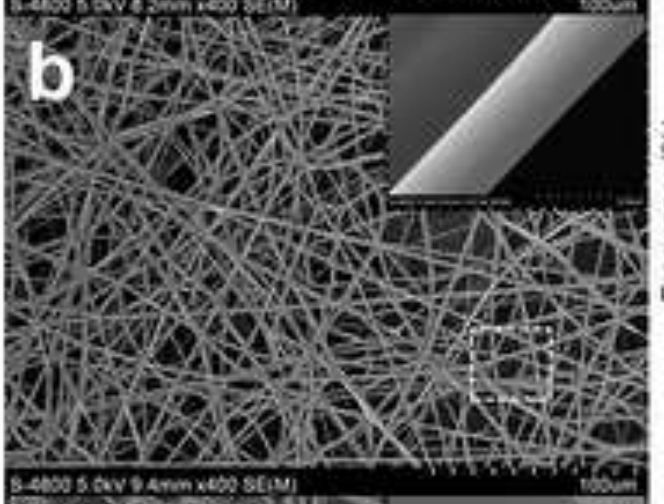

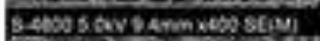
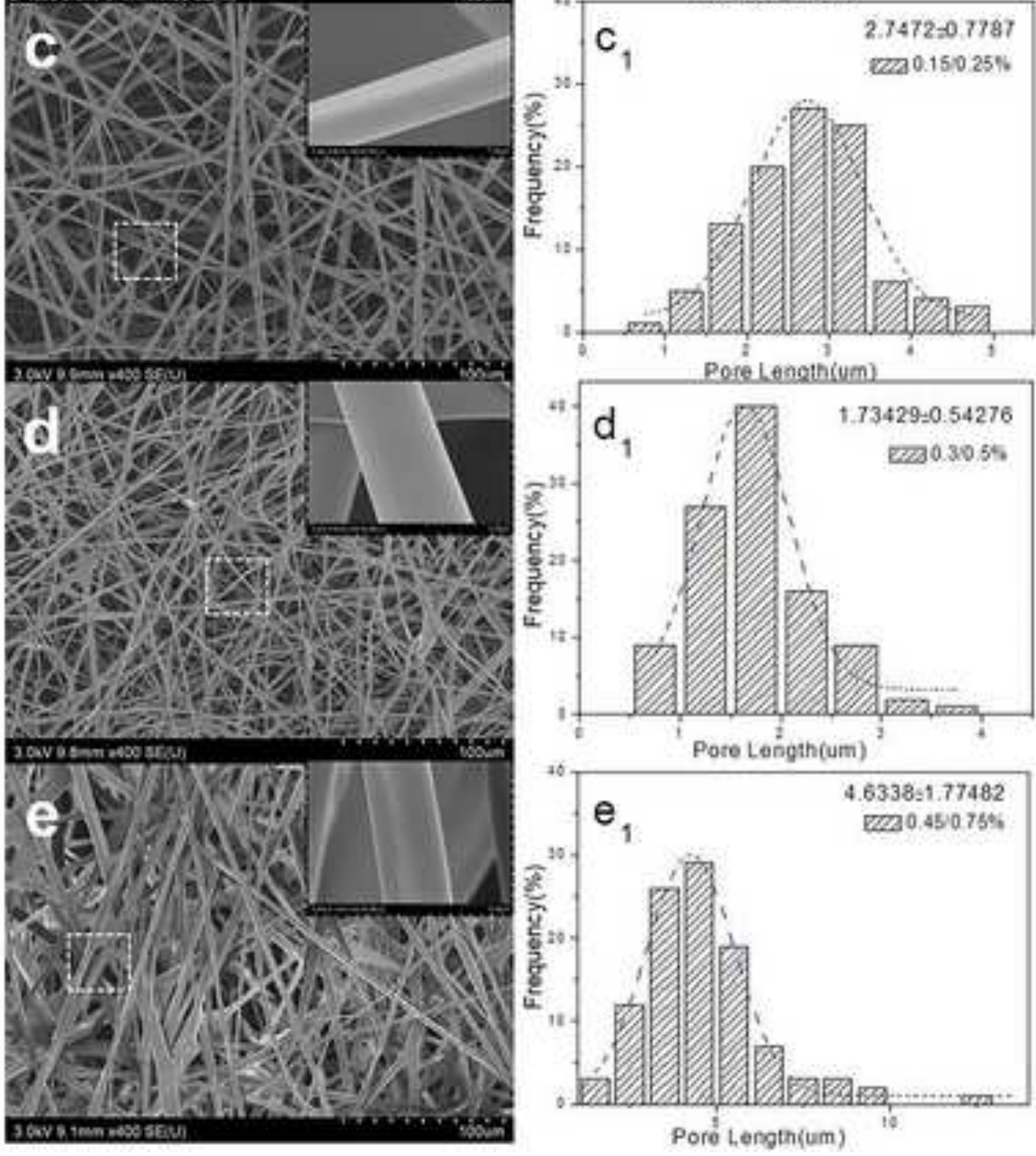


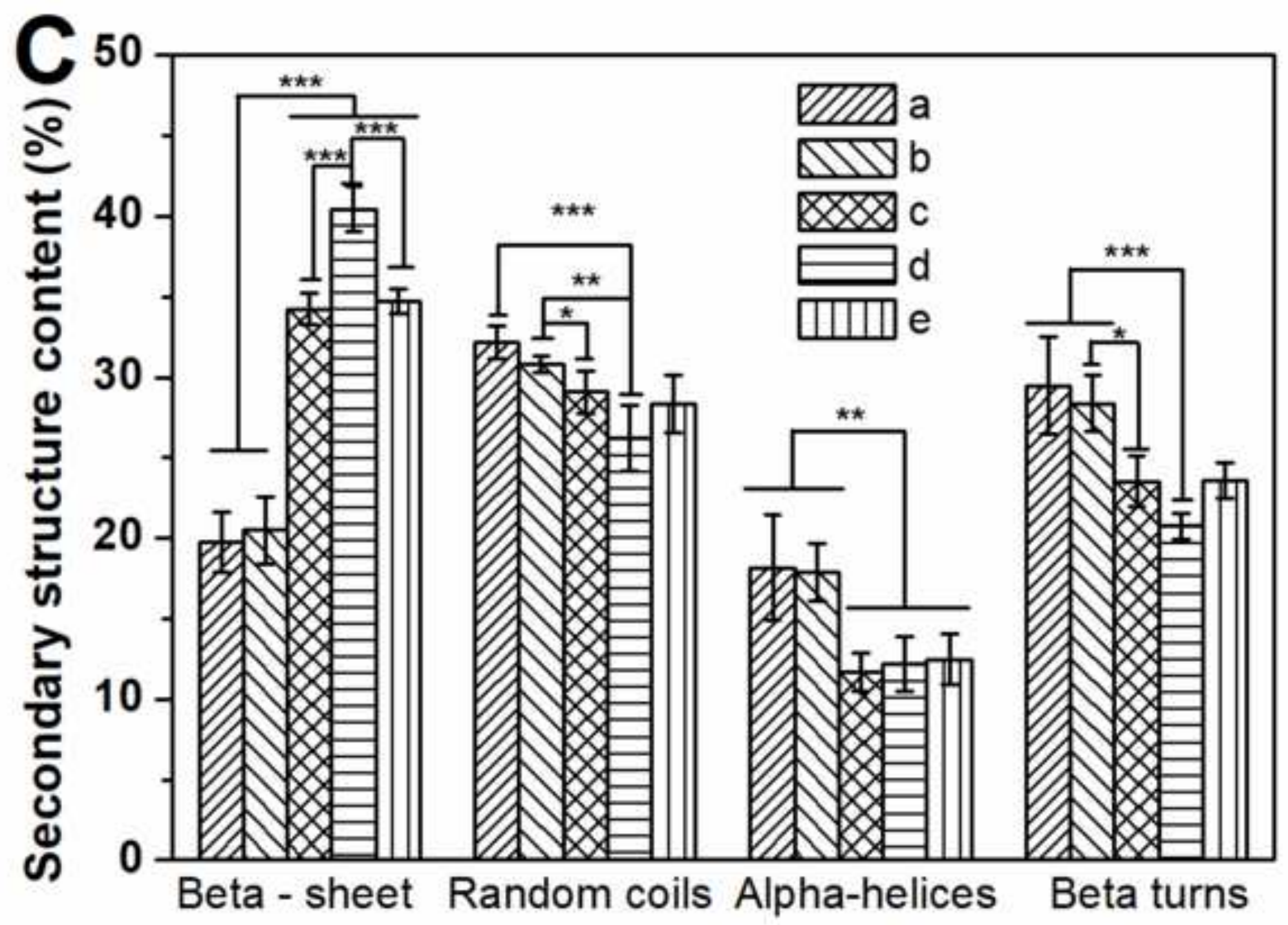




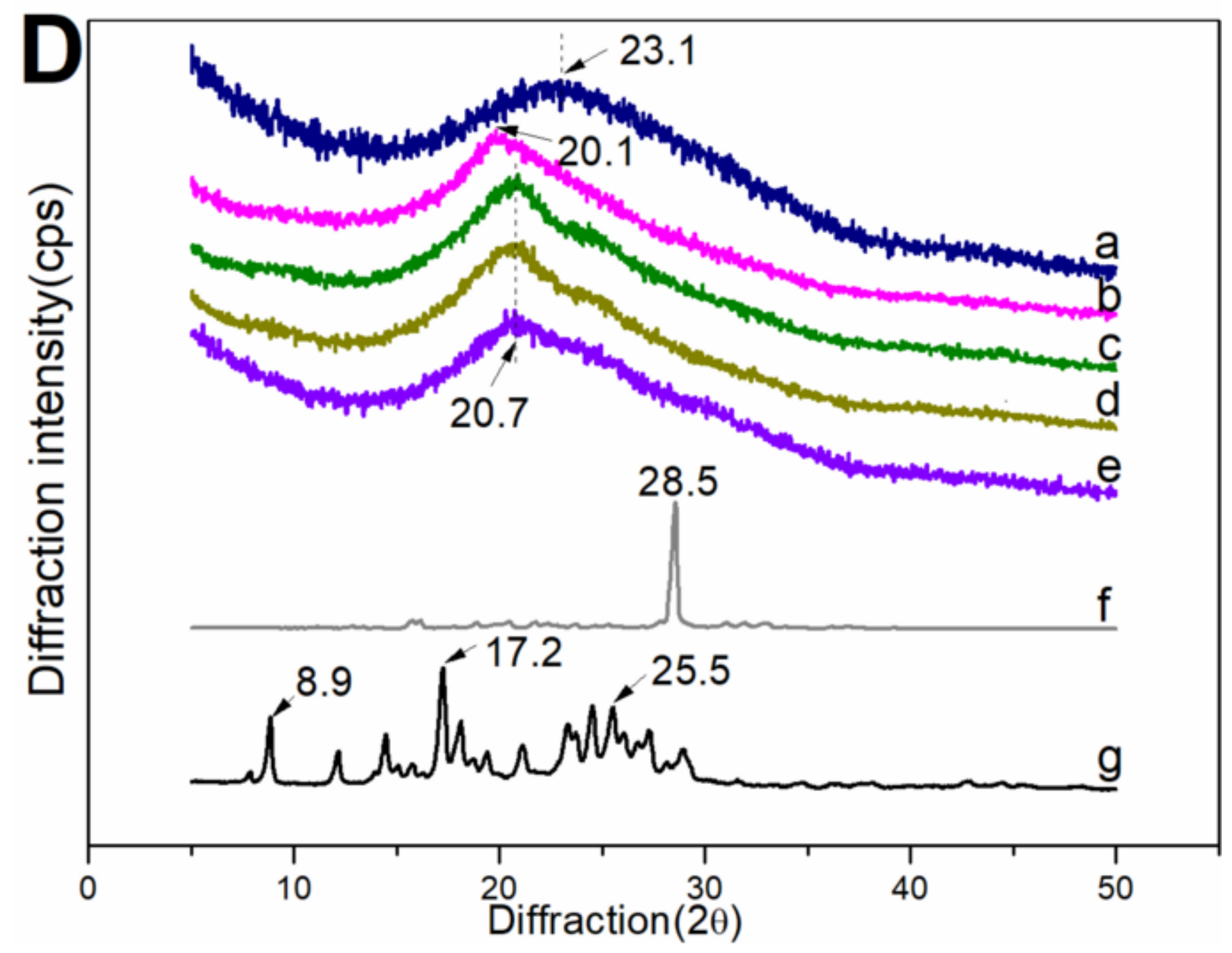


Click here to download high resolution image

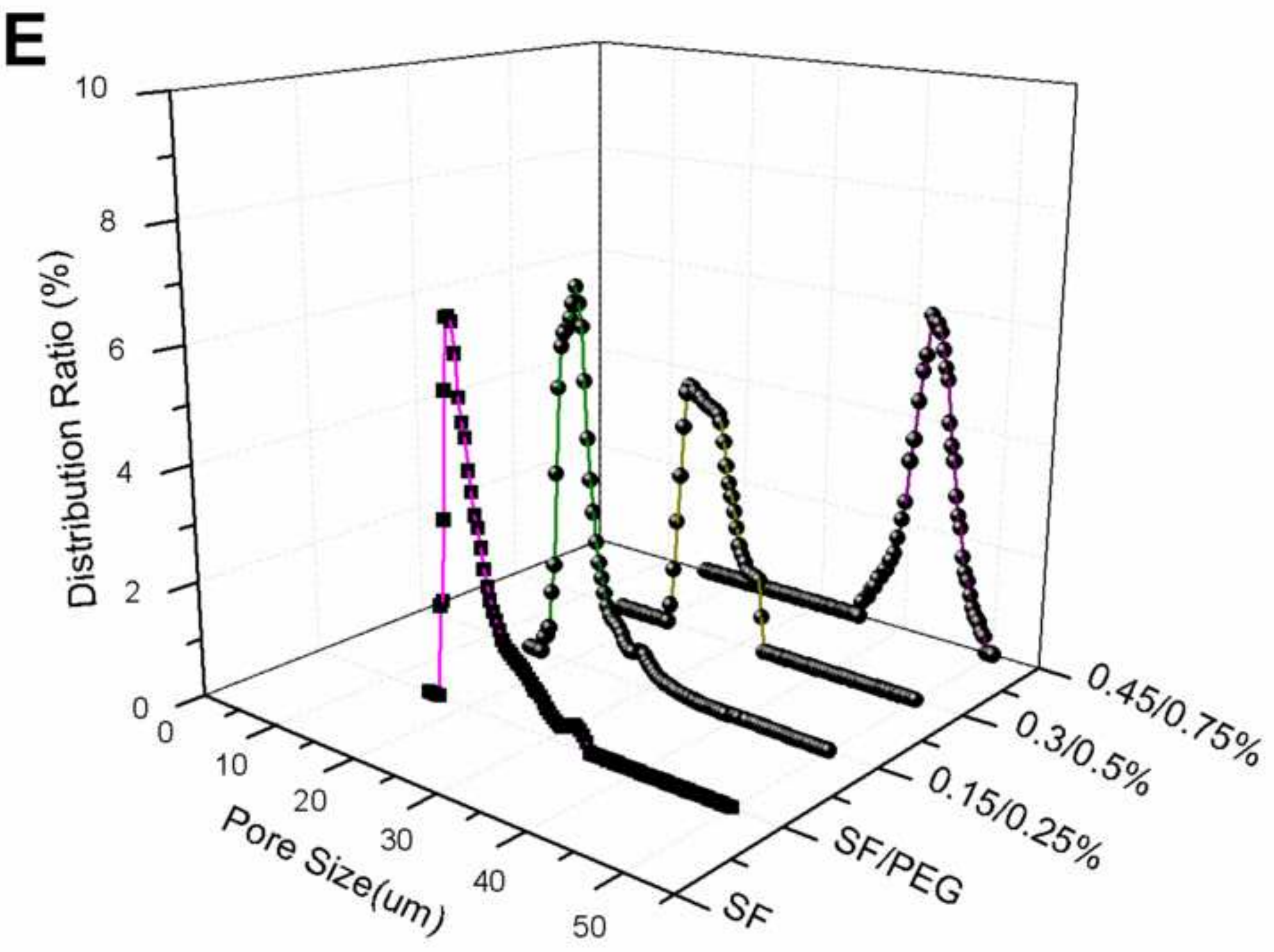

down 
Figure
Click here to download high resolution image
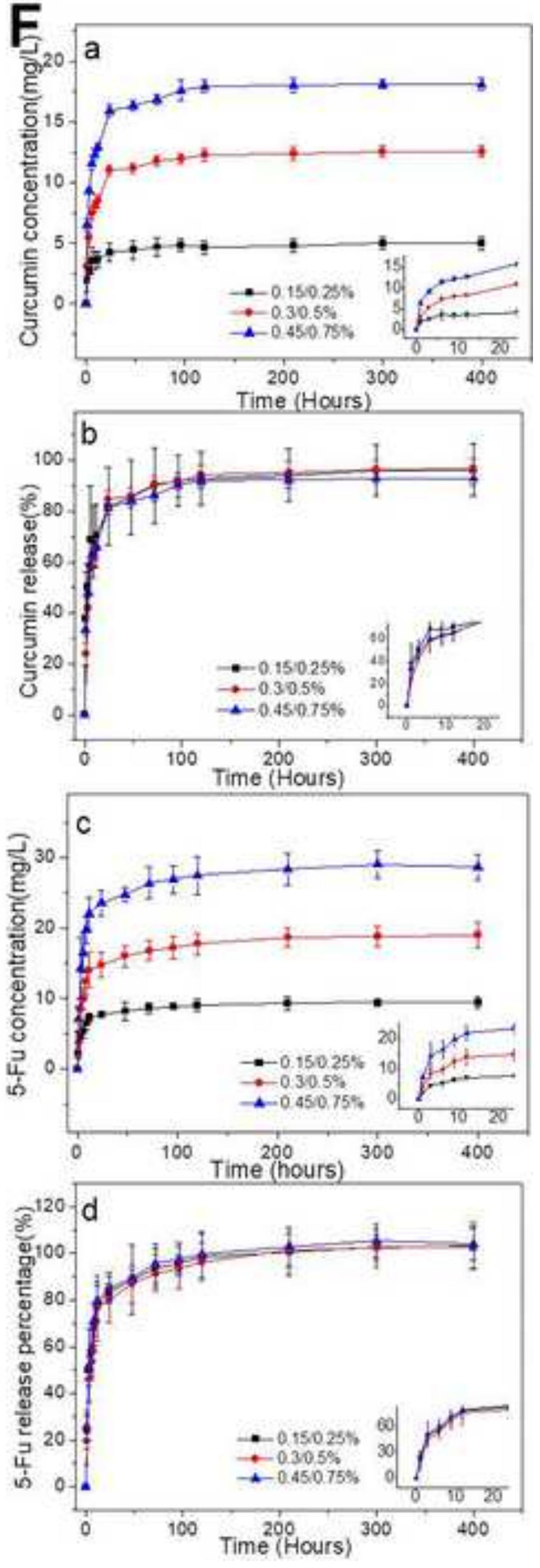


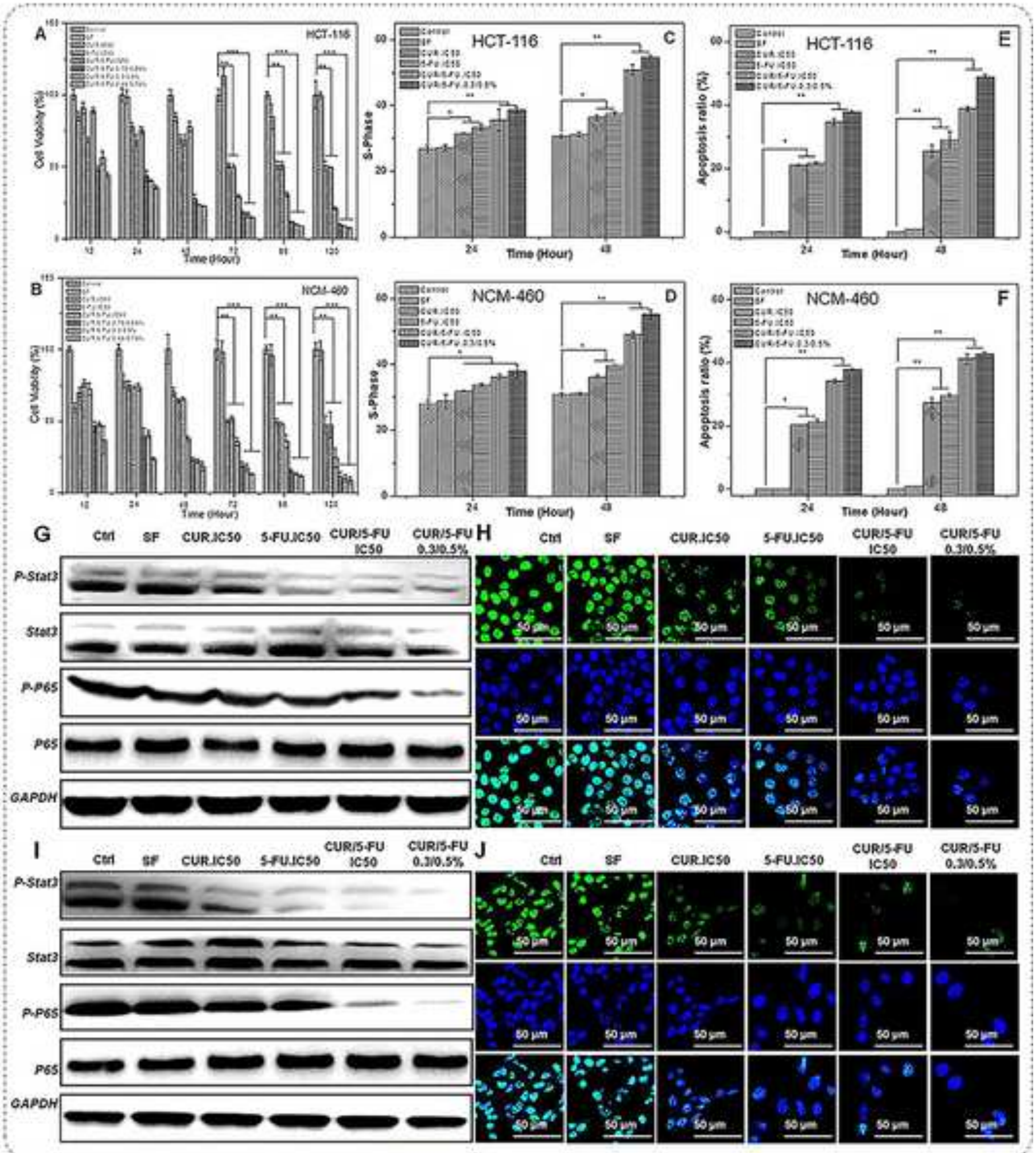




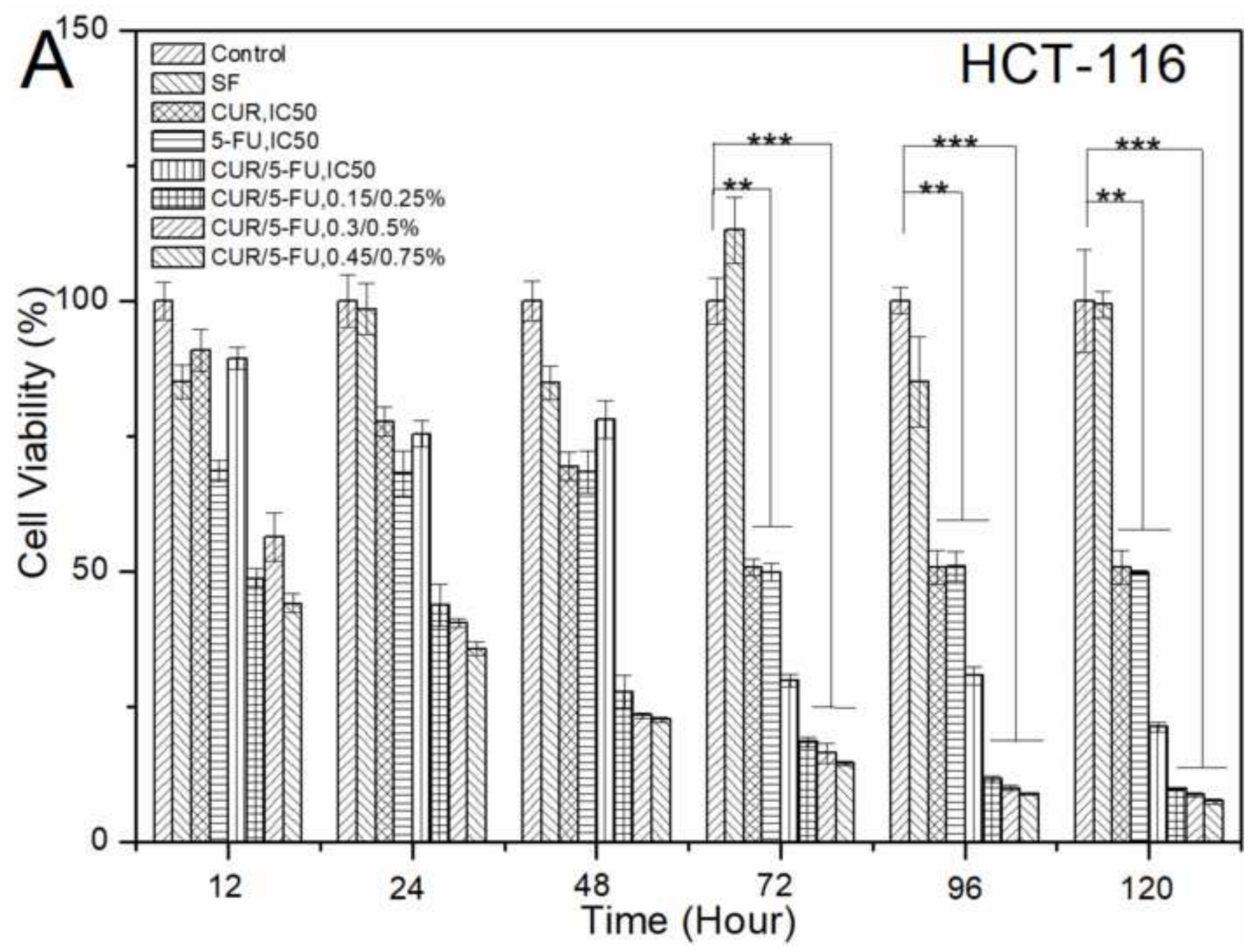




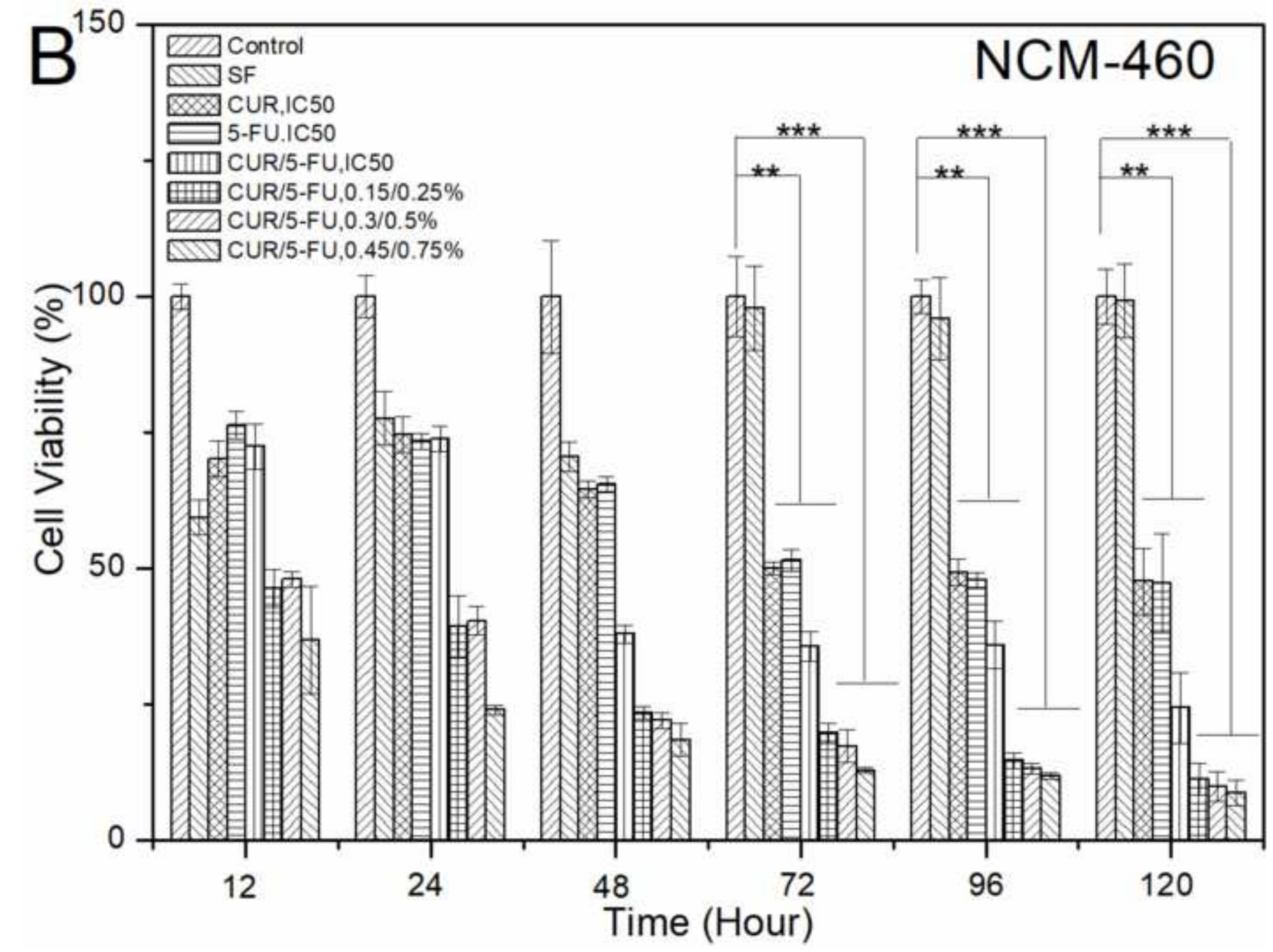


Click here to download high resolution image

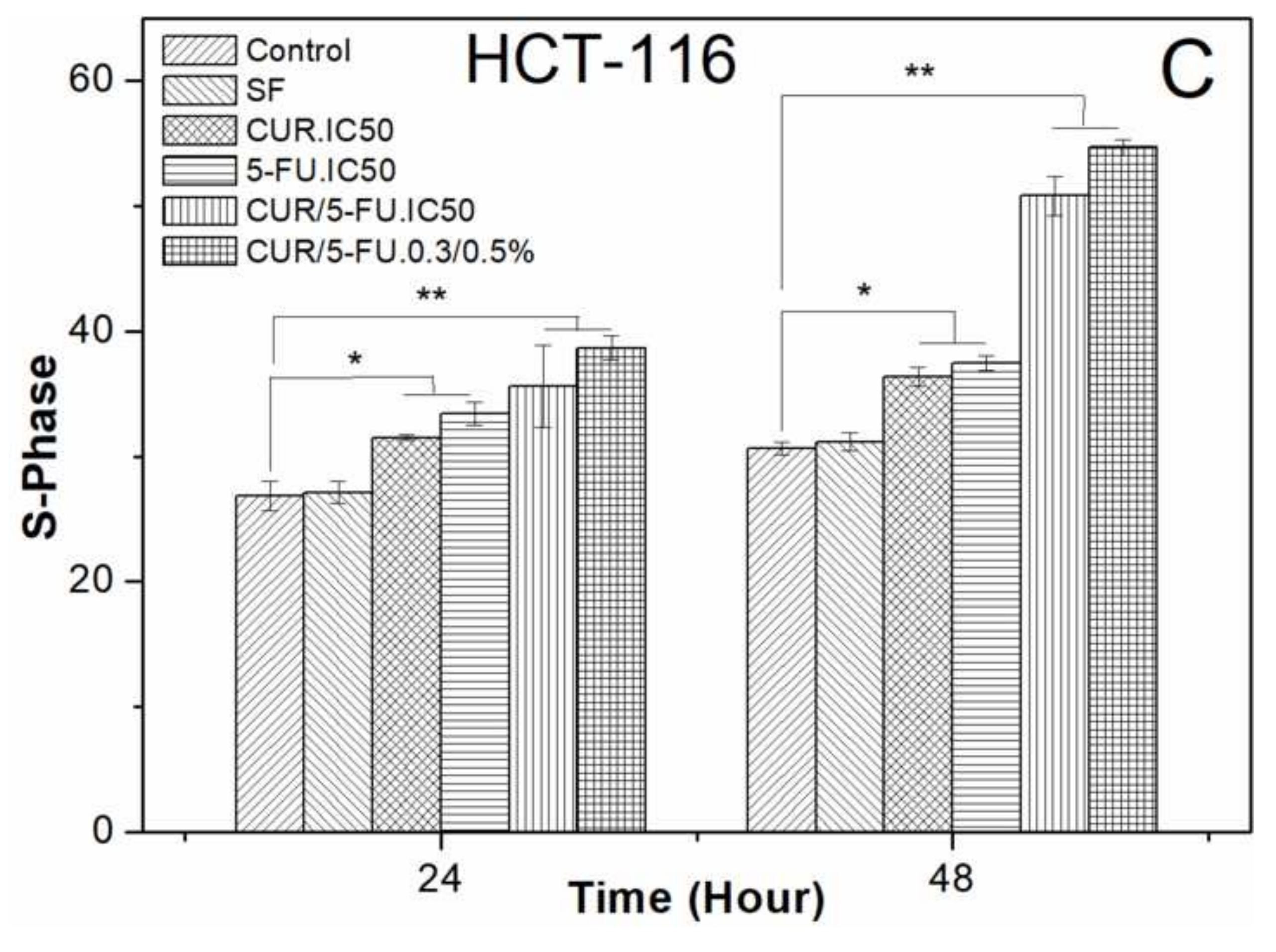


Click here to download high resolution image

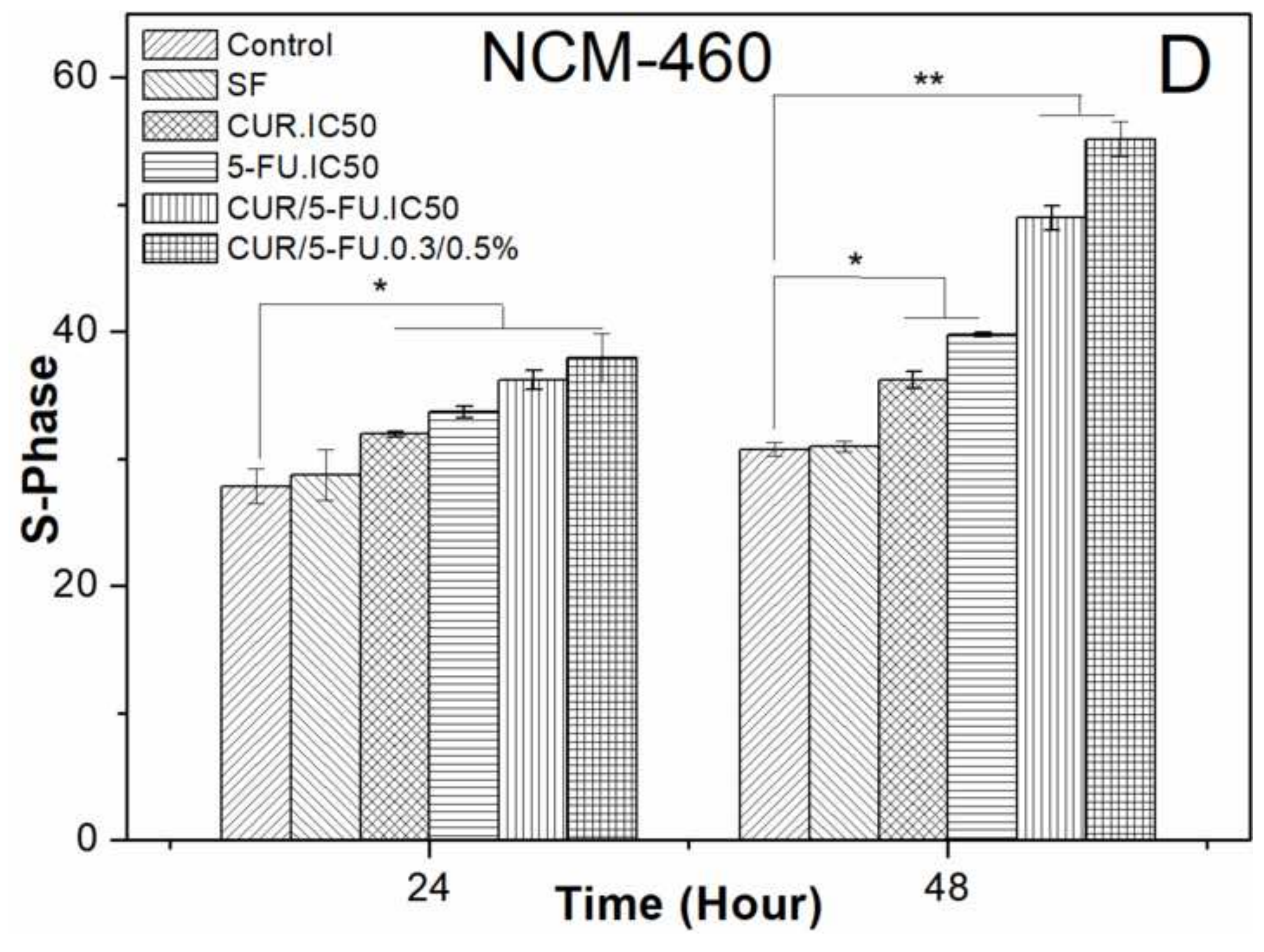




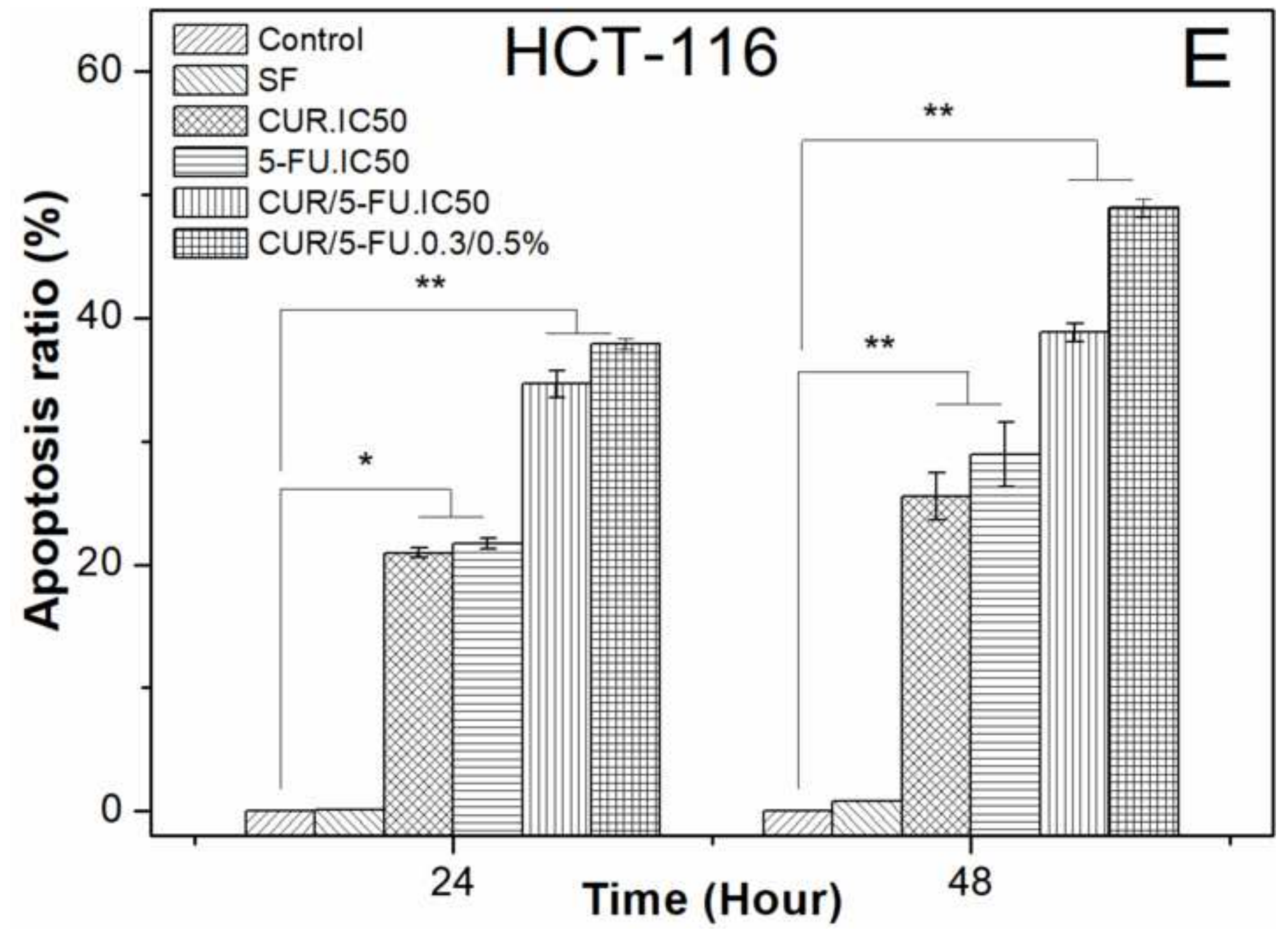



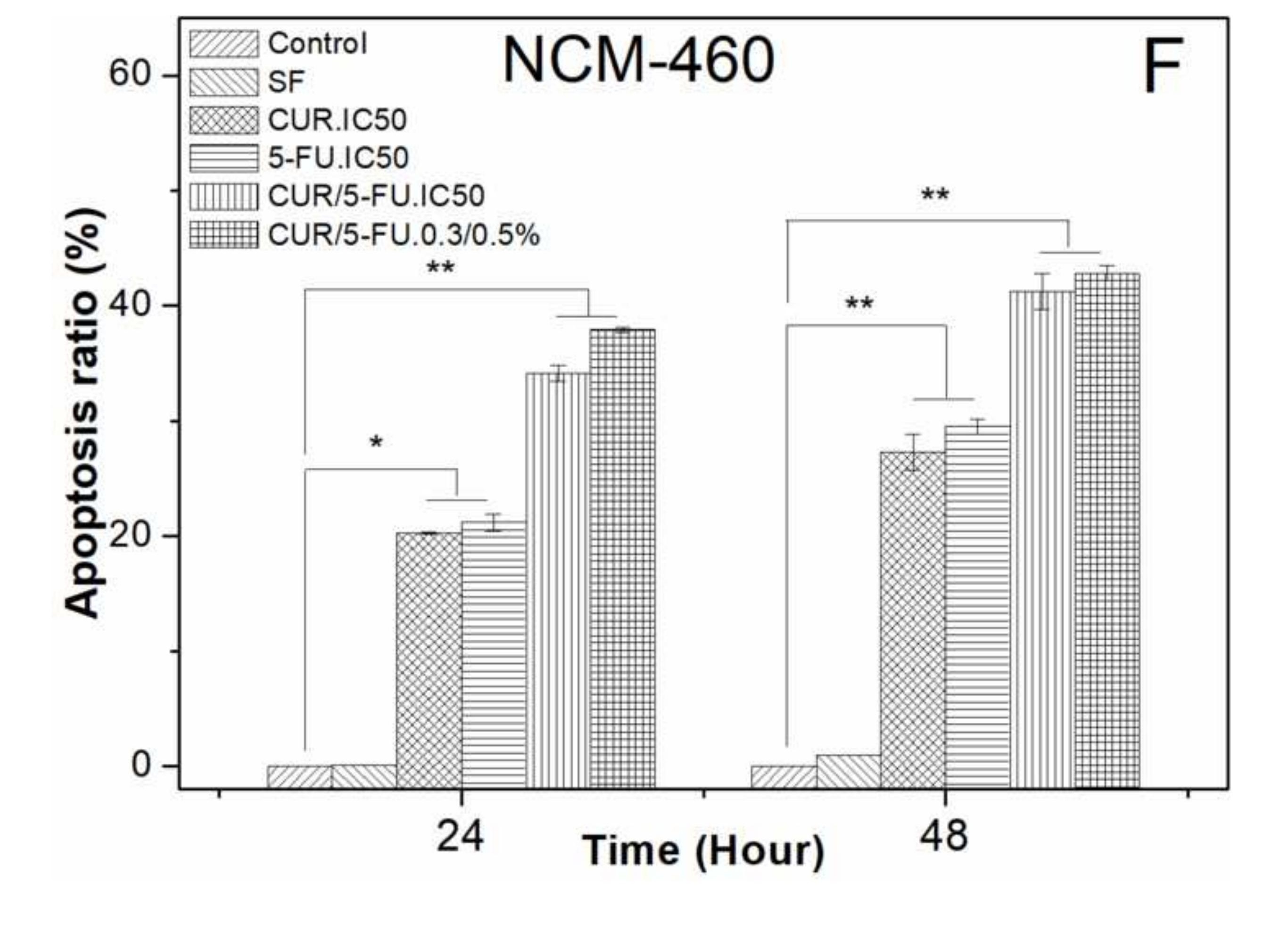

.

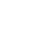

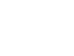

. 


\section{G Ctrl SF CUR.IC50 5-FU.IC50 CUR/5-FUCUR/5-FU IC50 $\quad 0.3 / 0.5 \%$}
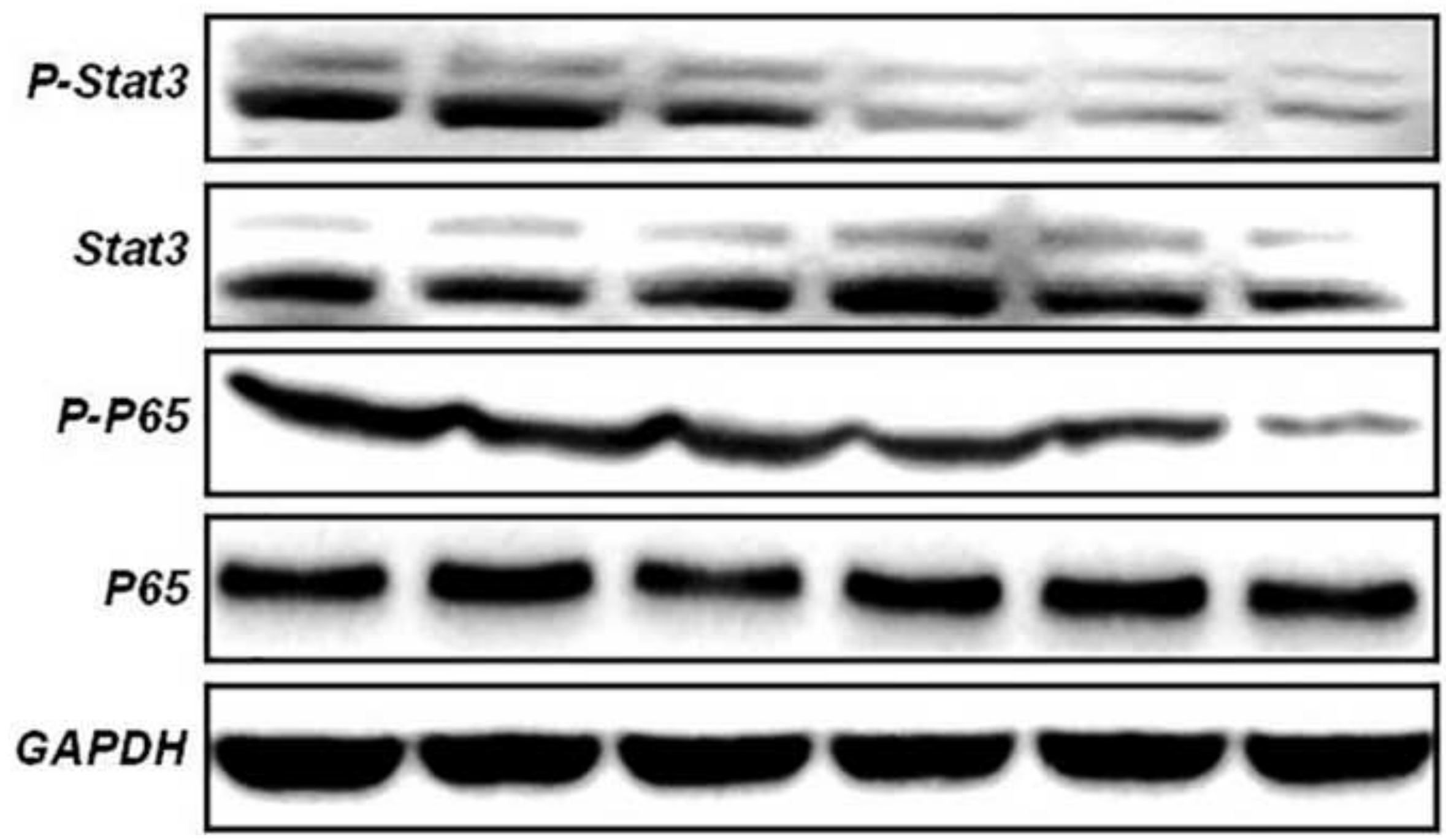


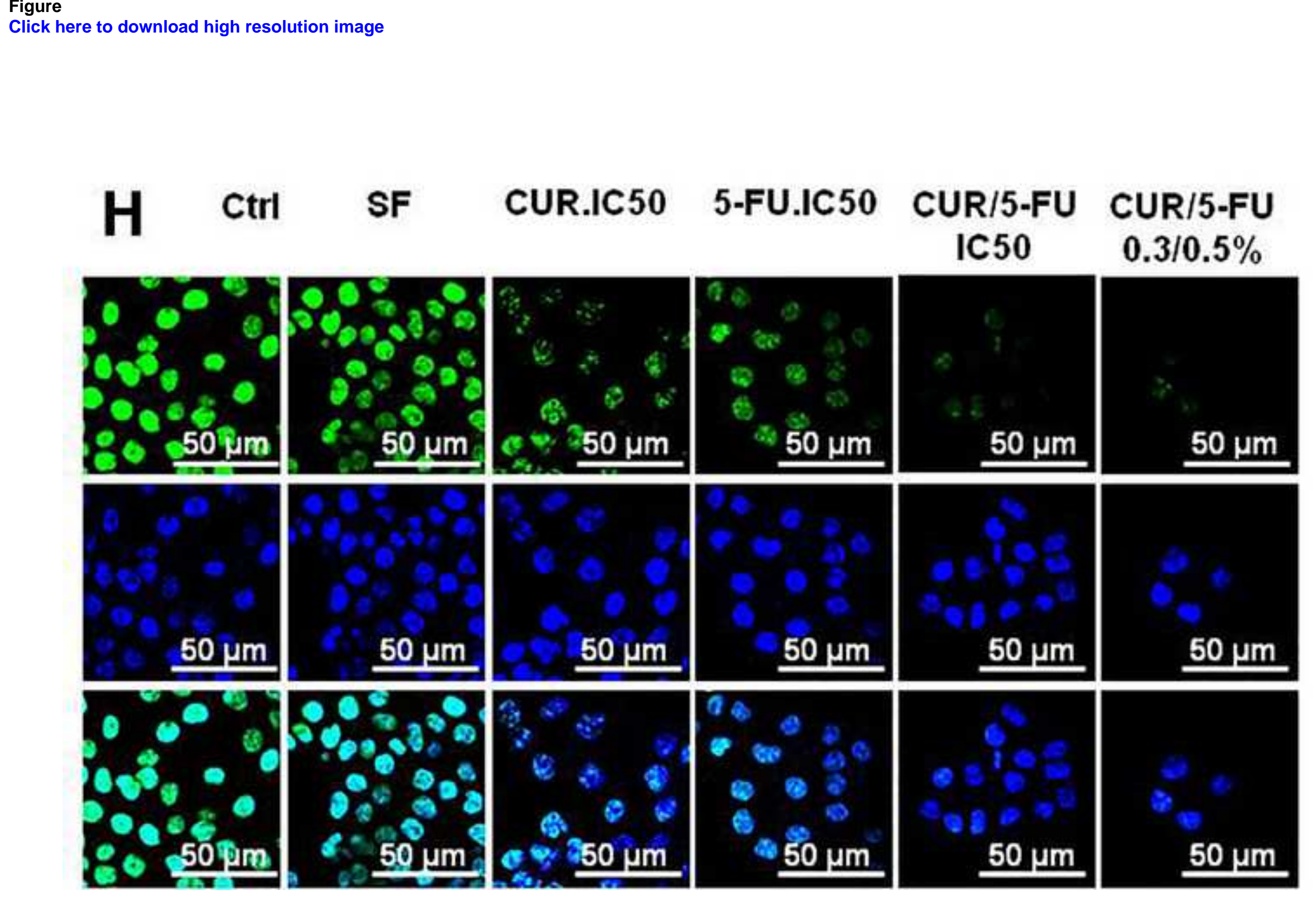


CUR/5-FU CUR/5-FU

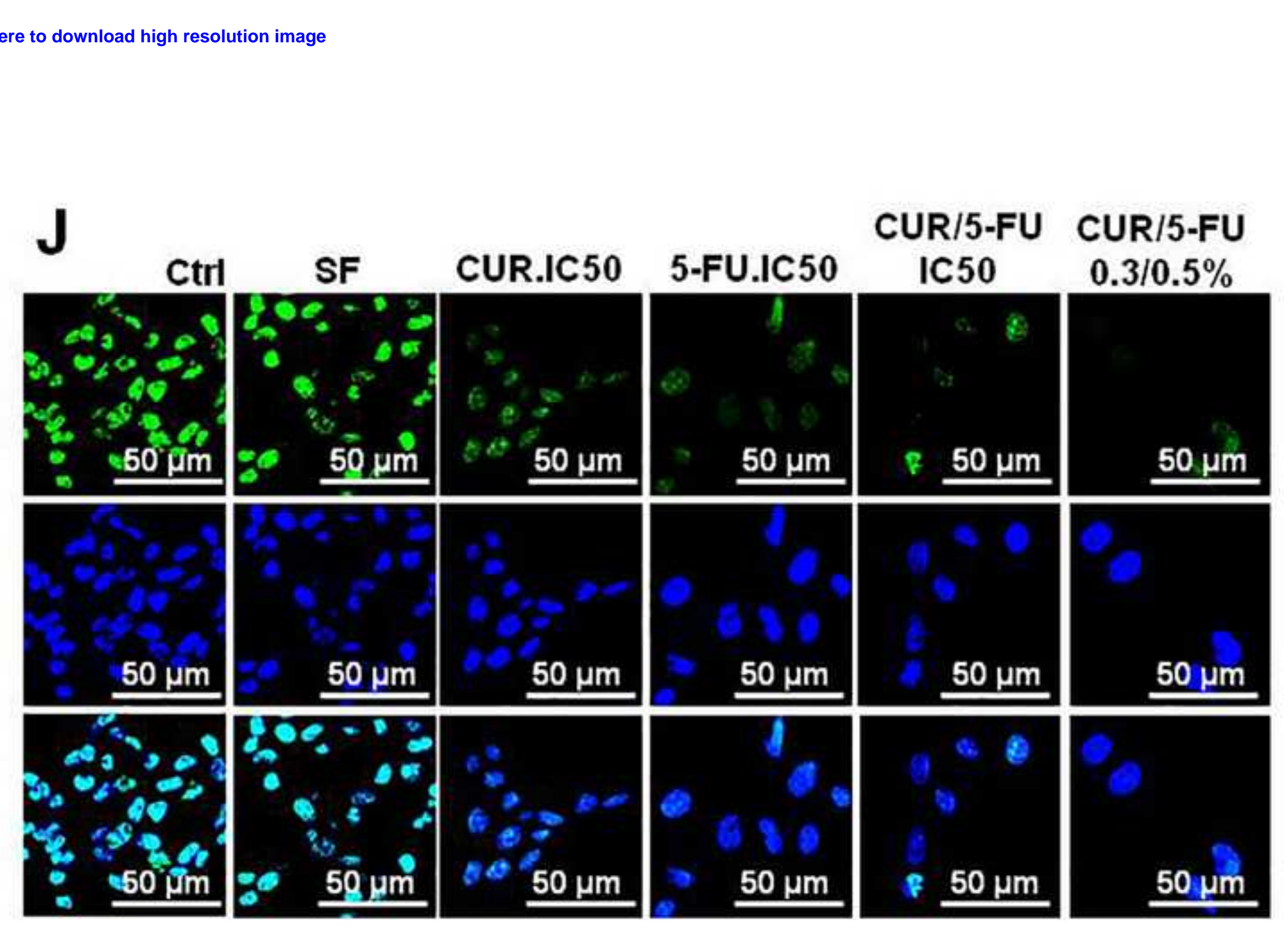


Figure

Click here to download high resolution image

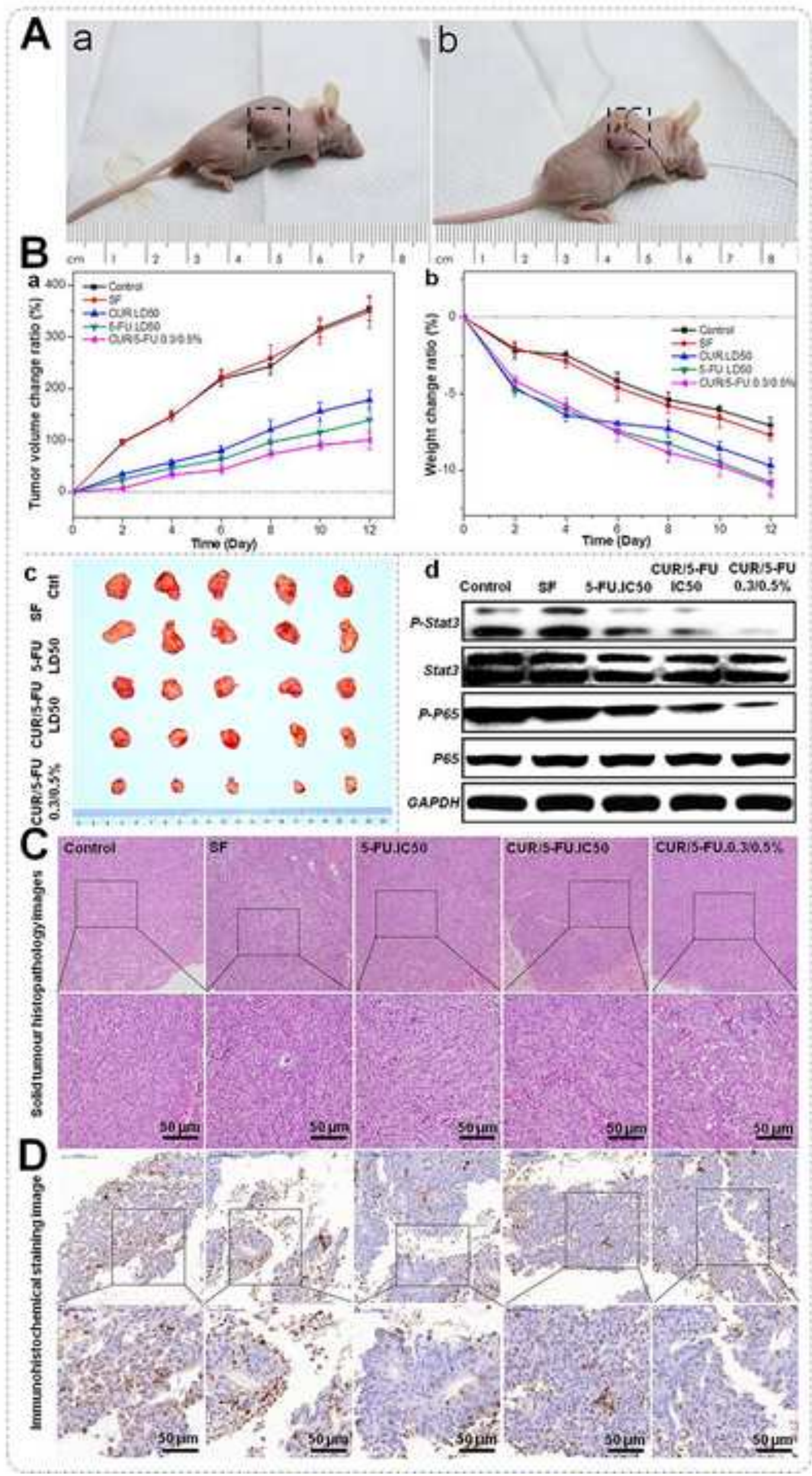


Click here to download high resolution image

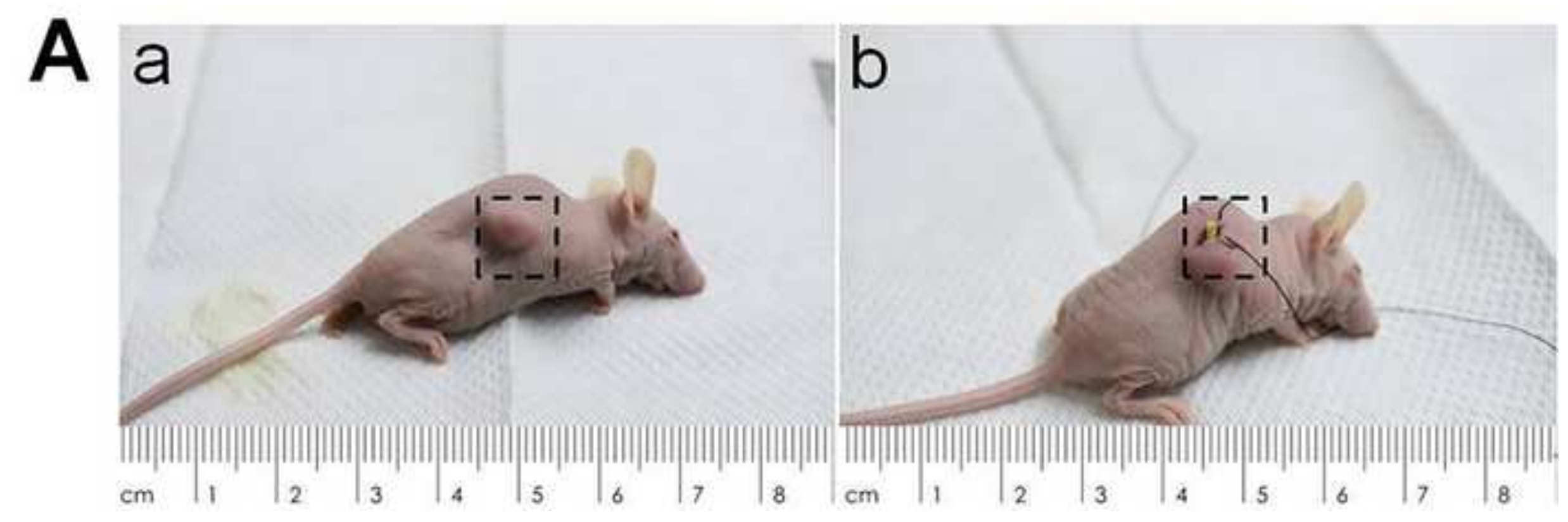

( he download high resolution ima 


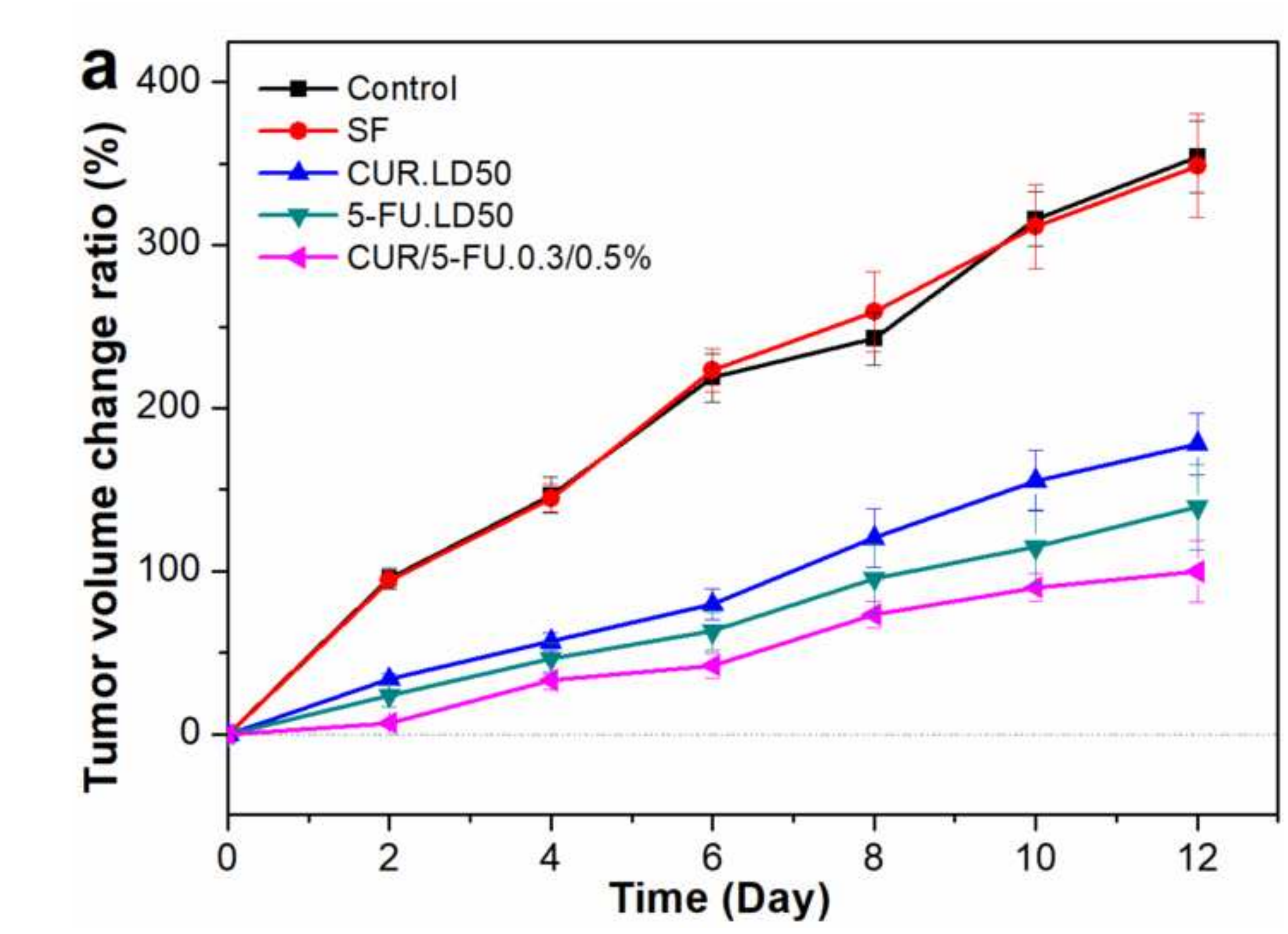


Click here to download high resolution image

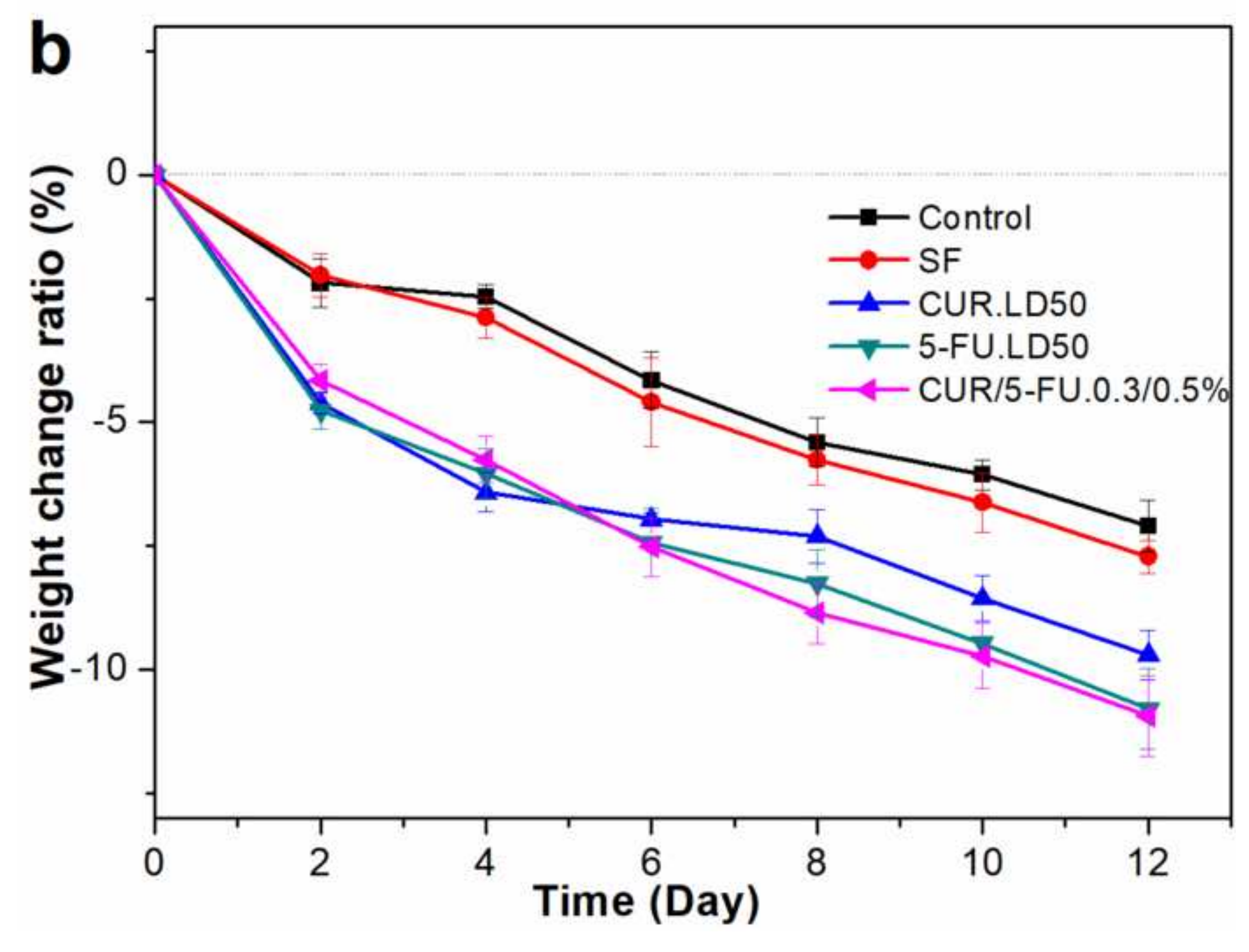



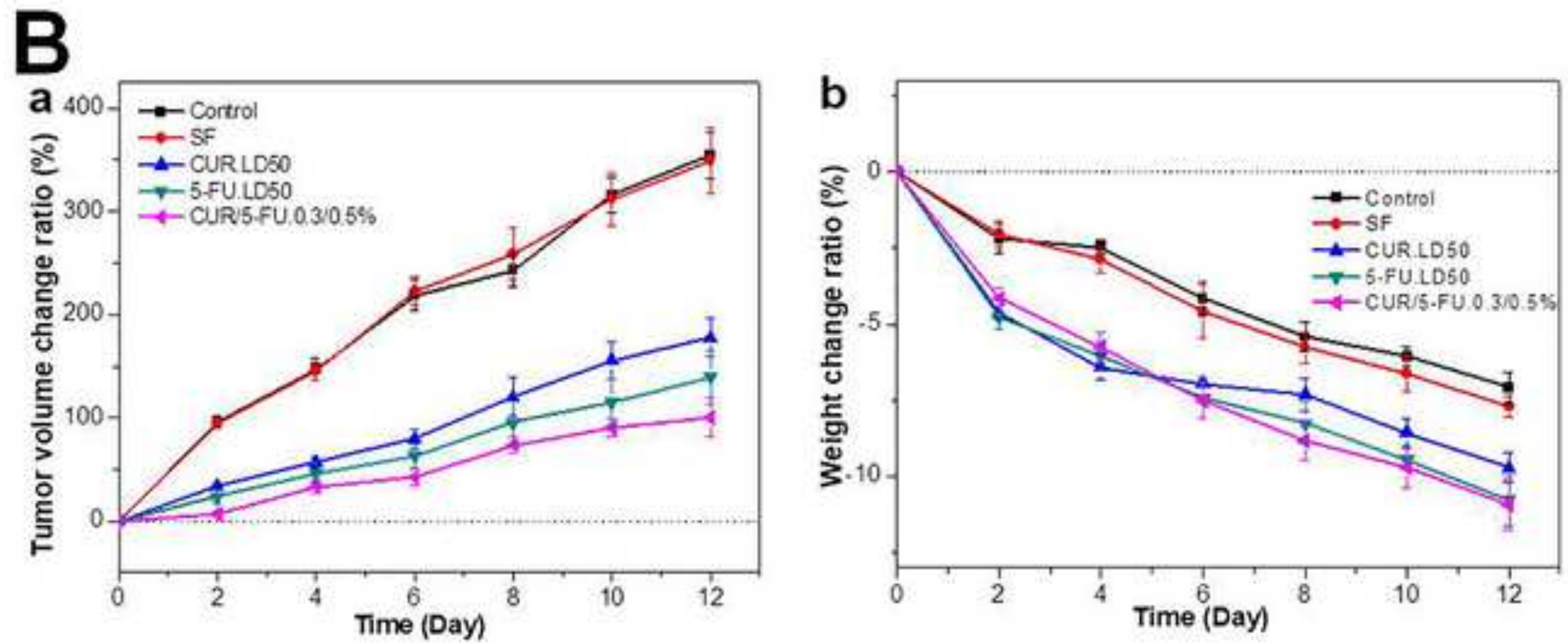

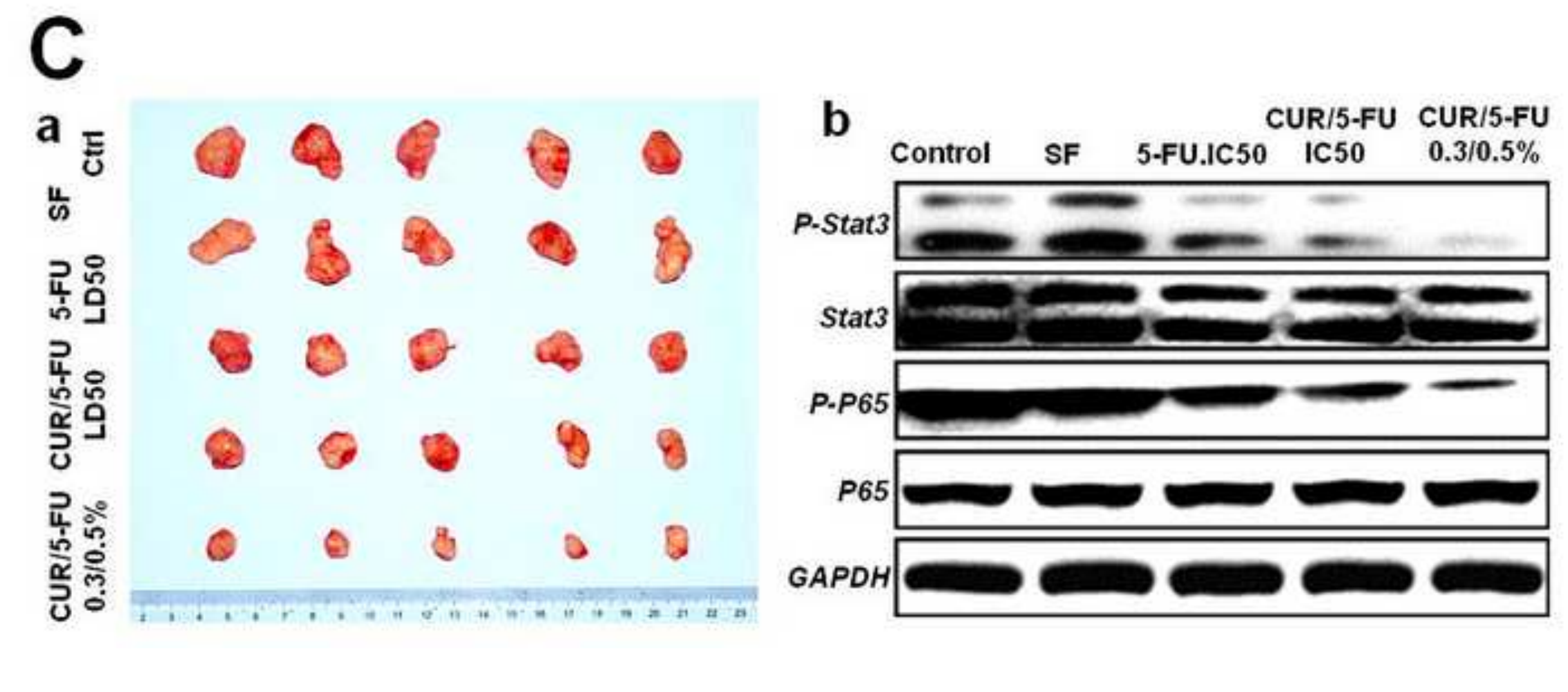
Click here to download high resolution image

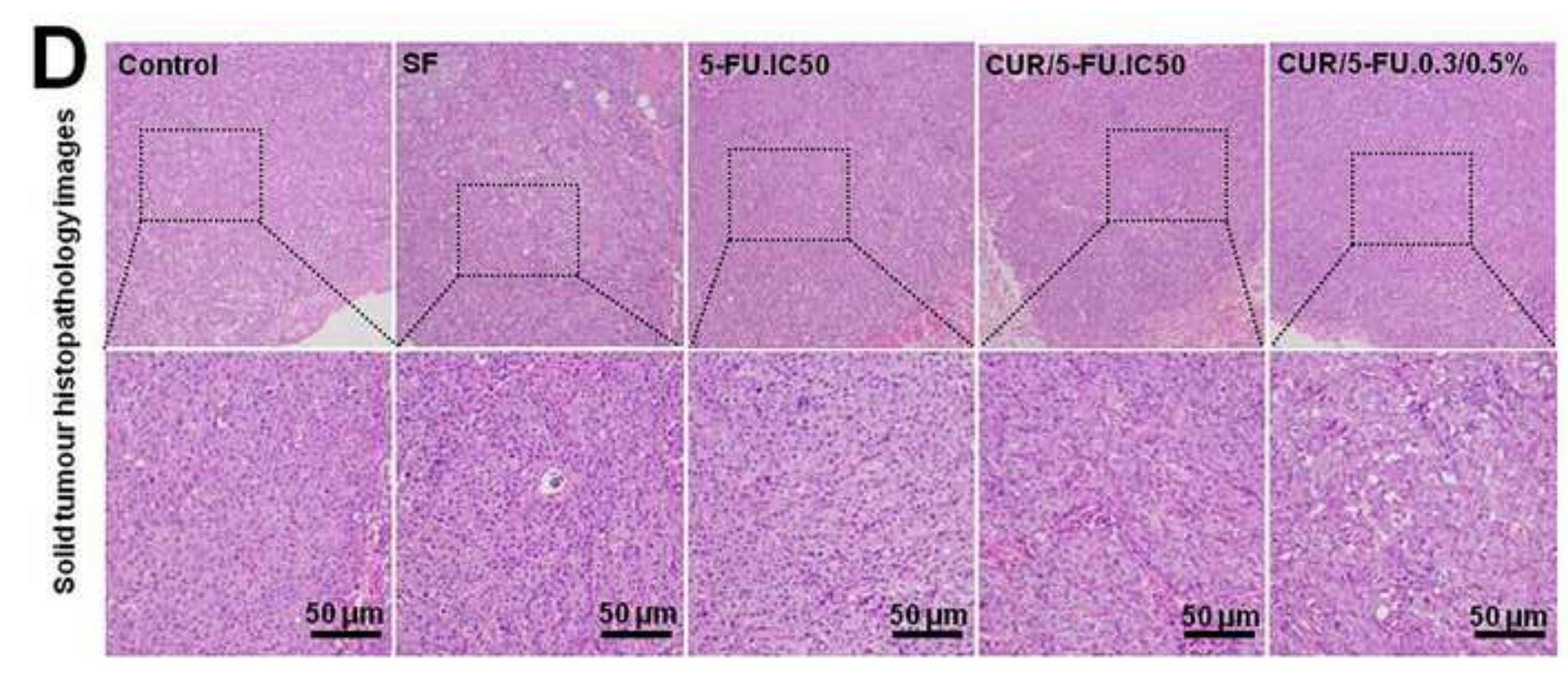

\author{
Click helo townload high resolution image
}


Click here to download high resolution image

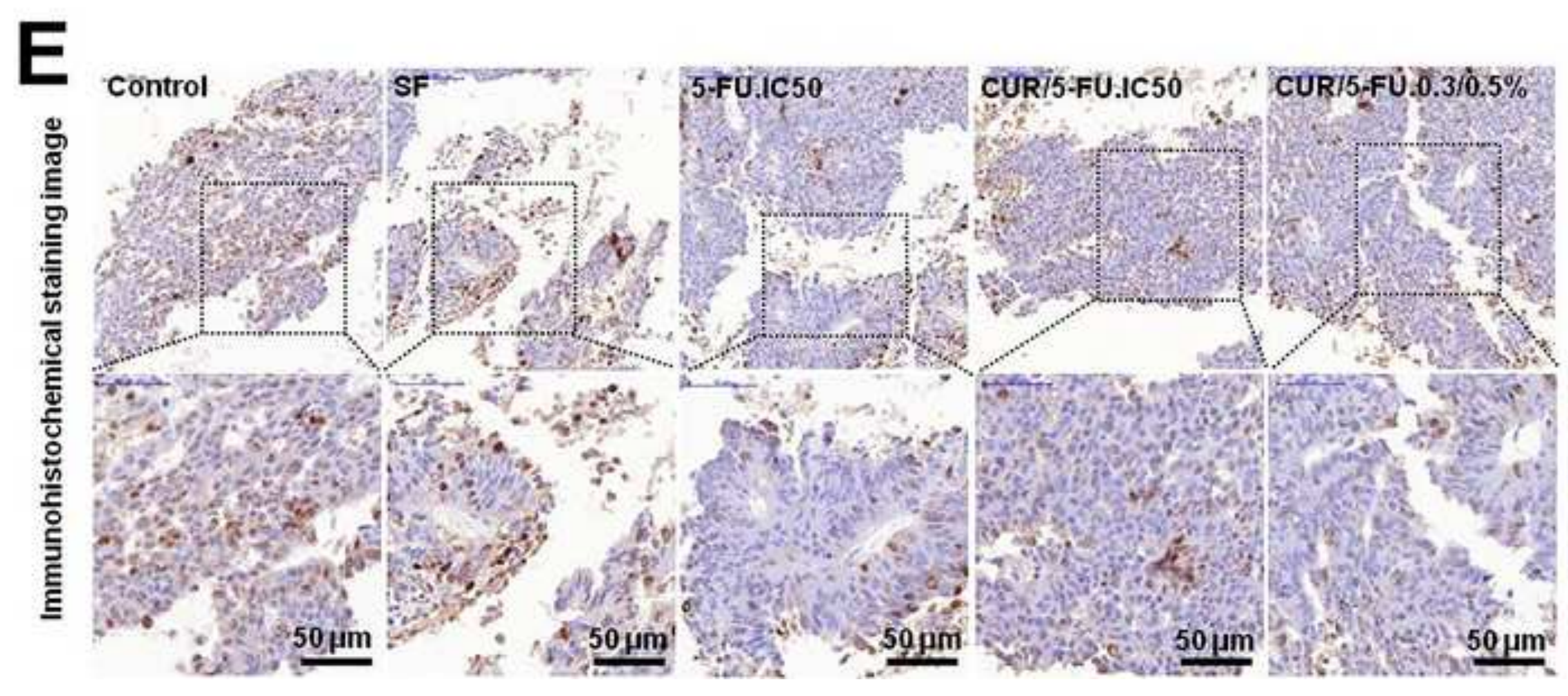


Click here to download high resolution image

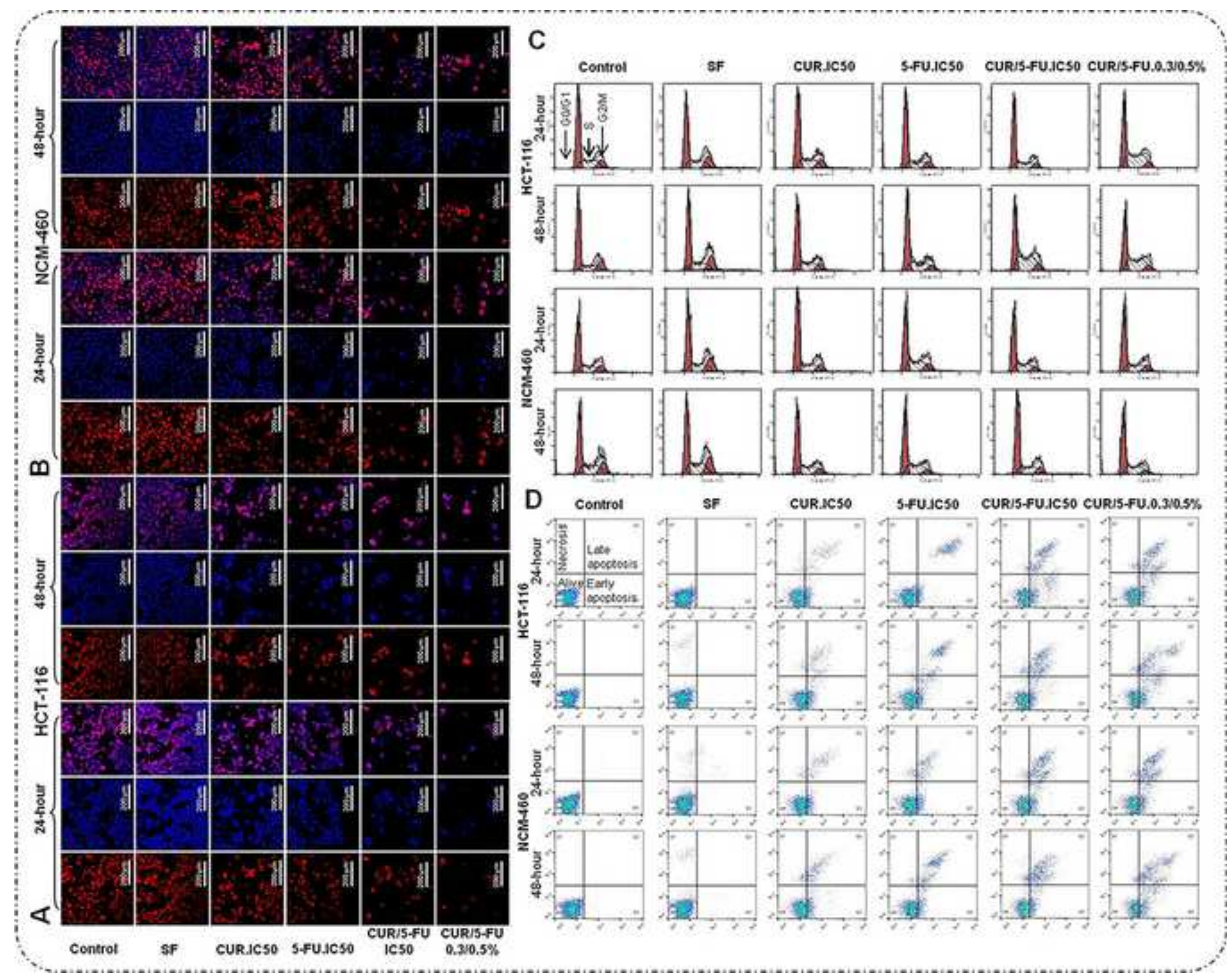




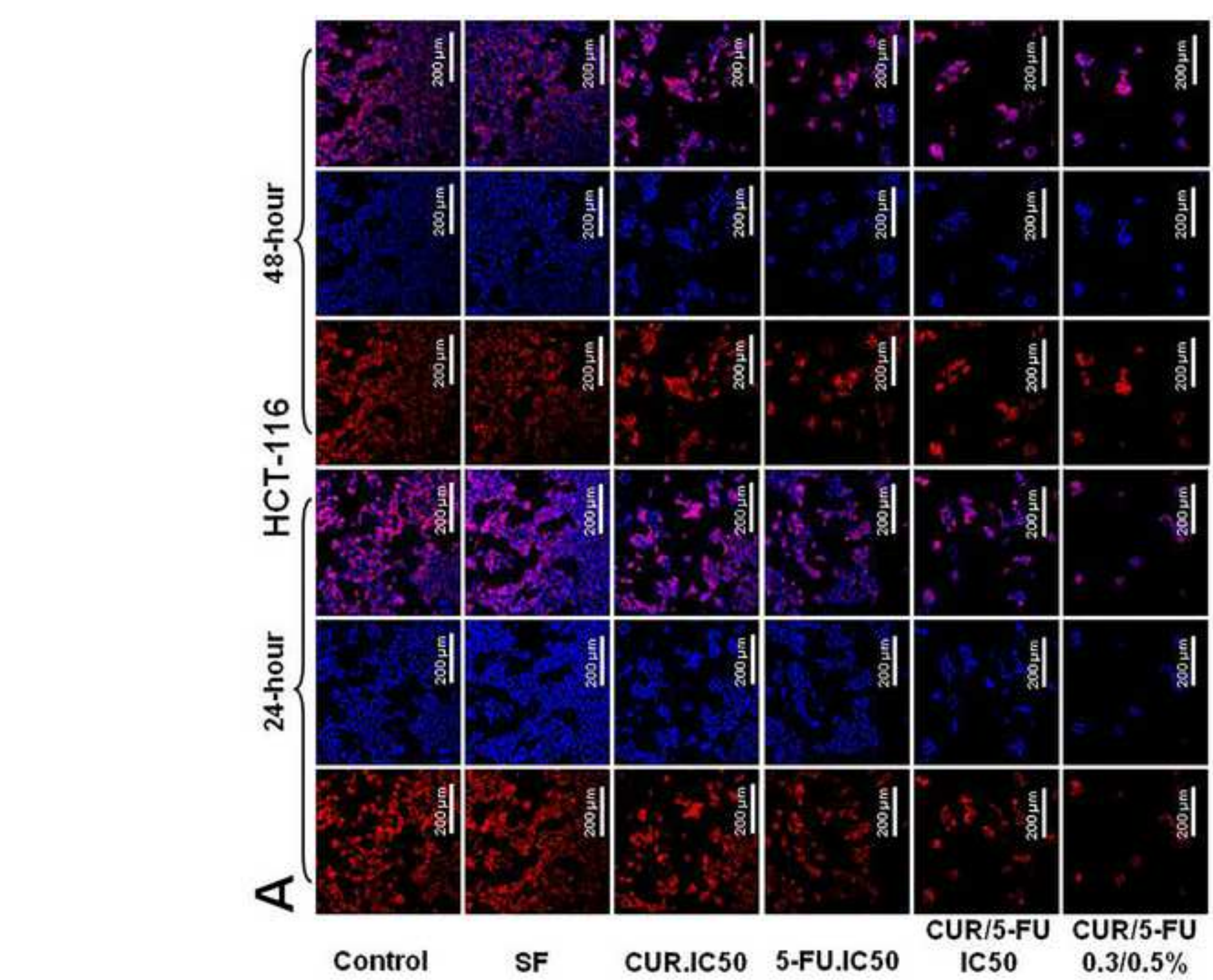


C
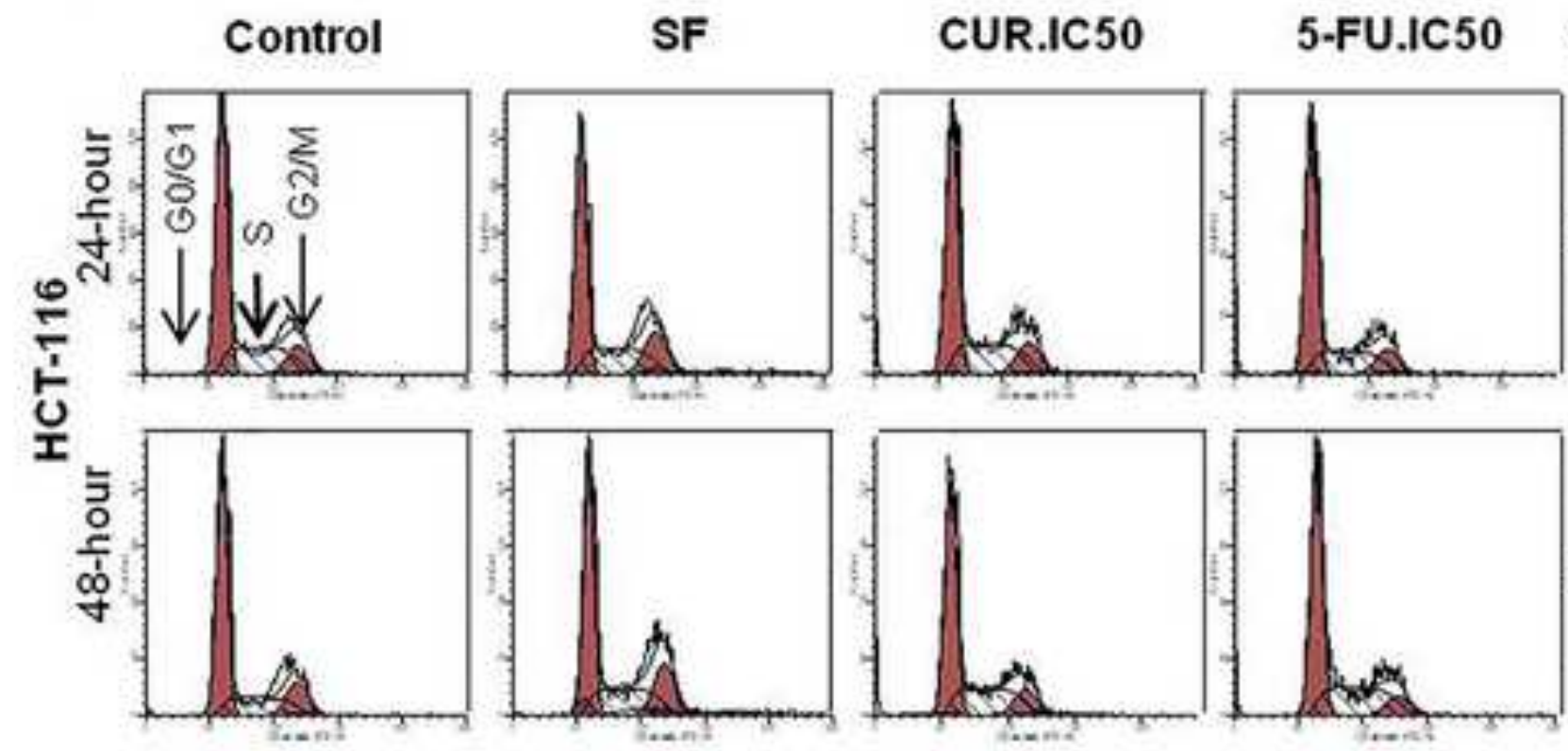

CUR/5-FU.IC50 CUR/5-FU.0.3/0.5\%
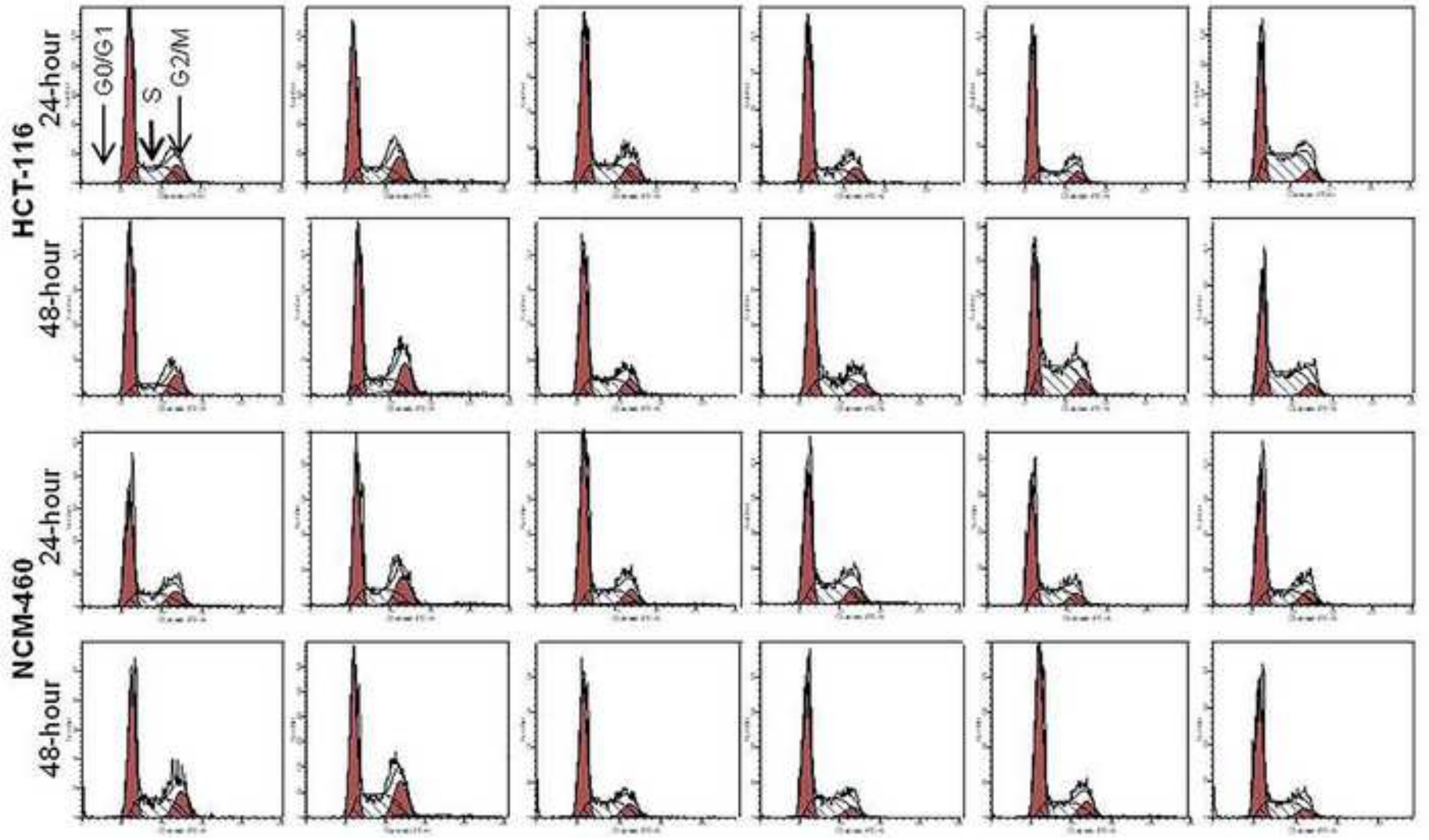
D control
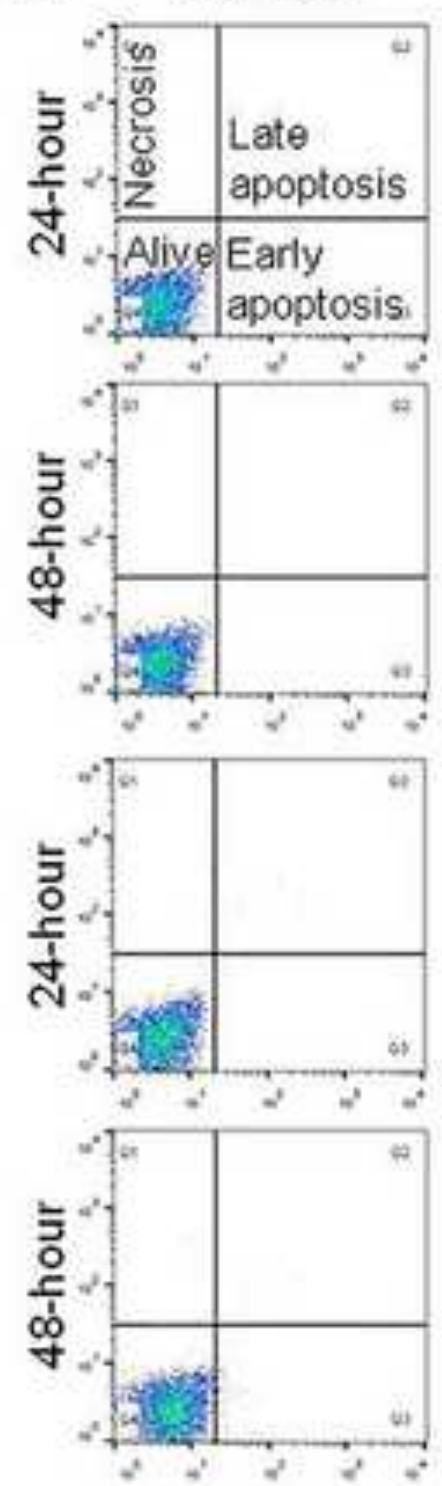

SF
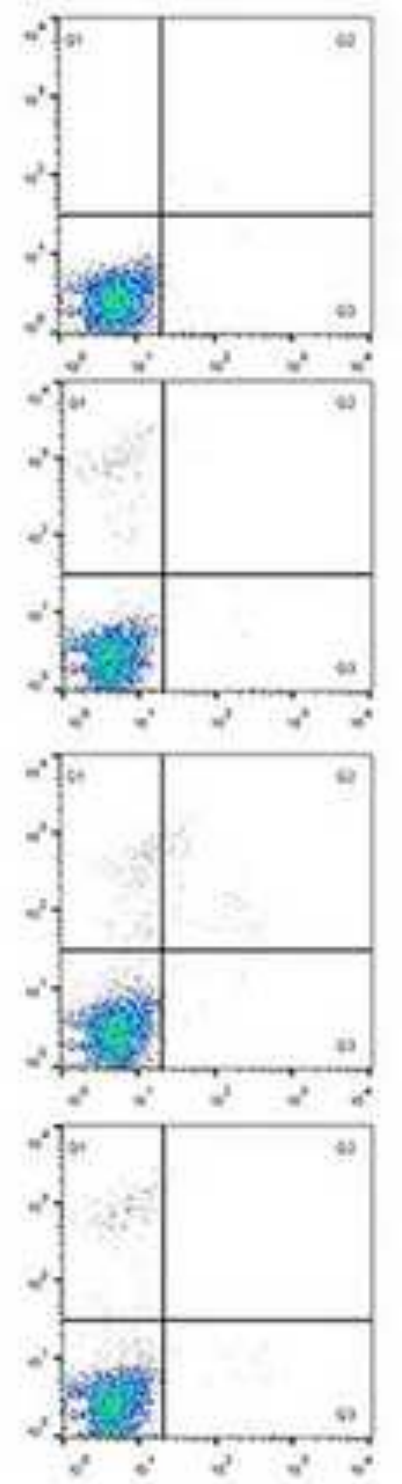

CUR.IC50
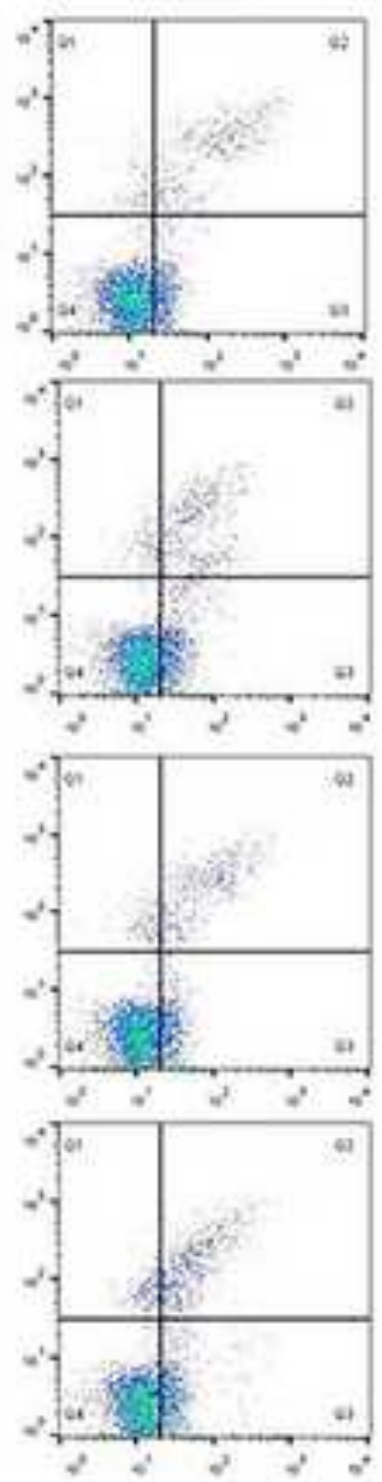

5-FU.IC50
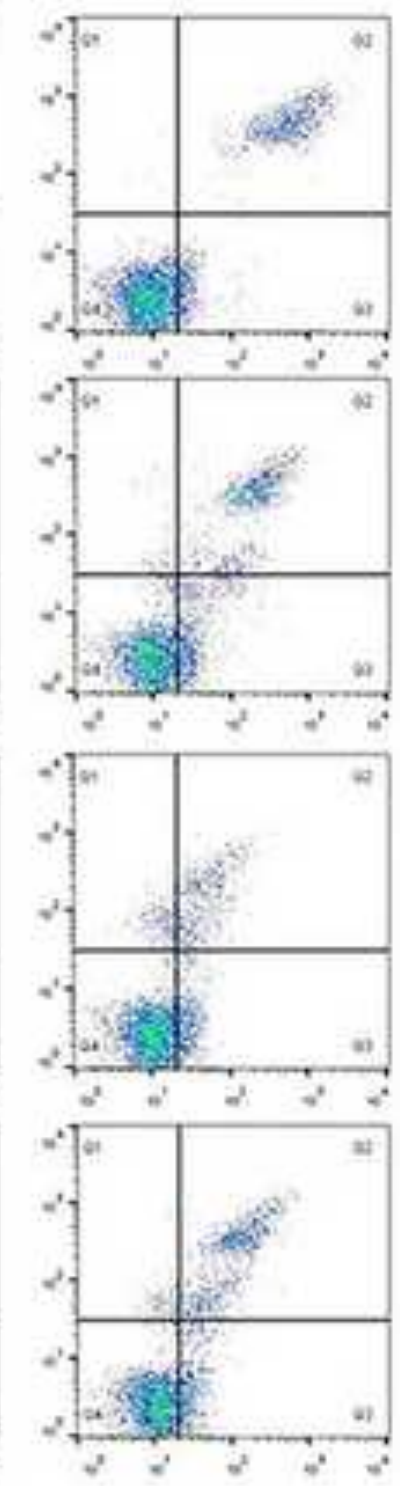

\section{CUR/5-FU.IC50 CUR/5-FU.0.3/0.5\%}
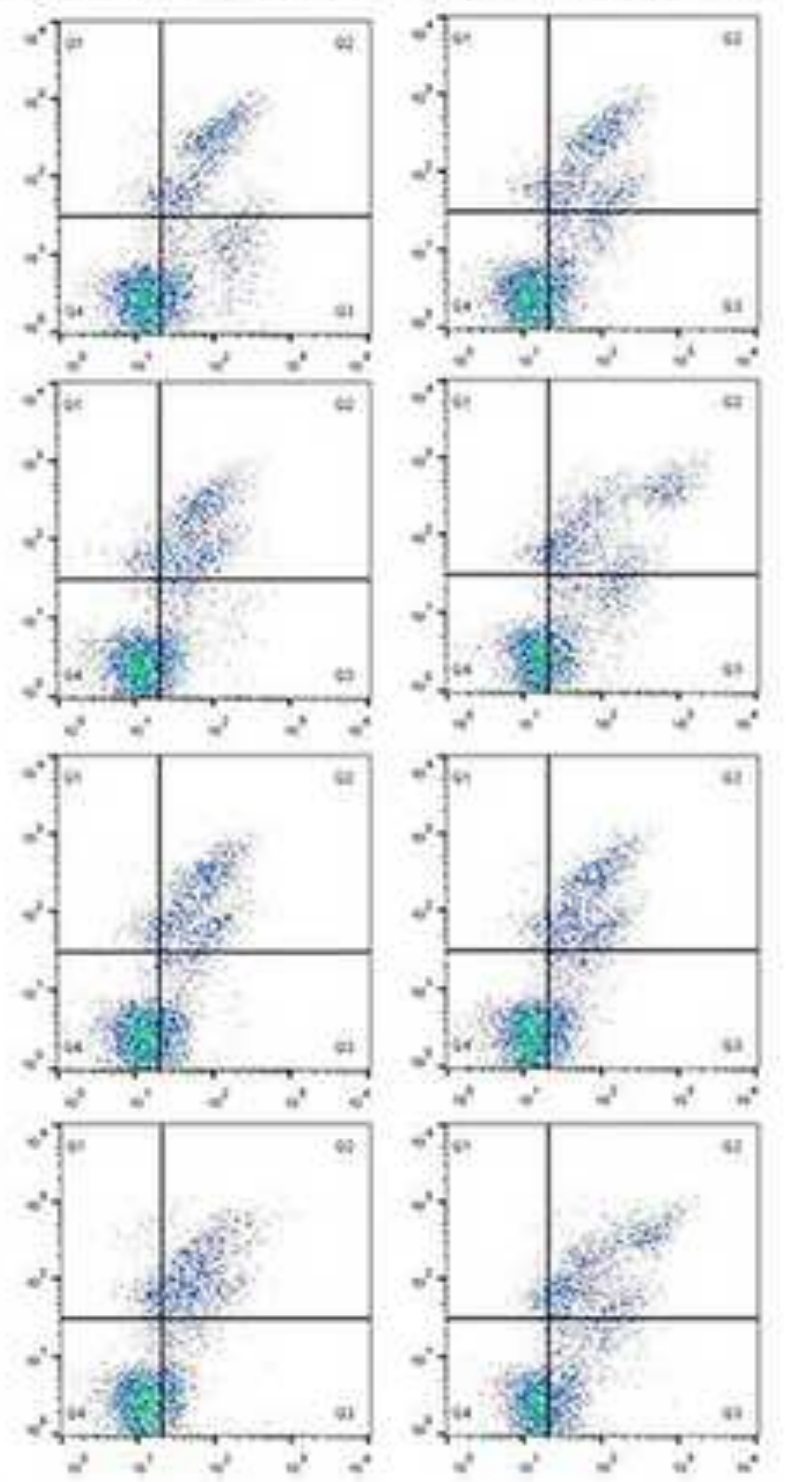
Supplementary Files
Click here to downloa

Click here to download Supplementary Files: Relevant data - subgraphs.rar

(n)

(1) Click here to download Supplementary Files: Relevant data - subgraphsirar 